\title{
THE INFLUENCE OF BREAST CANCER-RELATED LYMPHEDEMA ON WOMEN'S RETURN-TO-WORK
}

A Dissertation
presented to
the Faculty of the Graduate School
at the University of Missouri-Columbia
In Partial Fulfillment
of the Requirements for the Degree
Doctor of Philosophy
Dr. Jane M. Armer, Dissertation Chair
May 2018


The undersigned, appointed by the dean of the Graduate School, have examined the dissertation entitled

\section{THE INFLUENCE OF BREAST CANCER-RELATED LYMPHEDEMA ON WOMEN'S RETURN-TO-WORK}

presented by Yuanlu Sun, a candidate for the degree of doctor of philosophy, and hereby certify that, in their opinion, it is worthy of acceptance.

Jane M. Armer

Deidre D. Wipke-Tevis

Lorraine J. Phillips

Cheryl L. Shigaki

Guilherme DeSouza 


\section{ACKNOWLEDGEMENTS}

First of all, I wish to thank my dear mentor Dr. Armer who has guided and loved me since my first day in Columbia. Without her tireless effort and endless encouragement, there's no way I could walk through the dissertation and $\mathrm{PhD}$ journey. What I have learned from my mentor other than academic knowledge is her phenomenal interpersonal skills which make things work that others cannot. I have taken the whole dissertation process as a practice of what I have learned from my dear mentor.

To Dr. Shigaki, a great appreciation for helping me work on multiple manuscripts. You led me to enter the real world of scholarship.

To Dr. Deidre, greatest thanks for your valuable guidance and resources which helped me greatly, not only finishing the $\mathrm{PhD}$, but shaping my career.

To Dr. Phillips, your insightful advice significantly shaped every step of the dissertation. Thank you for bringing your expertise into my dissertation work and your support all along.

To Dr. Kandis Smith, thank you for standing by me along the journey.

To Dr. DeSouza, thank you for showing me the multidisciplinary research world. The collaboration between nurses and engineer will definitely makes a difference.

I would like to recognize and thank the clinicians (Mary, Elsa), the undergraduate assistants (Gia, Rachael, Leah, and Brandan), and most importantly, the participants. Without you, this dissertation would not be finished in time.

I am so blessed having the people watch me grow all these years. I appreciated the guidance, opportunities, and courage they provided me. In addition, a special thanks to the Toni and Jim Sullivan Endowed Research Fund that supported this dissertation study. 


\section{TABLE OF CONTENTS}

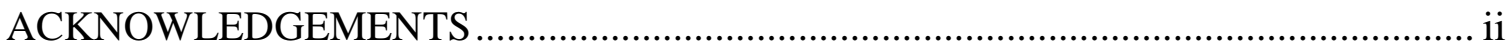

LIST OF TABLES, FIGURES, AND PHOTOGRAPHS ........................................... vi

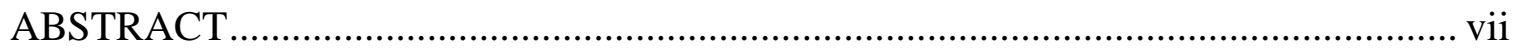

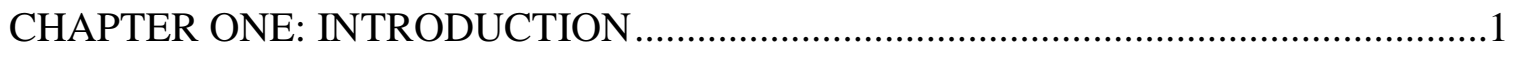

Employment Issues in Cancer Survivorship ........................................................2

The Problem of Breast Cancer-related Lymphedema (BCRL) ...................................3

Existing Knowledge on BCRL and Occupational Rehabilitation ...............................5

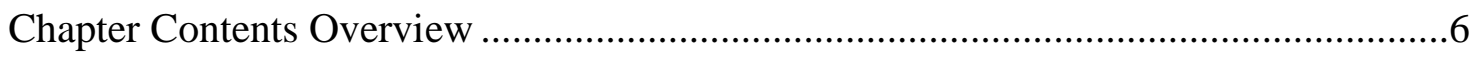

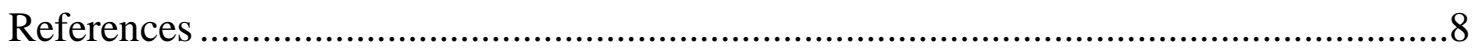

CHAPTER TWO: RETURN-TO-WORK AMONG BREAST CANCER SURVIVORS:

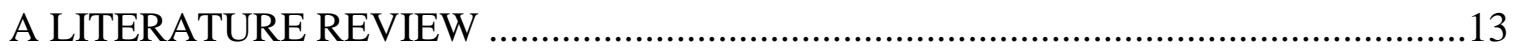

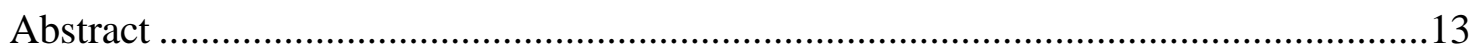

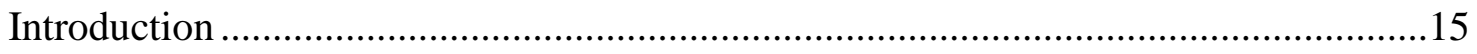

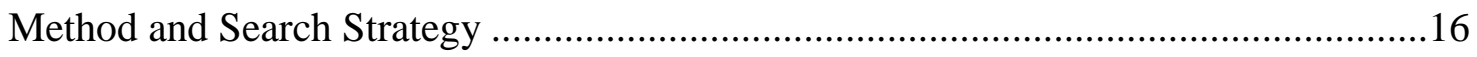

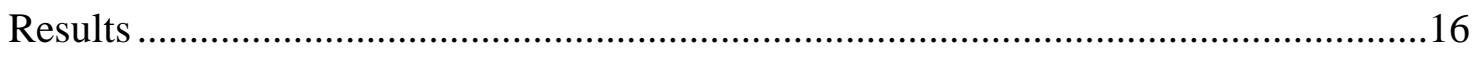

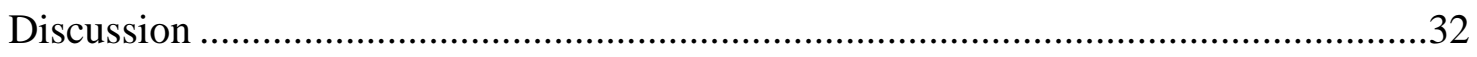

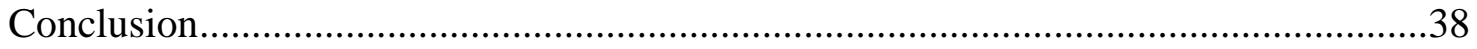

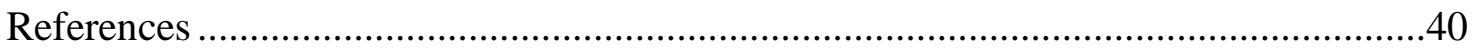

CHAPTER THREE: A NURSE'S TWENTY-FOUR-YEAR JOURNEY WITH BREAST

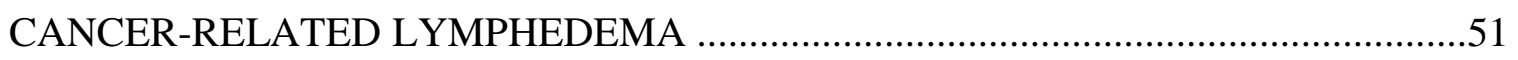

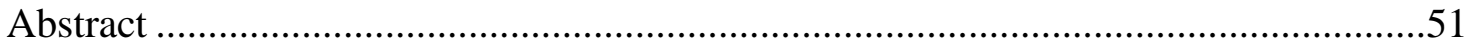


Introduction

Methods

Results

Discussion

Conclusion

References

CHAPTER FOUR: RESEARCH DESIGN AND METHODS ...................................76

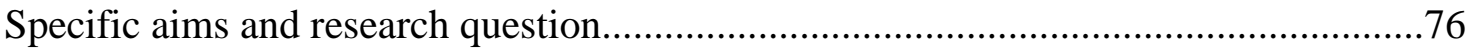

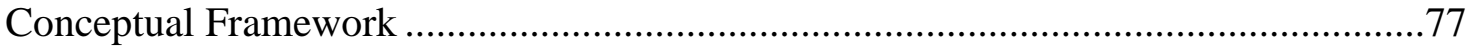

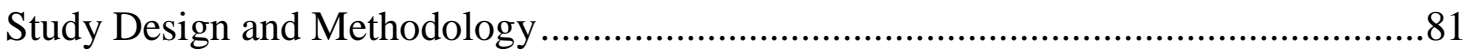

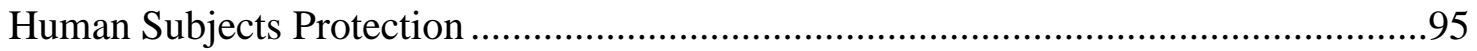

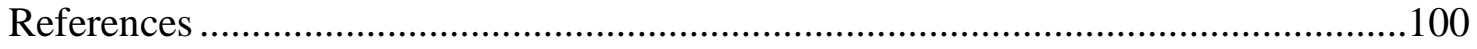

CHAPTER FIVE: THE INFLUENCE OF BREAST CANCER-RELATED

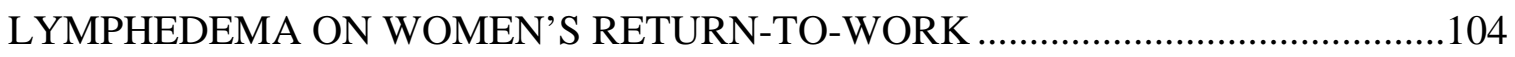

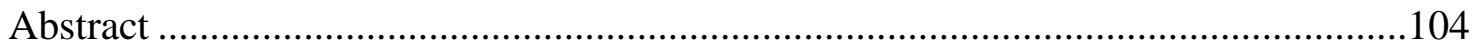

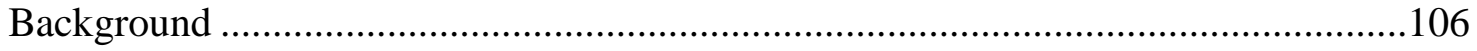

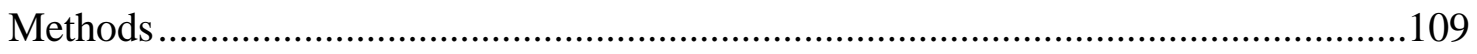

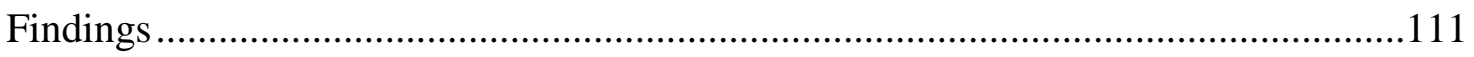

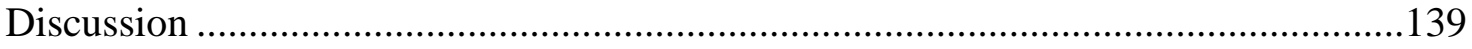

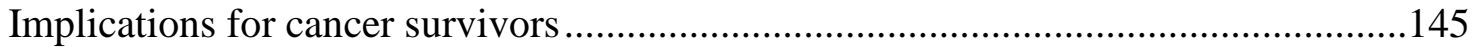

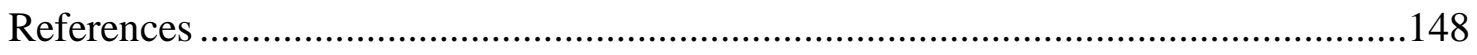

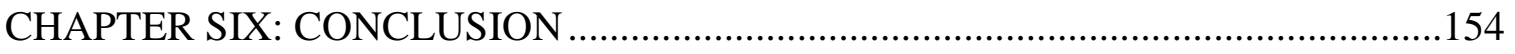

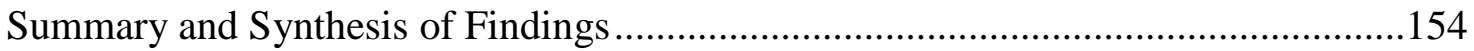




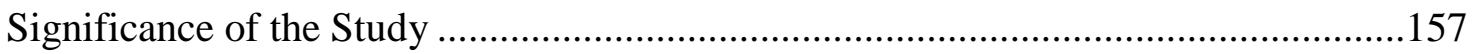

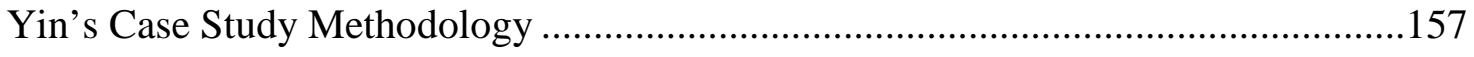

Challenges and Limitations of the Dissertation Work .................................................159

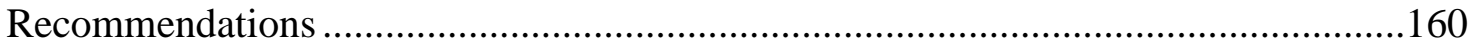

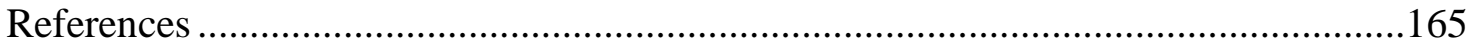

COMPREPHENSIVE REFERENCE LIST …………….........................................167

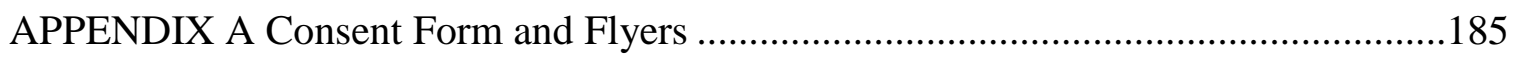

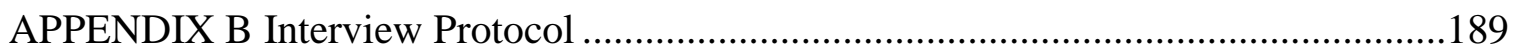

APPENDIX C Demographic Data Collection Tool.......................................................192

APPENDIX D License for Reuse of Published Manuscript (Chapter Two) .....................201

APPENDIX E Supplementary Table for Chapter Two ......................................................204

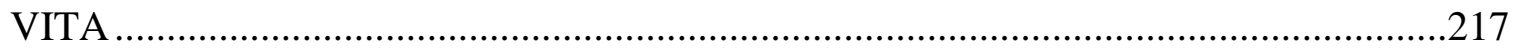




\section{LIST OF TABLES, FIGURES, AND PHOTOGRAPHS}

Table 2.1 Factors associated with negative outcomes in return-to-work following breast cancer diagnosis and treatment......................................................... 22

Table 5.1 Case Demographic Characteristics ....................................................... 114

Table 5.2 Case Disease-related Characteristics ....................................................... 115

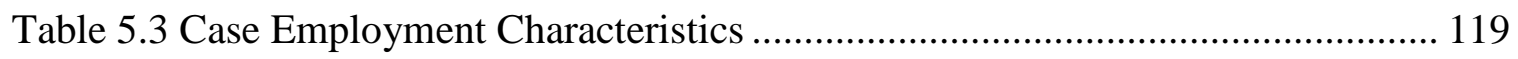

Photograph 3.1 Bandaging treatment for breast cancer related lymphedema ................. 59

Photograph 3.2 Compression sleeve and gauntlet for breast cancer related lymphedema 60

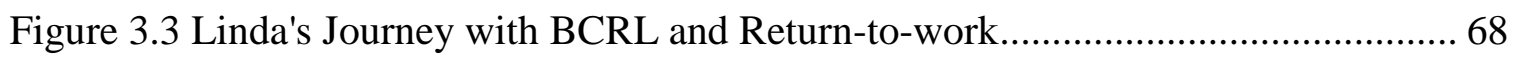

Figure 4.1 Phenomenon of "BCRL and work" explained by the International Classification of Functioning, Disability and Health (ICF) ........................ 80

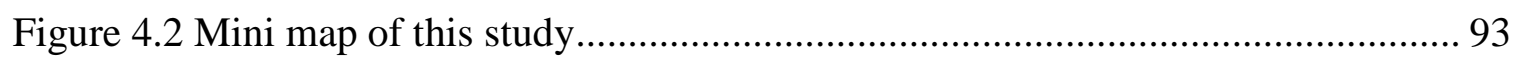


The Influence of Breast Cancer-Related Lymphedema on Women's Return-to-Work Yuanlu Sun, RN, BSN, CLT

\begin{abstract}
The majority of women who develop breast cancer are under retirement age. Therefore, occupational functioning and employment are issues of significant concern. Breast cancer-related lymphedema (BCRL) is one of the major treatment complications for breast cancer patients and it has been shown to be associated with adverse work outcomes. This study is one of the first to ask "how and why" lymphedema may interact with breast cancer survivors' return-to-work. The International Classification of Functioning, Disability, and Health (ICF), which was adopted to guide research design and analysis of data related to health outcomes, was used as a platform for thinking about the phenomenon of return-to-work. Case study methodologies drawn from Yin's (2014) definition were employed in this dissertation study. Thirteen women with BCRL were enrolled in this study. Participants completed a survey and then participated in a sixtyminute semi-structured individual interview. The results suggested that the return-towork experience was shaped by interactions of the disease processes, the work activities required, the individual, and an array of environmental factors. Four main themes emerged: 1) BCRL affects physical and emotional functioning associated with work; 2) On-going treatment for BCRL creates challenges for work; 3) Environmental factors affect the work experience; and 4) Personal factors play a key role in adjusting to returnto-work. The findings shared considerable agreement with ICF model and suggested new perspectives towards understanding the model. This study suggests implications for BCRL education, clinical practice, health policy, and research.
\end{abstract}




\section{CHAPTER ONE INTRODUCTION}

More than 15 million people in the United State are living after cancer diagnoses as of January 2016, and the number increases every day (Bluethmann, Mariotto, \& Rowland, 2016). Long-term cancer survivors face many challenges to return to their normal lives after primary treatment. For women, breast cancer is one of the most common types of cancer, with recent estimates suggesting there are more than 3.1 million breast cancer survivors in the United States (American Cancer Society, 2014a). The median age at breast cancer diagnosis was 61 years (Howlader et al., 2015a), which means that the majority of women are in their employment age when developing breast cancer. Work not only provides individuals with financial resources, but also meaningful life activity, social support and networking opportunities, structure in daily life, and occupational identity (Smith, 1975).

Lymphedema is one of the major treatment complications for breast cancer patients undergoing axillary lymph node dissection and radiation; this is referred to as breast cancer-related lymphedema (BCRL). Lymphedema refers to a disruption of the lymphatic transport system caused by the cancer treatment(s) in which fluid and protein accumulate in the extravascular interstitial spaces. The condition is associated with feelings of discomfort and heaviness, functional limitation, disfigurement, elevated risk of recurrent infection, and associated emotional distress (American Cancer Society, 2014b). Lymphedema can develop in breast cancer survivors at any point following primary treatment and conservative estimates indicate LE occurs in $20-40 \%$ of breast cancer survivors (Armer \& Stewart, 2010; Rebegea, Firescu, Dumitru, \& Anghel, 2015; 
Yang et al., 2016). To date, lymphedema cannot be completely cured or prevented. As such, lymphedema has become the second greatest fear for survivors, following cancer reoccurrence (Bernas, Askew, Armer, \& Cormier, 2010).

\section{Employment Issues in Cancer Survivorship}

As diagnosis and treatment of cancer have evolved in the past decades, survival rates following cancer have continued to increase. While we look forward to further improvements in cancer treatment, the evidence, resources, and educational information to address the physical, psychological, economic, and quality-of-life needs of cancer survivors remain limited (Richardson et al., 2011). This is especially true for long-term cancer survivors, who face many challenges as they return to their normal life after primary treatment. For example, little is known about how cancer and treatment affect survivors' occupational functioning or the factors associated with their employment outcomes (Richardson et al., 2011). Employment not only affects financial resources, but also social support and social networking resources, which makes it an even greater concern. With a median age of 61 years at diagnosis (Howlader et al., 2015b), breast cancer survivors occupational functioning and employment represent issues of significant concern.

Chapter Two reviewed the literature on return-to-work among breast cancer survivors (Sun, Shigaki, \& Armer, 2017). While the literature is not extensive, there was consistency in terms of findings. Outcomes such as return to work rate, work ability, and job performance were greatly decreased among breast cancer survivors compared to healthy populations (Sun et al., 2017). Factors associated with these outcomes have 
included physical and cognitive functioning; personal factors such as marital status, socioeconomic status, stage of breast cancer and treatment, and work characteristics (Sun et al., 2017). Arm morbidity, including decreased range of motion and lymphedema symptoms also increase work disability (Hayes, Rye, Battistutta, \& Newman, 2010a; Quinlan et al., 2009; Yang, Kang, Kim, \& Lim, 2015). A longitudinal study by Quinlan et al. (2009) indicated that survivors with arm morbidity, including motion limitation and pain, were more than two-and-a-half times more likely to experience decreased productivity, compared to their cancer survivor counterparts without arm morbidity. Specific occupations are likely affected in specific ways. For example, one study showed that limited upper extremity movement, numbness in chest and arm, and pain diminished survivors' capacity to function as musicians (Schmalenberger, Gessert, Giebenhain, \& Starr, 2012a, 2012b). So it seems important to look at person, task, and work environment factors in order to best understand the phenomenon.

\section{The Problem of Breast Cancer-related Lymphedema (BCRL)}

Lymphedema can occur any time, from immediately after treatment until some 30 years later (Armer \& Stewart, 2010; Brennan \& Weitz, 1992). Lymphedema cannot yet be completely cured and symptoms and related distress may lead to poor quality of life (QOL) in the long term (Ridner et al., 2012). Chronic symptoms and associated distress can have negative impact on functional ability, self-esteem, social activities, and overall health and well-being (American Occupational Therapy Association, 2011; Cormier et al., 2010). 
The most frequently reported symptoms and signs associated with BCRL were upper limb swelling (Armer, Radina, Porock, \& Culbertson, 2003; Degnim et al., 2012; Hayes, Rye, Battistutta, \& Newman, 2010b), heaviness (Armer et al., 2003; Norman et al., 2009; Ridner, 2005), tightness (Fu \& Rosedale, 2009; Norman et al., 2009), stiffness (Fu \& Rosedale, 2009; Hayes, Janda, Cornish, Battistutta, \& Newman, 2008), numbness (Armer et al., 2003; Fu \& Rosedale, 2009; Tsauo, Hung, Tsai, \& Huang, 2011), pain (Fu \& Rosedale, 2009; Hayes et al., 2008; Norman et al., 2009; Tsauo et al., 2011), decreased range of motion (Armer et al., 2003; Hayes et al., 2010b), and thickening of the skin (Degnim et al., 2012; Sclafani \& Baron, 2008). Individuals also reported tiredness (Fu \& Rosedale, 2009) and discomfort with and limitation in activities of daily living (Sclafani \& Baron, 2008). Lymphedema also has been associated with loss of confidence in the body, fearfulness (e.g. of injuring the affected arm), and sleep disturbance (Ridner, 2005).

Survivors with BCRL may face financial concerns. Based on a study by Moffatt et al. (2003) in the UK, more than $80 \%$ of individuals diagnosed with lymphedema experienced absenteeism from work and 9\% experienced a negative effect on their employment status. Survivors may also face barriers associated with insurance coverage for long-term therapy. Moreover, breast cancer survivors with lymphedema often suffer from psychosocial distress and have a poor self-image; therefore, they may withdraw from social activities. In one study, survivors with lymphedema indicated that living with the constant symptoms of discomfort made them feel they lost the life they had before lymphedema (Fu \& Rosedale, 2009). 


\section{Existing Knowledge on BCRL and Occupational Rehabilitation}

We searched for studies about the effects of lymphedema on patients’ occupational lives using a broad searching strategy. However, very few studies were available $(\mathrm{N}=7)$. The results of this limited set of studies suggests that patients with lymphedema take longer to return to work after their breast cancer treatment than those without this complication (Peugniez et al., 2011). Other studies found that breast cancer survivors with BCRL had lower earnings (Babu, Swain, \& Rath, 2006), greater unemployment (Bifulco et al., 2012; Moffatt et al., 2003), more time off from work (Babu et al., 2006; Bifulco et al., 2012; Boyages et al., 2016), and reduced work capacity (Babu et al., 2006; Quinlan et al., 2009). Interpretation about the effects of BCRL should be made with caution, however, as some of these studies did not study BCRL specifically, but rather examined it as one of several variables affecting work outcomes (Bifulco et al., 2012; Peugniez et al., 2011). We found only three studies targeted lymphedema specifically for its effects on work outcomes (Babu et al., 2006; Boyages et al., 2016; Moffatt et al., 2003).

A study in India by Babu and colleagues (2006) assessed weavers and the impact of lymphedema and hydrocele caused by filariasis on work productivity. This study showed that the weavers who developed lymphedema and hydrocele worked significantly less time than weavers who are lymphedema/hydrocele-free (control group), which makes sense since weaving is physically demanding and requires primarily upper body function. The weavers with lymphedema/hydrocele also earned less than the control group, as income depended on productivity. In a single case study about breast cancer 
survivor's work re-entry, Carter (1994) reported that lymphedema had created the subject's great emotional distress. A recent online survey compared breast cancer survivors without BCRL (Group 1, n = 209) and with BCRL (Group 2, n = 152). Results from this study indicated that the BCRL group reported decreased work attendance and work performance where the impact of lymphedema increased incrementally, corresponding with level of lymphedema severity (Boyages et al., 2016).

Despite acknowledging the trend of less satisfactory work outcomes among survivors with BCRL, compared to lymphedema-free survivors, we still do not clearly understand how and why these differences occur. This lack of knowledge creates barriers to interventions that might facilitate work re-entry and addressing this gap has the potential to improve productivity and quality of life among breast cancer survivors with lymphedema.

\section{Chapter Contents Overview}

Chapters Two through Six work together to explore the complexities of the return-to-work phenomenon among breast cancer survivors who have finished their treatment, but have developed BCRL. Chapters Two and Three provide the background of the problem. Chapter Two is a published literature review that reviews the extant literature on return to work among breast cancer survivors. Chapter Three is a single-case study reporting a nurse's more- than-two-decades' journey with BCRL. Chapter Four provides an expanded description of the research questions, study design, methods, and procedures of the dissertation study, including consideration of the limitations of the study and information about the study's human subject protection. It is a modified 
version of the funded proposal for the Toni and Jim Sullivan Endowed Research Fund. Chapter Five presents the study that was proposed for the dissertation. It reports findings from a multiple-case study of 13 breast cancer survivors with BCRL, who have returned to work, in manuscript form. Chapter Six concludes the dissertation by synthesizing the findings from the entire line of research, discussing the methodology, challenges, and significance of this work, and suggesting future directions for research. 


\section{References}

American Cancer Society (2014a). Cancer treatment \& survivorship facts \& figures 2014-2015. Retrieved from http://www.cancer.org/acs/groups/content/@research/documents/document/acspc042801.pdf

American Cancer Society (2014b). Lymphedema PDQ ${ }^{\circledR}$. Retrieved from https://www.cancer.org/treatment/treatments-and-side-effects/physical-sideeffects/lymphedema.html

American Occupational Therapy Association (2011). Tips for living life to its fullest: Living with breast cancer. Retrieved From https://www.aota.org//media/Corporate/Files/AboutOT/consumers/Health-andWellness/Breast\%20Cancer\%20tip\%20sheet.pdf

Armer, J. M., Radina, M. E., Porock, D., \& Culbertson, S. D. (2003). Predicting breast cancer-related lymphedema using self-reported symptoms. Nursing Research, 52(6), 370-379.

Armer, J. M., \& Stewart, B. R. (2010). Post-breast cancer lymphedema: Incidence increases from 12 to 30 to 60 months. Lymphology, 43(3), 118-127.

Babu, B. V., Swain, B. K., \& Rath, K. (2006). Impact of chronic lymphatic filariasis on quantity and quality of productive work among weavers in an endemic village from India. Tropical Medicine \& International Health, 11(5), 712-717.

Bernas, M. J., Askew, R. L., Armer, J. M., \& Cormier, J. N. (2010). Lymphedema: How do we diagnose and reduce the risk of this dreaded complication of breast cancer 
treatment? Current Breast Cancer Reports, 2(1), 53-58. doi:10.1007/s12609-0100009-1

Bifulco, G., De Rosa, N., Tornesello, M. L., Piccoli, R., Bertrando, A., Lavitola, G., . . . Nappi, C. (2012). Quality of life, lifestyle behavior and employment experience: A comparison between young and midlife survivors of gynecology early stage cancers. Gynecologic Oncology, 124(3), 444-451.

Bluethmann, S. M., Mariotto, A. B., \& Rowland, J. H. (2016). Anticipating the "Silver Tsunami": Prevalence Trajectories and Comorbidity Burden among Older Cancer Survivors in the United States. Cancer Epidemiology Biomarkers \& Prevention, 25(7), 1029-1036. doi:10.1158/1055-9965.Epi-16-0133

Boyages, J., Kalfa, S., Xu, Y., Koelmeyer, L., Mackie, H., Viveros, H., . . G Gollan, P. (2016). Worse and worse off: The impact of lymphedema on work and career after breast cancer. SpringerPlus, 5(1), 1-8. doi:10.1186/s40064-016-2300-8

Brennan, M. J., \& Weitz, J. (1992). Lymphedema 30 years after radical mastectomy. American journal of physical medicine \& rehabilitation / Association of Academic Physiatrists, 71(1), 12-14.

Carter, B. J. (1994). Surviving breast cancer: a problematic work re-entry. Cancer Practice, 2(2), 135-140.

Cormier, J. N., Askew, R. L., Mungovan, K. S., Xing, Y., Ross, M. I., \& Armer, J. A. (2010). Lymphedema beyond breast cancer: A systematic review and metaanalysis of cancer-related secondary lymphedema. Cancer, 6 (1), 5138-5149.

Degnim, A. C., Miller, J., Hoskin, T. L., Boughey, J. C., Loprinzi, M., Thomsen, K., . . . Cheville, A. L. (2012). A prospective study of breast lymphedema: Frequency, 
symptoms, and quality of life. Breast Cancer Research \& Treatment, 134(3), 915922. doi:http://dx.doi.org/10.1007/s10549-012-2004-x

Fu, M. R., \& Rosedale, M. (2009). Breast cancer survivors' experiences of lymphedemarelated symptoms. Journal of Pain \& Symptom Management, 38(6), 849-859. doi: http://dx.doi.org/10.1016/j.jpainsymman.2009.04.030

Hayes, S. C., Janda, M., Cornish, B., Battistutta, D., \& Newman, B. (2008).

Lymphedema after breast cancer: Incidence, risk factors, and effect on upper body function. Journal of Clinical Oncology, 26(21), 3536-3542.

Hayes, S. C., Rye, S., Battistutta, D., \& Newman, B. (2010a). Prevalence of upper-body symptoms following breast cancer and its relationship with upper-body function and lymphedema. Lymphology, 43(4), 178-187.

Hayes, S. C., Rye, S., Battistutta, D., \& Newman, B. (2010b). Prevalence of upper-body symptoms following breast cancer and its relationship with upper-body function and lymphedema. Lymphology, 43(4), 178-187.

Howlader, N., Noone, A. M., Krapcho, M., Garshell, J., Miller, D., Altekruse, S. F., . . . Cronin, K. A. (2015a). SEER Cancer Statistics Review. Retrieved 2015, from National Cancer Institute http://seer.cancer.gov/csr/1975_2012

Howlader, N., Noone, A. M., Krapcho, M., Garshell, J., Miller, D., Altekruse, S. F., . . . Cronin, K. A. (2015b). SEER Cancer Statistics Review, 1975-2012. Available from based on November 2014 SEER data submission based on November 2014 SEER data submission Retrieved 2015, from National Cancer Institute http://seer.cancer.gov/csr/1975_2012 
Moffatt, C. J., Franks, P. J., Doherty, D. C., Williams, A. F., Badger, C., Jeffs, E., . . Mortimer, P. S. (2003). Lymphoedema: an underestimated health problem. Qjm, 96(10), 731-738.

Norman, S. A., Localio, A. R., Potashnik, S. L., Simoes Torpey, H. A., Kallan, M. J., Weber, A. L., . . S Solin, L. J. (2009). Lymphedema in breast cancer survivors: Incidence, degree, time course, treatment, and symptoms. J Clin Oncol, 27(3), 390-397. doi:10.1200/jco.2008.17.9291

Peugniez, C., Fantoni, S., Leroyer, A., Skrzypczak, J., Duprey, M., \& Bonneterre, J. (2011). Return to work after treatment for breast cancer: Single center experience in a cohort of 273 patients. Bulletin du Cancer, 98(7), E69-79.

Quinlan, E., Thomas-MacLean, R., Hack, T., Kwan, W., Miedema, B., Tatemichi, S., .. . Tilley, A. (2009). The impact of breast cancer among Canadian women: Disability and productivity. Work: Journal of Prevention, Assessment \& Rehabilitation, 34(3), 285-296.

Rebegea, L., Firescu, D., Dumitru, M., \& Anghel, R. (2015). The incidence and risk factors for occurrence of arm lymphedema after treatment of breast cancer. Chirurgia (Bucur), 110(1), 33-37.

Richardson, A., Addington-Hall, J., Amir, Z., Foster, C., Stark, D., Armes, J., . . Sharpe, M. (2011). Knowledge, ignorance and priorities for research in key areas of cancer survivorship: Findings from a scoping review. British Journal of Cancer, 105(SUPPL. 1), S82-S94. 
Ridner, S. H. (2005). Quality of life and a symptom cluster associated with breast cancer treatment-related lymphedema. Supportive Care in Cancer, 13(11), 904-911. doi:10.1007/s00520-005-0810-y

Sclafani, L. M., \& Baron, R. H. (2008). Sentinel lymph node biopsy and axillary dissection: Added morbidity of the arm, shoulder and chest wall after mastectomy and reconstruction. Cancer Journal, 14(4), 216-222.

Smith, D. F. (1975). The functions of work. Omega, 3(4), 383-393. doi:https://doi.org/10.1016/0305-0483(75)90002-X

Sun, Y., Shigaki, C. L., \& Armer, J. M. (2017). Return to work among breast cancer survivors: A literature review. Supportive Care in Cancer, 25(3), 709-718. doi:10.1007/s00520-016-3446-1

Tsauo, J. Y., Hung, H. C., Tsai, H. J., \& Huang, C. S. (2011). Can ICF model for patients with breast-cancer-related lymphedema predict quality of life? Supportive Care in Cancer, 19(5), 599-604. doi:http://dx.doi.org/10.1007/s00520-010-0857-2

Yang, E. J., Ahn, S., Kim, E. K., Kang, E., Park, Y., Lim, J. Y., \& Kim, S. W. (2016). Use of a prospective surveillance model to prevent breast cancer treatment-related lymphedema: A single-center experience. Breast Cancer Res Treat, 160(2), 269276. doi:10.1007/s10549-016-3993-7

Yang, E. J., Kang, E., Kim, S. W., \& Lim, J. Y. (2015). Discrepant Trajectories of Impairment, Activity, and Participation Related to Upper-Limb Function in Patients With Breast Cancer. Arch Phys Med Rehabil, 96(12), 2161-2168. doi:10.1016/j.apmr.2015.08.426 


\title{
CHAPTER TWO \\ RETURN-TO-WORK AMONG BREAST CANCER SURVIVORS: A LITERATURE REVIEW
}

Published Manuscript: Sun, Y., Shigaki, C. L., \& Armer, J. M. (2017). Return to work among breast cancer survivors: A literature review. Supportive Care in Cancer, 25(3), 709-718. doi: 10.1007/s00520-016-3446-1

Permission letter from Springer can be found in Appendix D.

\begin{abstract}
Purpose: Breast cancer survivors in their employment years are likely to try to go back to work after the primary treatment. Because the literature on return-to-work among breast cancer survivors is limited, we have undertaken a review of the literature to summarize what is known, including identifying important contributing variables and outcomes. This knowledge may be used to develop hypotheses and potential interventions to support breast cancer survivors who wish to return to work. Method: We searched the following databases: CINAHL, MEDLINE, SCOUP, and PUBMED, within a ten-year timeframe (2004 to 2014). Results: The majority of reviewed articles (N=25) focused on three outcomes: return-to-work time frame, work ability, and work performance. The most frequently studied independent variables were collapsed into the following groups: health and well-being, symptoms and functioning, work demands and work environment, individual characteristics, and societal and cultural factors. Gaps in the literature include evidence of effective interventions to support return to work among breast cancer survivors, and research to better understand the roles of government and
\end{abstract}


business-related policy. Conclusion: All the studies reported a reduced work engagement and work ability. Employment status and work performance is associated with a combination of individual factors, work environment, culture, and resources.

Implications: Significant gaps are apparent in the literature addressing breast cancer survivorship and return-to-work. This is a complex problem and it will likely require interdisciplinary research teams to develop effective and feasible interventions for this population.

Keywords: Breast cancer, return to work, review 


\section{RETURN-TO-WORK AMONG BREAST CANCER SURVIVORS:}

\section{A LITERATURE REVIEW}

\section{Introduction}

Breast cancer is the most common cancer affecting women globally (American Cancer Society, 2015). It is also the second most common cancer among women in the United States, following skin cancer. Recent estimates suggest there are 2.9 million breast cancer survivors in the United States (American Cancer Society, 2013). Despite increasing knowledge about diagnosis and treatment, our knowledge about functioning among women in the chronic stages of breast cancer survivorship remains quite limited (Richardson et al., 2011). For example, little is known about the factors affecting breast cancer survivors' occupational functioning, or how breast cancer and treatment affect employment (Richardson et al., 2011). This informational gap is especially important as employment not only affects the survivor's financial resources, but also social networks. During 2008-2012, the median age at breast cancer diagnosis was 61 years. Thus, the majority of women who develop breast cancer are under the age of retirement (Howlader et al., 2015) and occupational functioning and employment represent issues of significant concern.

In this paper we have undertaken a review of the breast cancer survivorship literature focusing on occupational functioning and return to work. Specifically, we reviewed the literature in order to identify the types of outcomes that have been assessed, variables describing the barriers and facilitators associated with return-to-work, and intervention trials aimed at improving or facilitating return-to-work. 


\section{Method and Search Strategy}

The following databases were searched: CINAHL, MEDLINE, SCOPUS, and PUBMED. The search was restricted using the parameters: publications from January 2004 to March 2014, full text availability, and English or Chinese languages. The search term combinations comprised: 1) breast cancer, breast neoplasms; 2) survivors, survivorship, patients; and 3) return to work, work (ability), un-/ employment, job performance, job retention. Our search returned total of 361 articles, of which 63 articles were deemed appropriate after screening the title and abstract.

The inclusion criteria used to identify the final set of articles were: 1) the study sample included only breast cancer survivors; and 2) the study was an empirical article with outcomes related to work ( $\mathrm{N}=17$ articles), or qualitative/exploratory articles exploring factors affecting work ( $\mathrm{N}=8$ articles). The exclusion criteria were: 1 ) studies addressing cancer types other than breast cancer; 2) studies that focused on the effects of work on breast cancer survivors, (e.g. studies of job hazard); and 3) studies where work was only a minor factor within a large set of psychosocial factors affected by breast cancer. In all, 25 articles met the criteria and were reviewed (Appendix E Supplementary table).

\section{Results}

We report our findings in two general sections, outcomes and the variables affecting outcomes. Three areas of outcomes dominated the literature: return-to-work timeframe, work ability, and work performance. These outcomes were typically addressed using forms of quantitative analysis including frequencies or by comparing breast cancer 
survivors to individuals who were free from cancer. The second general section addresses variables found to influence work outcomes. These factors were investigated using both qualitative approaches, which typically reviewed concerns from the perspective of survivors (Schmalenberger, Gessert, Giebenhain, \& Starr, 2012b; Tamminga, de Boer, Verbeek, \& Frings-Dresen, 2012; Tan, Loh, Su, Veloo, \& Ng, 2012; Tiedtke, de Rijk, Donceel, Christiaens, \& de Casterle, 2012; Tiedtke, Donceel, et al., 2012) and quantitative approaches, which typically identified and tested factors using regression statistics (Ahn et al., 2009; Fantoni et al., 2010; Hansen, Feuerstein, Calvio, \& Olsen, 2008; Johnsson, Fornander, Rutqvist, \& Olsson, 2011; Johnsson et al., 2009; Molina Villaverde et al., 2008; Mujahid et al., 2010; Petersson, Wennman-Larsen, Nilsson, Olsson, \& Alexanderson, 2011; Schmalenberger, Gessert, Giebenhain, \& Starr, 2012a). We have organized this section by collapsing the variables into five broad categories: health and well-being, symptoms and functioning, work demands and work environment, individual characteristics, and societal and cultural factors. Finally, we discuss the limited set of intervention studies found.

\section{Outcomes}

Return to work timeframe. The quantitative studies in this review consistently showed that employment decreased in breast cancer survivors compared to counterparts without cancer. However, the literature reporting time-frames for returning to work reflects a broad range, which is likely due in part to differences in study design (e.g. if working status at early post-diagnosis was of interest) and approaches to data collection (Ahn et al., 2009; Balak, Roelen, Koopmans, Ten Berge, \& Groothoff, 2008; Fantoni et al., 2010; Hauglann, Benth, Fossa, \& Dahl, 2012; Johnsson et al., 2011; Johnsson et al., 
2009; Molina Villaverde et al., 2008; Petersson et al., 2011). Petersson, Wennman-Larsen et al. (2011) aimed to examine the effects of a number of post-breast cancer treatment variables on employment status at 4-6 weeks post-surgery. They found that at that point in recovery, $56 \%(n=426)$ of participants $(N=756)$ were still on sick leave (Petersson et al., 2011). Many studies selected one-year post-treatment or post-diagnosis as the target milestone for examining the rate of return-to-work. Using this milestone, Johnsson et al. (2009) showed 59\% ( $n=60)$ of subjects in their sample $(\mathrm{N}=102)$ had returned to work (Johnsson et al., 2009). Balak et al. (2008) waited until 24 months post diagnosis to survey respondents $(\mathrm{N}=72)$ and reported a mean delay in return to work of $11.4(+/-5.5)$ months (Balak et al., 2008). The same study showed 35\% $(n=25)$ of participants $(\mathrm{N}=72)$ reported being absent from work longer than one year after diagnosis (Balak et al., 2008).

Other studies looked at return-to-work over longer post-treatment timeframes. For example, Molina et al. (2008) studied a sample of survivors ( $\mathrm{N}=96)$ in which the mean interval before returning to work was 32.5 months post-diagnosis (Molina Villaverde et al., 2008). In this sample, $80 \%(n=77)$ of participants took a break from work after diagnosis, but only 56\% $(n=54)$ returned to work at the end of treatment (Molina Villaverde et al., 2008). Fantoni et al. (2010) followed a sample of survivors (N=379) for 36 months post-diagnosis and reported that $82.1 \%(n=311)$ had returned to work by that time point; with median leave time being 10.8 months (Fantoni et al., 2010). Overall, it seems that many women return to work somewhere between shortly after their treatment to one-year post-treatment, but that the number returning to work may continue to increase even after the one-year mark. 
Work ability. A number of symptoms may affect ability to work, arm morbidity and cognitive impairment being particularly prevalent complaints following breast cancer treatment (Molina Villaverde et al., 2008; Mujahid et al., 2010). Hansen et al. (2008) surveyed 100 breast cancer survivors and found more frequent work limitation in this sample than in a group of women who were cancer-free ( $N=103)$ (Hansen et al., 2008). Work by Carlsen, et al. (2013) suggests that age may not have a significant impact on this trend - at least within the fourth and fifth decade. Hansen et al. (2008) found similarly poor work ability among survivors and controls who were somewhat older (mean age: 54.2 years for breast cancer survivors and 52.4 for cancer-free group, vs. 49.5 years and 39.8 years, respectively) (Johnsson et al., 2011; Johnsson et al., 2009). Convergent evidence for decreased work ability among breast cancer survivors may be determined by examining the frequency of disability benefits received. Hauglann et al. (2012) examined this variable and found a significantly higher ratio of disability pension received by breast cancer survivors and cancer-free controls (Hauglann et al., 2012).

A limitation of the literature was that the existing studies differed in the time point at which the work ability was evaluated. For example, the period of post-treatment of the survivors varied in different studies and some are not clearly defined. Quinlan et al. (2009) recruited from 6 to 12 months post-surgery, with arm morbidity as a target variable (E. Quinlan et al., 2009). The participants in Carlsen et al.’s (2013) study had survived at least 5 years post-treatment (Carlsen et al., 2013). Hansen et al. (2008) did not clearly state a time point for their participants’ reported work ability (Hansen et al., 2008). Thus, the differences in work ability in short- vs. long-term survivorship and its change along the survivorship trajectory remain unclear. 
Another limitation of the literature was that the method of measuring work ability varied and thus findings could not be directly compared. Hansen et al. (2008) (Hansen et al., 2008) and Lavigne et al. (2008) (Lavigne, Griggs, Tu, \& Lerner, 2008) used the Work Limitation Questionnaire (WLQ) - a tool designed for measuring the impact that chronic conditions and treatment have on work limitations and productivity (Lerner et al., 2001). Quinlan et al. (2009) focused more narrowly on breast-cancer related arm problems and changes (e.g. lymphedema, the range of motion limitations and arm pain), and work limitations due to arm morbidity (e.g. inability to perform typing or lifting) (E. Quinlan et al., 2009). In Carlsen et al.’s (2013) study, work ability was measured only by a single Likert-type rating (participants rated themselves on a 0-to-10-point scale) and dichotomized by the researchers as high ability with score of 9-10 and low with score below 8 . This way of measurement could be a limitation of validity compared to a more validated survey (Carlsen et al., 2013). As noted above, Hauglann et al. (2012) used disability pension as a proxy for lost work ability (Hauglann et al., 2012), an indirect measure which may be limited in interpretability, as there may be other physical and psychosocial factors affecting receipt of disability pension (Fantoni et al., 2010).

Despite these methodological discrepancies and problems, the results reported in the extant literature appear fairly consistent in suggesting decreased work ability among breast cancer survivors, at least within the first year following diagnosis and treatment (Carlsen et al., 2013; Hansen et al., 2008; Hauglann et al., 2012).

Work Performance. Work performance is frequently operationalized as "work productivity.” Unfortunately, similar to work ability, work productivity has been defined 
differently in different studies. Calvio, Peugeot et al. (2010) and Lavigne, Griggs et al. (2008) used the Work Output Demands scale from the Work Limitation Questionnaire (WLQ) to assess work performance (Calvio, Peugeot, Bruns, Todd, \& Feuerstein, 2010; Lavigne et al., 2008). Items on this scale included: "Handle workload," "Work fast enough,” "Finish all work,” "Finish work on time," “Meet simultaneous demands,” "Put in extra hours to keep up," "Work without mistakes,” "Do work over," "Work safely,” “Satisfy others,” and “Feel sense of accomplishment” (Lerner et al., 2001). In contrast, Quinlan, Thomas-MacLean et al. (2009) specifically defined their "loss of productivity" variable as arm problems-induced decrease of work capacity, changes in occupational status, and sick leave (E. Quinlan et al., 2009). All three of these studies, however, were consistent in demonstrating loss of productivity in survivor vs. healthy worker norm.

\section{Variables Influencing Work Outcomes}

Almost all of the studies included in this review reported on investigations of barriers and facilitators associated with return-to-work. As return-to-work is a complex social problem, there were numerous constructs identified. Based on the recommendations of several occupational rehabilitation models (Désiron, Donceel, de Rijk, \& Van Hoof, 2013; Duijts, Spelten, \& Verbeek, 2014; Mehnert, de Boer, \& Feuerstein, 2013), we have therefore organized this section by collapsing discussion into five broad categories: health and well-being, symptoms and functioning, work demands and work environment, individual characteristics, and societal and cultural factors (Table 2.1). 
Table 2.1 Factors associated with negative outcomes in return-to-work following breast cancer diagnosis and treatment

\begin{tabular}{|c|c|}
\hline Factors & Sub-components of each factor \\
\hline $\begin{array}{l}\text { Health and } \\
\text { well-being }\end{array}$ & $\begin{array}{l}\text { Lower self-rated health, }{ }^{1} \text { decline in health following diagnosis, } \\
\text { low satisfaction with activities of daily living }\end{array}$ \\
\hline $\begin{array}{l}\text { Symptoms and } \\
\text { Function }\end{array}$ & $\begin{array}{l}\text { Pain, }{ }^{4} \text { anxiety, }{ }^{5} \text { fatigue },{ }^{6} \text { cognitive symptoms, }{ }^{7} \text { depression, }{ }^{8} \text { hot } \\
\text { flashes, }{ }^{9} \text { self-image disorder, }{ }^{10} \text { arm morbidity, }{ }^{11} \text { cognitive } \\
\text { impairments }{ }^{12}\end{array}$ \\
\hline $\begin{array}{l}\text { Work demands } \\
\text { and } \\
\text { Work } \\
\text { environment }\end{array}$ & $\begin{array}{l}\text { (Work demands) stress associated with specific job, }{ }^{13} \text { flexibility of } \\
\text { work schedule, }{ }^{14} \text { high-demand job, potential environmental } \\
\text { hazards }{ }^{15} \text { (Work environment) Lack of acceptance by peers and } \\
\text { supervisors, }{ }^{16} \text { lack of perceived support from work colleagues and } \\
\text { employers, }{ }^{17} \text { less privacy for employee, }{ }^{18} \text { deficit in knowledge of } \\
\text { work environment, }{ }^{19} \text { "job lock” (the situation in which an } \\
\text { employee is unable to leave a job because he/she is afraid of losing } \\
\text { the benefits. In this case, it refers to inability to change to a job } \\
\text { which is better fitted after diagnosis with breast cancer) }{ }^{20}\end{array}$ \\
\hline $\begin{array}{l}\text { Individual } \\
\text { characteristics }\end{array}$ & $\begin{array}{l}\text { Decreased desire to keep job, }{ }^{21} \text { decreased self-efficacy, }{ }^{22} \text { work was } \\
\text { not part of maintaining sense of normalcy, }{ }^{23} \text { racial minority, }{ }^{24} \\
\text { marital/partner status, }{ }^{25} \text { gender, educational level, }{ }^{26} \text { better }\end{array}$ \\
\hline
\end{tabular}

\footnotetext{
1 Johnsson et al., 2011; Petersson et al., 2011;

2 Johnsson et al., 2011; Petersson et al., 2011;

${ }^{3}$ Johnsson et al., 2011; Petersson et al., 2011;

${ }^{4}$ Quinlan et al., 2009;

${ }^{5}$ Ahn et al., 2009; Calvio et al., 2010; Carlsen et al., 2013; Hansen et al., 2008; Todd et al., 2011;

${ }^{6}$ Ahn et al., 2009; Calvio et al., 2010; Carlsen et al., 2013; Hansen et al., 2008; Todd et al., 2011;

${ }^{7}$ Boykoff et al., 2009; Breckenridge, Bruns, Todd, \& Feuerstein, 2012; Calvio et al., 2010; Cheung, Tan, \& Chan, 2012; Munir et al., 2010; Oberst, Bradley, Gardiner, Schenk, \& Given, 2010; Ottati \& Feuerstein, 2013; Todd et al., 2011; Von Ah, Habermann,

Carpenter, \& Schneider, 2013

${ }^{8}$ Ahn et al., 2009; Calvio et al., 2010; Carlsen et al., 2013; Hansen et al., 2008; Todd et al., 2011;

${ }^{9}$ Lavigne, Griggs et al., 2008;

${ }^{10}$ Blinder, Murphy, et al.,2012;

${ }^{11}$ Quinlan et al., 2009;

${ }^{12}$ Calvio et al., 2010; Munir et al., 2010;

${ }^{13}$ Hansen et al., 2008; Calvio et al., 2010;

${ }^{14}$ Blinder, Murphy et al. 2012; Mujahid et al., 2010;

${ }^{15}$ Tan et I., 2012;

${ }^{16}$ Hakanen \& Lindbohm, 2008;

${ }^{17}$ Carlsen et al.,2013; Fantoni et al., 2010; Blinder, Murphy, et al., 2012;

${ }^{18}$ Blinder, Murphy et al. 2012;

${ }^{19}$ Blinder, Murphy et al. 2012; Mujahid et al., 2010;

${ }^{20}$ Tamminga et al., 2012;

${ }^{21}$ Tiedtke, de Rijk et al., 2012;

${ }^{22}$ Fantoni et al. (2010)

${ }^{23}$ Blinder, Murphy, et al.,2012;

${ }^{24}$ Mujahid et al., 2010;

${ }^{25}$ Ahn et al., 2009; Lavigne, Griggs et al., 2008; Mujahid et al., 2010;

${ }^{26}$ Ahn et al., 2009; Fantoni et al., 2010;
} 


\begin{tabular}{|c|c|}
\hline & $\begin{array}{l}\text { household income }{ }^{27} \text { poor coping skills, }{ }^{28} \text { over protective family, }{ }^{29} \\
\text { age (direction not clear), }{ }^{30} \text { pessimism, temperament } \& \\
\text { personality, }{ }^{31} \text { not financially dependent upon working, } \\
\text { higher disease stage, }{ }^{33} \text { sequel of the disease (e.g. lymphedema), }{ }^{34} \\
\text { multiple comorbidities, }{ }^{35} \text { treatments (e.g. mastectomy, axillary } \\
\text { node dissection, chemotherapy \& radiotherapy) }{ }^{36}\end{array}$ \\
\hline $\begin{array}{l}\text { Societal and } \\
\text { culture factors }\end{array}$ & $\begin{array}{l}\text { Negative societal attitudes, social coping resources unavailable, }{ }^{37} \\
\text { lack of advisement from health professional, }{ }^{38} \text { less family } \\
\text { support, }{ }^{39} \text { lower priority of career in women's life in some social } \\
\text { culture }^{40}\end{array}$ \\
\hline
\end{tabular}

Health and well-being. Not surprisingly, overall well-being has been identified as a correlate to successful work outcomes among breast cancer survivors. Satisfaction with daily living also has been associated with favorable work outcomes (Johnsson et al., 2011; Petersson et al., 2011). Lower self-rated health and decreased global well-being were associated with barriers to work performance, such as amount of sick leave taken (Johnsson et al., 2011). Breast cancer survivors frequently identify depressive symptoms and fatigue as the most problematic in the context of work (Ahn et al., 2009; Calvio et al., 2010; Carlsen et al., 2013; Hansen et al., 2008; Todd, Feuerstein, \& Feuerstein, 2011). Importantly, Johnsson et al. (2011) found higher global life satisfaction among survivors who had returned to work (Johnsson et al., 2011).

\footnotetext{
${ }^{27}$ Carlsen et al., 2013;

28 Johnsson, Fornander et al. 2011, Tamminga, de Boer et al. 2012; Fantoni et al. 2010;

${ }^{29}$ Tan et al., 2012;

${ }^{30}$ Fantoni et al., 2010;

${ }^{31}$ Hakanen \& Lindbohm, 2008; Tamminga et al., 2012; Tiedtke, de Rijk, et al., 2012;

32 Ahn et al., 2009;

${ }^{33}$ Hakanen \& Lindbohm, 2008; Tamminga et al., 2012; Tiedtke, de Rijk, et al., 2012

${ }^{34}$ Hakanen \& Lindbohm, 2008; Tamminga et al., 2012; Tiedtke, de Rijk, et al., 2012

${ }^{35}$ Hakanen \& Lindbohm, 2008; Tamminga et al., 2012; Tiedtke, de Rijk, et al., 2012

${ }^{36}$ Balak et al., 2008; Hauglann et al., 2012; Johnsson et al., 2009;

${ }^{37}$ Tamminga et al., 2012;

38 Tiedke et al.,2012;

${ }^{39}$ Tamminga et al., 2012;

${ }^{40}$ Ahn et al., 2009; Tan et al., 2012;
} 
Symptoms and functioning. Depressive and fatigue symptoms were the most reported symptoms related to work problems (Ahn et al., 2009; Calvio et al., 2010; Carlsen et al., 2013; Hansen et al., 2008; Todd et al., 2011). In Hansen et al.'s (2008) study, fatigue contributed to $71 \%$ of the symptom burden, and depressive symptoms interacted significantly with fatigue (Hansen et al., 2008). Arm morbidity also was frequently cited as a contributor to work-related disability and may relate to job posture. The longitudinal study by Quinlan et al. (2009) indicated that the survivors with arm morbidity, including range of motion limitation and pain, are more than 2.5 times more likely to have a decrease in work productivity compared to their counterparts without arm morbidity (E. Quinlan et al., 2009). One study found that upper extremity movement, numbness in the chest and arm, limitations of upper body, and pain were especially likely to be associated with diminished ability to function as a musician (Schmalenberger et al., 2012a, 2012b). Appearance is an important concern among survivors (Blinder, Murphy, et al., 2012). Concerns about self-image likely influence return-to-work among some occupations more than some others. For example, in the study of Blender et al. (2012), women in the field of acting, waitressing, and teaching all identified this as an area of concern.

Another focus of survivorship research has been cognitive impairment (Boykoff, Moieni, \& Subramanian, 2009; Breckenridge, Bruns, Todd, \& Feuerstein, 2012; Calvio et al., 2010; Cheung, Tan, \& Chan, 2012; Munir, Burrows, Yarker, Kalawsky, \& Bains, 2010; Oberst, Bradley, Gardiner, Schenk, \& Given, 2010; Ottati \& Feuerstein, 2013; Todd et al., 2011; Von Ah, Habermann, Carpenter, \& Schneider, 2013). Quite a few studies ( $\mathrm{n}=9$ studies) investigated its relation to work barriers in breast cancer survivors. 
It has been demonstrated that cognitive effects and associated treatment-induced work disability lead to low work output of breast cancer survivors (Calvio et al., 2010; Munir et al., 2010). Compared to physical disability, “chemo-brain” may temporary and resolve once treatment stops. However, when they are experienced, breast cancer survivors may perceive cognitive effects as more stressful than physical impairments. Boykoff et al. (2009) noted that cognitive impairment was reported by many breast cancer survivors as the most troublesome symptom they experienced at work, ultimately resulting in diminished quality of life (Boykoff et al., 2009). Calvio et al. (2010) found that depression and fatigue were highly correlated with cognitive impairment (Calvio et al., 2010). This is apparent in the interaction between symptoms and the compounding effects of multiple symptoms.

Using qualitative methods, Munir et al. (2010) identified ways that cognitive impairments influence the work ability of breast cancer survivors. These researchers found that the effects of cognitive impairment on work ability depended upon whether the survivors were aware of their cognitive limitation, whether it affected their own confidence in their work, the level of their cognitive functioning, and their knowledge of common cognitive side effects (Munir et al., 2010).

Work demands and work environment. The effects of breast cancer and treatment on work demands depend to some degree on the nature of the work in which survivors are engaged. This is illustrated by one study which examined the effects of breast cancer treatment on musicians and identified need for sufficient upper extremity range of motion and strength (Babu, Swain, \& Rath, 2006; Schmalenberger et al., 2012a, 
2012b). In the study by Blinder, Patil et al. (2012), different job types appeared to significantly influence the work return rate in Latinas (Blinder, Patil, et al., 2012). Aside from these two studies, the difference in occupational demands on return to work has been largely unexplored.

Environmental factors in the workplace include both factors associated with the environment where the survivors participate in work activities and macro-level societal factors. Concerns associated with work environment include the ability to be accepted in the work place, identity, privacy, flexibility of the work, normalcy, physical appearance, privacy, and employer support (Blinder, Murphy, et al., 2012; Mujahid et al., 2010). In turn, employers’ support, including schedule flexibility, medical confidentiality, and especially maintaining a normal work environment, have been identified as important concerns by breast cancer survivors (Blinder, Murphy, et al., 2012).

Unfortunately, breast cancer survivors may face a number of challenges in the workplace. Tiedtke et al. (2012) reported the dilemma experienced by employers who feel pressured by the need to balance their business interests with the needs of employees who are breast cancer survivors (Tiedtke, Donceel, et al., 2012). Many studies have reported the importance of colleagues' and supervisors' attitudes toward survivors who are returning to work and whether offers of help have been made. Hakanen and Lindbohm (2008) reported that supervisors' avoidance and isolating behaviors were strongly associated with (and negatively affected) survivors' ability to remain engaged with their work (Hakanen \& Lindbohm, 2008). Carlsen et al. (2013) showed that work ability among survivors is negatively affected when help and support from a supervisor 
are insufficient (Carlsen et al., 2013) and Fantoi and colleagues (2010) showed that perceived lack of moral support from colleagues hindered work resumption (Fantoni et al., 2010).

Individual characteristics. There are many person-characteristics or demographic variables that could potentially influence breast cancer survivors’ choices about returning to work. In the literature reviewed, medical/treatment-related characteristics associated with work outcomes included later disease stage, surgical type of mastectomy, axillary node dissection, undergoing chemotherapy treatment (Hauglann et al., 2012; Johnsson et al., 2009), and multi-model treatment (Balak et al., 2008). Lower educational level was reported to be negatively associated with work resumption (Ahn et al., 2009; Fantoni et al., 2010). Individual personality, temperament, and optimism have been identified as factors which positively influence return-to-work and optimism and pessimism have been shown to be strongly associated with work engagement (Hakanen \& Lindbohm, 2008; Tamminga et al., 2012; Tiedtke, de Rijk, et al., 2012). Optimism was especially strongly associated with higher work engagement and buffered against negative environmental impact on work reentry (Blinder, Murphy, et al., 2012; Hakanen \& Lindbohm, 2008; Tamminga et al., 2012; Tiedtke, de Rijk, et al., 2012). Blinder and colleagues (2012) found the attitude of acceptance of the cancer diagnosis were likely contributors to continuing work throughout breast cancer diagnosis (Blinder, Murphy, et al., 2012).

Both the meaning of work and the perception of illness are individually related and influence choices about returning to work. For some, return-to-work may serve as a 
way to move forward, out a "sick role" and back into a sense of normalcy (Blinder, Murphy, et al., 2012; Tiedtke, de Rijk, et al., 2012). Others may question whether the effort needed to return to work is worth it, or search for the meaning of returning to work after experiencing a life-threatening illness (Tiedtke, de Rijk, et al., 2012). Self-perceived constraints and self-appraisal of ability to work are also factors which are likely to influence survivors' choices about returning to the workforce (Elizabeth Quinlan et al., 2009; Tan et al., 2012). These factors are tied to personal values, but also may be influenced by psychosocial factors such as depression, anxiety and stress. As such, they are essential to consider when designing interventions to support women who are considering return to work following breast cancer treatment.

Intuitively, it can be assumed that having a repertoire of coping skills can help survivors deal with potential barriers to re-entry into the work. Johnsson et al. (2011) demonstrated that coping resources were used by working breast cancer survivors more than by nonworking survivors (Johnsson et al., 2011) and two studies discussed resources that may help to improve coping skills (Johnsson et al., 2011; Tamminga et al., 2012), supporting this assumption.

Societal and cultural factors. Societal factors include attitudes and social norms about the value of survivors' return-to-work and also the resources that society can provide for this process. Societal attitudes may influence breast cancer survivors' decision about whether or not to even attempt to return to work. Studies showed that survivors neither want to be labeled as a disabled person, nor as a completely healthy person (Tamminga et al., 2012). Tamminga et al. (2012) provide an example of this 
struggle, describing a participant who returned to work, but gave up wearing wigs, thus showing her illness in order to gain understanding and support (Tamminga et al., 2012).

Participants from both the Tamminga et al. (2012) and Tiedtke et al. (2012) qualitative studies discussed the involvement of occupational physicians, important others who monitor patients’ medical progress, in their care. These professionals could potentially be helpful in survivors’ return-to-work plan. Despite its importance, healthcare professionals in the U.S. struggle with non-reimbursement for engaging in this type of work (Tamminga et al., 2012). In other countries, physicians, nurses, occupational/physical therapists and psychologists are able to provide consultation regarding return-to-work, but may still be hindered by lack training or competency in this specialty area (Tiedtke, Donceel, et al., 2012).

Family, friends, and significant others play an important role for survivors in the return-to-work decision process. Studies suggest that positive engagement may make survivors feel they were not struggling alone, therefore facilitating survivors' return-towork (Tamminga et al., 2012). On the other hand, studies showed that married women living with their spouses were less likely to go back to work quickly (Ahn et al., 2009; Lavigne et al., 2008; Mujahid et al., 2010). Marital status became a negative predictor, possibly due to the reason that the spouse provided financial support. Cultural mores and social norms may be moderator variables, such as influences on the attitudes of these important others, as well (Ahn et al., 2009; Blinder, Murphy, et al., 2012; Blinder, Patil, et al., 2012). Tan et al. (2012) surmised that overprotection from family may hinder the process of going back to work and may relate to cultural coping patterns (Tan et al., 
2012). Anh et al. (2009) also discussed that East Asian women had more expectations for family commitments and thus were likely to stop working, as they were usually not the main earner of their household income (Ahn et al., 2009). However, whether BCRL's influence is negative or not depends on the comparison with the survivors' own willingness towards work.

Regarding other sociodemographic variables, such as ethnicity effects, Mujahid et al. (2010) studied employment barriers among Latina and African-American breast cancer survivors and found that these women were more likely to stop working following treatment, compared to white women (Mujahid et al., 2010). We found no studies that explored the potential effects of rural vs. urban residence on survivors' employment. Additionally, we did not find studies specifically focusing on the effects of age in postbreast cancer return-to-work and findings from the few studies that reported on age as a secondary consideration were inconsistent.

\section{Intervention Studies}

The works above suggest an emerging literature that focuses on describing factors that affect breast cancer survivors who return to work or are considering returning to work. Within this literature, a very small number of studies have attempted interventions to facilitate the process of returning to work in this population.

Hoving, Broekhuizen, and Frings-Dresen (2009) published a systematic review of the literature between 1970 and 2007 and reported only four intervention studies that targeted breast cancer survivors and work (Fismen et al., 2000; Maguire, Brooke, Tait, Thomas, \& Sellwood, 1983; Sachs et al., 1980; Winick \& Robbins, 1977). It is difficult 
to draw conclusions from these studies to inform current practice, however, since three of the studies were published more than 25 years ago. Moreover, "return to work," per se, was not the primary target of treatment for any of the four studies. Rather, the interventions sought to improve "physical and social recovery" within a more traditional rehabilitation context. Notably, it is unclear whether the rehabilitation interventions improved outcome by any measure, as three of the four studies did not include a comparison group.

In the current review, only one intervention study was found published after 2007. This study which was conducted by Hubbard and colleagues (2013) reported on the effectiveness of case management and vocational rehabilitation services to help breast cancer survivors who wished to return to work Following an assessment of individuals' needs, the participants were referred to treatment services such as physiotherapy, occupational therapy, medical care for cancer treatment-related effects, psychological counseling, and/or complementary therapy. Despite the use of an intensive, multidisciplinary treatment model, no statistically significant differences were found between the experimental group and the control group (Hubbard et al., 2013). This may be due in part to the restrictive study criteria (e.g. the exclusion of participants with high levels of emotional distress) (Hubbard et al., 2013; Lewis, Sheng, Rhodes, Jackson, \& Schover, 2012; Tiedtke, de Rijk, et al., 2012), nonspecific program content, and/or small sample size. Tiedke et al. (2012) reported on systemic problems such as healthcare providers' limited competence with regard to advising survivors, and the shortage of occupational medicine physicians to assess work ability and facilitate return to work (Tiedtke, Donceel, et al., 2012). Thus, while the results of Hubbard's study were 
disappointing, it does provide a valuable service model for incorporating vocational rehabilitation care as part of comprehensive breast cancer survivorship care. It is noteworthy that in one study resources for supervisors and colleagues to help breast cancer survivors returning back to work were in demand (Tamminga et al., 2012). This might be an important area to explore in future intervention trials.

\section{Discussion}

In this review of the research we sought to better understand the issues faced by women treated for breast cancer, who consider returning to work after treatment. We found within this body of literature significant overlap in factors of interest and the studies showed good consistency in terms of findings. In terms of outcomes, breast cancer survivors showed lower rates of working, work ability, and performance, compared to corresponding healthy populations. Variables from the broad categories of health and well-being, symptoms and function, work demands and the work environment, individual characteristics, and societal and cultural factors, all bore on the outcomes of interest. Importantly, the literature is unbalanced with an overabundance of descriptive studies. Very few papers engaged in hypothesis-testing or examining interventions have been developed to ameliorate negative influences on return-to-work outcomes and mitigate unnecessary disability. This presents a significant gap in the research literature that should be addressed.

Our review identified some inconsistency with report of age effects on return-towork. The inconsistency is not wholly unexpected, as there are a number of inconsistent contextual factors in the two included studies that reported on this variable. For example, 
in France, where one sample was recruited, survivors may receive replacement income through the social protection system, a factor which may encourage retirement (Fantoni et al., 2010). The other study was conducted in Sweden, a country which has one of the highest employment rates for individuals over 55 years and thus may reflect differing societal values (Petersson et al., 2011). Thus, differing social contexts are important to consider when interpreting findings about return-to-work.

Findings compared and contrasted with a general cancer model. In our review of the literature, we found no models specifically addressing return-to-work among breast cancer survivors. Feuerstein and colleagues (2010), however, have constructed a model of chronic cancer survivorship and return-to-work (i.e. not limited to breast cancer survivors), which can be used for the purpose of comparing and contrasting what is known and what should be addressed in future research (Feuerstein et al., 2010).

The Feuerstein et al. (2010) model, which is conceptually- rather than empirically-founded, includes work outcomes similar to those identified in our review: return to work (timeframe), work ability, and work performance. These researchers also discussed sustainability and job retention, although we found no corresponding topics in the research specific to breast-cancer survivors. And while few intervention studies have been undertaken for breast cancer survivors, Feuerstein and colleagues (2010) argued for a number of logical intervention targets including health and well-being, symptoms, function, work demands, work environment, work-related policies and procedures, economic factors, and individual characteristics. 
Limitations of using general models in breast cancer populations. Our breast cancer-specific review shares conceptual similarities and therefore lends support for Feuerstein and colleagues' model. Notably, however, our review identifies some variables that were not included in Feuerstein's model, such as the concept of “coping.” Coping may potentially influence outcomes by mediating functional impairment and work demands. For example, breast cancer survivors undergoing chemotherapy frequently report “chemo brain,” which has the potential to interfere with learning and memory and could conceivably lead to decreased productivity or increased absences from work. Some of these individuals, however, may cope effectively with the problems they experience by taking notes, using electronic reminders, and/or using repetition to learn a new task, which in turn may allow them to maintain productivity and avoid absences. Feuerstein and colleagues (2010) also do not discuss certain individual factors associated with personality, such as pessimism vs. optimism, attitude toward work, response to difficulties, and spiritual beliefs. The breast cancer literature suggests that personalityrelated factors play an important role in both the decision to re-enter the workforce and in work performance.

Breast cancer survivors may deal with side effects that are unique to this type of cancer or which are gender-specific. Breast cancer survivors are more likely to suffer from upper extremity impairments or lymphedema than other cancer survivors (Assis, Marx, Magna, \& Ferrigno, 2013; Devoogdt et al., 2011; Hayes, Rye, Battistutta, DiSipio, \& Newman, 2010; Stubblefield \& Keole, 2014). These secondary functional problems compound any difficulties for returning to or remaining at work (Boyages et al., 2016; Chachaj et al., 2010; Dawes, Meterissian, Goldberg, \& Mayo, 2008; Hormes et al., 2010; 
Peugniez et al., 2011; Pyszel, Malyszczak, Pyszel, Andrzejak, \& Szuba, 2006; E. Quinlan et al., 2009; Smoot et al., 2010; Taghian, Miller, Jammallo, O'Toole, \& Skolny, 2014). "Induced menopause" also is common in female breast cancer survivors who are not yet menopausal. It can cause intense menopausal symptoms such as hot flashes, vaginal dryness, sleep disturbance, urinary tract problems, painful intercourse, and bone loss (Henry \& Griggs, 2009; Howard-Anderson, Ganz, Bower, \& Stanton, 2012). These symptoms can create significant emotional burden and reduced work productivity among breast cancer survivors (Gupta et al., 2006; Lavigne et al., 2008; Mortimer \& Behrendt, 2013).

Gender-based cultural views, such as attitudes towards the importance of women's careers, are more likely to be at play in breast cancer survivors, including having an impact on survivors' decisions to return to work. As an example, we noted a study with Korean participants (Ahn et al., 2009), many of whom did not return to work purportedly because of overprotective family and historical de-emphasis of women's careers. Changes in self-image and reduced self-esteem may be more prominent among female breast cancer survivors, compared to general cancer survivorship (Arroyo \& Lopez, 2011; Howard-Anderson et al., 2012; Peppercorn, 2009). Body image concerns and low self-compassion have been shown to be associated with increased psychological distress and depression (Anitei, Chraif, Vasile, \& Enache, 2012; Przezdziecki et al., 2013).

Motivation and reappraisal of values. At the core of research examining return to work among cancer survivors is the assumption that survivors seek normalcy or have 
an intrinsic desire to return-to-work. However, whether cancer patients and survivors return to work or not could be drastically affected by a re-evaluation of life priorities. The self-perceived meaning of work after being confronted with cancer is important information that should be evaluated by professionals before making occupational rehabilitation plans. For some breast cancer survivors, being freed from stressful work responsibilities, or changing to a new occupational role, including "homemaker," could be a better fit than returning to their previous occupational role.

\section{Disparity Concerns}

While very limited information is available regarding disparities and return-to-work among breast cancer survivors, this is an important topic in healthcare that can affect clinical care and population outcomes. The majority of studies looked at return-to-work in the white population. We know much less about the situation for other minorities, such as non-white American and numerous immigrants who make up a large proportion of the U.S. workforce and are even more underserved.

Minority survivors. We found two studies that investigated underrepresented populations in the U.S. Mujahid et al. (2010) studied employment barriers among Latina and African-American breast cancer survivors and found that these women were more likely to stop working following treatment, compared to white women (Mujahid et al., 2010). In a focus group study, Blinder, Murphy et al. (2012) examined breast cancer survivors from several underserved and minority populations in the U.S., including African-American, African-Caribbean, Chinese, Filipina, Latina, and non-Latina whites. The major themes identified in this sample with regard to returning-to-work were 
consistent with findings of the studies' sampled majority populations. The disparities exist among the minority groups. For example, acceptance of diagnosis stood out as an important concern among Chinese women, while change in appearance was rated as a very low concern (although an important concern in other minority groups). Normalcy, privacy, and employers' support, which were highly related to each other, were particularly important to all minority groups (Blinder, Murphy, et al., 2012).

Molina Villaverde et al. (2008) looked at job discrimination as survivors attempted to return to work. They found no clear evidence of job discrimination reported. Many survivors reported supportiveness from their co-workers (Molina Villaverde et al., 2008). However, two studies on Latinas and African-American survivors reported more women in these populations had longer delay in return-to-work, comparing to non-Latina white women (Blinder, Patil, et al., 2012; Mujahid et al., 2010). It is hard to draw any firm conclusions from these studies, as to whether this difference is due to work-related discrimination and how much discrimination exists in the workplace. The phenomenon is complexly related to social contexts and studies are needed to address this at later time points during the trajectory of rehabilitation.

Specific professions. Several papers examined specific factors as they relate to specific work roles. For example, Schmalenberger and colleagues investigated a sample of musicians using online survey methods. This group surveyed specific side effects or symptoms experienced by participants, the severity and duration of these symptoms, the treatment related to these symptoms, and the effects of symptoms on participants' ability to make music. Fatigue, cognition, upper body limitation, and pain were reported by 
study participants as most likely to diminish functional ability to perform. Especially problematic were upper body pain and morbidity, upper extremity numbness and movement limitations, chest contracture, and shortness of breath (Schmalenberger et al., 2012a, 2012b).

Loss of function within such a specific occupation and skill set may be associated with more severe psychological effects than in other careers. Based on this inference, similar effects were expected to occur among athletes, photographers, chefs, etc. More studies are needed to examine people's experience in these highly affected occupations. When working with breast cancer survivors, healthcare providers' awareness of their patients' occupational specialties can help them to be empathic and support the survivor.

\section{Conclusion}

This review evaluated the literature regarding return to work among breast cancer survivors within a 10-year timeframe. Without exception, all of the studies reported a reduced work engagement and work ability among breast cancer survivors. Employment status and work quality depends, however, on the combination and interaction of individual factors, occupation and work demands, and environmental factors. The complexity and potential for interactions among variables add challenges to health providers’ vocational rehabilitation service. A collaborative effort among interdisciplinary clinicians and researchers is needed to develop effective and feasible intervention under specific societal context (culture, economic, health care policy, etc.). Finally, studies on disparities in treatment and successful return to work among breast 
cancer survivors are needed to develop interventions for patients in underserved or underresearched populations.

Acknowledgements: It is acknowledged that no Veterans Affairs resources were used for the conduct of this work.

Compliance with Ethical Standards

Conflict of Interest: Yuanlu Sun declares that she has no conflict of interest. Cheryl L. Shigaki declares that she has no conflict of interest. Jane M. Armer declares that she has no conflict of interest.

Ethical approval: This article does not contain any studies with human participants performed by any of the authors. 


\section{References}

Ahn, E., Cho, J., Shin, D. W., Park, B. W., Ahn, S. H., Noh, D. Y., . . Yun, Y. H. (2009). Impact of breast cancer diagnosis and treatment on work-related life and factors affecting them. Breast Cancer Research \& Treatment, 116(3), 609-616.

American Cancer Society. (2013). Breast Cancer Facts \& figures 2013-2014. Atlanta, GA. Retrieved from

http://www.cancer.org/acs/groups/content/@research/documents/document/acspc042725.pdf

American Cancer Society. (2015). Global Cancer Facts \& Figures 3rd Edition. Atlanta, GA. Retrieved from https://www.cancer.org/content/dam/cancerorg/research/cancer-facts-and-statistics/global-cancer-facts-and-figures/globalcancer-facts-and-figures-3rd-edition.pdf

Anitei, M., Chraif, M., Vasile, C., \& Enache, R. G. (2012). The relationship between anxiety, depression and self-esteem in women with breast cancer after surgery. Procedia - Social and Behavioral Sciences, 33, 124-127. doi:http://dx.doi.org/10.1016/j.sbspro.2012.01.096

Arroyo, J. M., \& Lopez, M. L. (2011). Psychological Problems Derived from Mastectomy: A Qualitative Study. International Journal of Surgical Oncology, Vol. 2011, 132461. doi:10.1155/2011/132461

Assis, M. R., Marx, A. G., Magna, L. A., \& Ferrigno, I. S. (2013). Late morbidity in upper limb function and quality of life in women after breast cancer surgery. Braz J Phys Ther, 17(3), 236-243. 
Babu, B. V., Swain, B. K., \& Rath, K. (2006). Impact of chronic lymphatic filariasis on quantity and quality of productive work among weavers in an endemic village from India. Tropical Medicine \& International Health, 11(5), 712-717.

Balak, F., Roelen, C. A., Koopmans, P. C., Ten Berge, E. E., \& Groothoff, J. W. (2008). Return to work after early-stage breast cancer: A cohort study into the effects of treatment and cancer-related symptoms. Journal of Occupational Rehabilitation, 18(3), 267-272.

Blinder, V. S., Murphy, M. M., Vahdat, L. T., Gold, H. T., de Melo-Martin, I., Hayes, M. K., . . . Mazumdar, M. (2012). Employment after a breast cancer diagnosis: a qualitative study of ethnically diverse urban women. Journal of Community Health, 37(4), 763-772.

Blinder, V. S., Patil, S., Thind, A., Diamant, A., Hudis, C. A., Basch, E., \& Maly, R. C. (2012). Return to work in low-income Latina and non-Latina white breast cancer survivors: A 3-year longitudinal study. Cancer, 118(6), 1664-1674.

Boyages, J., Kalfa, S., Xu, Y., Koelmeyer, L., Mackie, H., Viveros, H., . . Gollan, P. (2016). Worse and worse off: The impact of lymphedema on work and career after breast cancer. SpringerPlus, 5(1), 1-8. doi:10.1186/s40064-016-2300-8

Boykoff, N., Moieni, M., \& Subramanian, S. K. (2009). Confronting chemobrain: An indepth look at survivors' reports of impact on work, social networks, and health care response. Journal of Cancer Survivorship, 3(4), 223-232.

Breckenridge, L. M., Bruns, G. L., Todd, B. L., \& Feuerstein, M. (2012). Cognitive limitations associated with tamoxifen and aromatase inhibitors in employed breast cancer survivors. Psycho-Oncology, 21(1), 43-53. 
Calvio, L., Peugeot, M., Bruns, G. L., Todd, B. L., \& Feuerstein, M. (2010). Measures of cognitive function and work in occupationally active breast cancer survivors. Journal of Occupational \& Environmental Medicine, 52(2), 219-227.

Carlsen, K., Jensen, A. J., Rugulies, R., Christensen, J., Bidstrup, P. E., Johansen, C., . . . Dalton, S. O. (2013). Self-reported work ability in long-term breast cancer survivors. A population-based questionnaire study in Denmark. Acta Oncologica, 52(2), 423-429.

Chachaj, A., Malyszczak, K., Pyszel, K., Lukas, J., Tarkowski, R., Pudelko, M., .. . Szuba, A. (2010). Physical and psychological impairments of women with upper limb lymphedema following breast cancer treatment. Psychooncology, 19(3), 299305. doi:10.1002/pon.1573

Cheung, Y. T., Tan, E. H., \& Chan, A. (2012). An evaluation on the neuropsychological tests used in the assessment of postchemotherapy cognitive changes in breast cancer survivors. Supportive Care in Cancer, 20(7), 1361-1375.

Dawes, D. J., Meterissian, S., Goldberg, M., \& Mayo, N. E. (2008). Impact of lymphoedema on arm function and health-related quality of life in women following breast cancer surgery. J Rehabil Med, 40(8), 651-658. doi:10.2340/16501977-0232

Désiron, H. A. M., Donceel, P., de Rijk, A., \& Van Hoof, E. (2013). A conceptualpractice model for occupational therapy to facilitate return to work in breast cancer patients. Journal of Occupational Rehabilitation, 23(4), 516-526. doi:10.1007/s10926-013-9427-z 
Devoogdt, N., Van Kampen, M., Christiaens, M. R., Troosters, T., Piot, W., Beets, N., . . Gosselink, R. (2011). Short- and long-term recovery of upper limb function after axillary lymph node dissection. European Journal of Cancer Care, 20(1), 77-86. doi:10.1111/j.1365-2354.2009.01141.x

Duijts, S., Spelten, E., \& Verbeek, J. (2014). Behavioral determinants of employment status in cancer patients The Handbook of Behavioral Medicine (pp. 825-849): John Wiley \& Sons, Ltd.

Fantoni, S. Q., Peugniez, C., Duhamel, A., Skrzypczak, J., Frimat, P., \& Leroyer, A. (2010). Factors related to return to work by women with breast cancer in northern France. Journal of Occupational Rehabilitation, 20(1), 49-58.

Feuerstein, M., Todd, B. L., Moskowitz, M. C., Bruns, G. L., Stoler, M. R., Nassif, T., \& Yu, X. (2010). Work in cancer survivors: A model for practice and research. Journal of Cancer Survivorship, 4(4), 415-437.

Fismen, K., Osland, I. J., Fismen, E., Borge, L., Martinsen, E. W., Hjort, P., . . . Stanghelle, J. K. (2000). [Rehabilitation of women with breast cancer]. Tidsskr Nor Laegeforen, 120(23), 2749-2754.

Gupta, P., Sturdee, D. W., Palin, S. L., Majumder, K., Fear, R., Marshall, T., \& Paterson, I. (2006). Menopausal symptoms in women treated for breast cancer: the prevalence and severity of symptoms and their perceived effects on quality of life. Climacteric, 9(1), 49-58. doi:10.1080/13697130500487224

Hakanen, J. J., \& Lindbohm, M. L. (2008). Work engagement among breast cancer survivors and the referents: the importance of optimism and social resources at work. Journal of Cancer Survivorship, 2(4), 283-295. 
Hansen, J. A., Feuerstein, M., Calvio, L. C., \& Olsen, C. H. (2008). Breast cancer survivors at work. Journal of Occupational \& Environmental Medicine, 50(7), 777-784.

Hauglann, B., Benth, J. S., Fossa, S. D., \& Dahl, A. A. (2012). A cohort study of permanently reduced work ability in breast cancer patients. Journal of Cancer Survivorship, 6(3), 345-356.

Hayes, S. C., Rye, S., Battistutta, D., DiSipio, T., \& Newman, B. (2010). Upper-body morbidity following breast cancer treatment is common, may persist longer-term and adversely influences quality of life. Health and Quality of Life Outcomes, 8. doi:10.1186/1477-7525-8-92

Henry, N. L., \& Griggs, J. J. (2009). Complexities of adjuvant endocrine therapy in young premenopausal women. Oncology (Williston Park), 23(6), 482, 487.

Hormes, J. M., Bryan, C., Lytle, L. A., Gross, C. R., Ahmed, R. L., Troxel, A. B., \& Schmitz, K. H. (2010). Impact of lymphedema and arm symptoms on quality of life in breast cancer survivors. Lymphology, 43(1), 1-13.

Hoving, J. L., Broekhuizen, M. L., \& Frings-Dresen, M. H. (2009). Return to work of breast cancer survivors: a systematic review of intervention studies. BMC Cancer, 9, 117.

Howard-Anderson, J., Ganz, P. A., Bower, J. E., \& Stanton, A. L. (2012). Quality of life, fertility concerns, and behavioral health outcomes in younger breast cancer survivors: A systematic review. Journal of the National Cancer Institute, 104(5), 386-405. 
Howlader, N., Noone, A. M., Krapcho, M., Garshell, J., Miller, D., Altekruse, S. F., .. . Cronin, K. A. (2015). SEER Cancer Statistics Review, 1975-2012. Available from based on November 2014 SEER data submission based on November 2014 SEER data submission Retrieved 2015, from National Cancer Institute http://seer.cancer.gov/csr/1975_2012

Hubbard, G., Gray, N. M., Ayansina, D., Evans, J. M., \& Kyle, R. G. (2013). Case management vocational rehabilitation for women with breast cancer after surgery: A feasibility study incorporating a pilot randomised controlled trial. Trials [Electronic Resource], 14, 175.

Johnsson, A., Fornander, T., Rutqvist, L. E., \& Olsson, M. (2011). Work status and life changes in the first year after breast cancer diagnosis. Work, 38(4), 337-346.

Johnsson, A., Fornander, T., Rutqvist, L. E., Vaez, M., Alexanderson, K., \& Olsson, M. (2009). Predictors of return to work ten months after primary breast cancer surgery. Acta Oncologica, 48(1), 93-98.

Lavigne, J. E., Griggs, J. J., Tu, X. M., \& Lerner, D. J. (2008). Hot flashes, fatigue, treatment exposures and work productivity in breast cancer survivors. Journal of Cancer Survivorship, 2(4), 296-302.

Lerner, D., Amick Iii, B. C., Rogers, W. H., Malspeis, S., Bungay, K., \& Cynn, D. (2001). The work limitations questionnaire. Medical Care, 39(1), 72-82.

Lewis, P. E., Sheng, M., Rhodes, M. M., Jackson, K. E., \& Schover, L. R. (2012). Psychosocial concerns of young African American breast cancer survivors. Journal of Psychosocial Oncology, 30(2), 168-184. 
Maguire, P., Brooke, M., Tait, A., Thomas, C., \& Sellwood, R. (1983). The effect of counselling on physical disability and social recovery after mastectomy. Clin Oncol, 9(4), 319-324.

Mehnert, A., de Boer, A., \& Feuerstein, M. (2013). Employment challenges for cancer survivors. Cancer, 119(11, Suppl), 2151-2159. doi:10.1002/cncr.28067

Molina Villaverde, R., Feliu Batlle, J., Villalba Yllan, A., Jimenez Gordo, A. M., Redondo Sanchez, A., San Jose Valiente, B., \& Gonzalez Baron, M. (2008). Employment in a cohort of breast cancer patients. Occupational Medicine (Oxford), 58(7), 509-511.

Mortimer, J., \& Behrendt, C. E. (2013). Severe menopausal symptoms are widespread among survivors of breast cancer treatment regardless of time since diagnosis. $J$ Palliat Med, 16(9), 1130-1134. doi:10.1089/jpm.2012.0585

Mujahid, M. S., Janz, N. K., Hawley, S. T., Griggs, J. J., Hamilton, A. S., \& Katz, S. J. (2010). The impact of sociodemographic, treatment, and work support on missed work after breast cancer diagnosis. Breast Cancer Research \& Treatment, 119(1), 213-220.

Munir, F., Burrows, J., Yarker, J., Kalawsky, K., \& Bains, M. (2010). Women's perceptions of chemotherapy-induced cognitive side affects on work ability: A focus group study. Journal of Clinical Nursing, 19(9-10), 1362-1370.

Oberst, K., Bradley, C. J., Gardiner, J. C., Schenk, M., \& Given, C. W. (2010). Work task disability in employed breast and prostate cancer patients. Journal of Cancer Survivorship, 4(4), 322-330. 
Ottati, A., \& Feuerstein, M. (2013). Brief self-report measure of work-related cognitive limitations in breast cancer survivors. Journal of Cancer Survivorship, 7(2), 262273.

Peppercorn, J. (2009). Breast cancer in women under 40. Oncology (Williston Park), 23(6), 465-474.

Petersson, L. M., Wennman-Larsen, A., Nilsson, M., Olsson, M., \& Alexanderson, K. (2011). Work situation and sickness absence in the initial period after breast cancer surgery. Acta Oncologica, 50(2), 282-288.

Peugniez, C., Fantoni, S., Leroyer, A., Skrzypczak, J., Duprey, M., \& Bonneterre, J. (2011). Return to work after treatment for breast cancer: Single center experience in a cohort of 273 patients. Bulletin du Cancer, 98(7), E69-79.

Przezdziecki, A., Sherman, K. A., Baillie, A., Taylor, A., Foley, E., \& Stalgis-Bilinski, K. (2013). My changed body: Breast cancer, body image, distress and selfcompassion. Psycho-Oncology, 22(8), 1872-1879. doi:10.1002/pon.3230

Pyszel, A., Malyszczak, K., Pyszel, K., Andrzejak, R., \& Szuba, A. (2006). Disability, psychological distress and quality of life in breast cancer survivors with arm lymphedema. Lymphology, 39(4), 185-192.

Quinlan, E., Thomas-MacLean, R., Hack, T., Kwan, W., Miedema, B., Tatemichi, S., . . . Tilley, A. (2009). The impact of breast cancer among Canadian women: Disability and productivity. Work: Journal of Prevention, Assessment \& Rehabilitation, 34(3), 285-296. 
Quinlan, E., Thomas-MacLean, R., Hack, T., Kwan, W., Miedema, B., Tatemichi, S., .. . Tilley, A. (2009). The impact of breast cancer among Canadian women: Disability and productivity. Work, 34(3), 285-296.

Richardson, A., Addington-Hall, J., Amir, Z., Foster, C., Stark, D., Armes, J., . . Sharpe, M. (2011). Knowledge, ignorance and priorities for research in key areas of cancer survivorship: Findings from a scoping review. British Journal of Cancer, 105(SUPPL. 1), S82-S94.

Sachs, S. H., Davis, J. M., Reynolds, S. A., Spagnola, M., Hall, P., \& Bloch, A. (1980). Postmastectomy rehabilitation in a community hospital. J Fam Pract, 11(3), 395401.

Schmalenberger, S., Gessert, C. E., Giebenhain, J. E., \& Starr, L. D. (2012a). Livelihood vs. life: The occupational well-being of women musician survivors of breast cancer. Medical Problems of Performing Artists, 27(1), 15-20.

Schmalenberger, S., Gessert, C. E., Giebenhain, J. E., \& Starr, L. D. (2012b). Working after breast cancer treatment: Lessons from musicians. Medical Problems of Performing Artists, 27(4), 175-180.

Smoot, B., Wong, J., Cooper, B., Wanek, L., Topp, K., Byl, N., \& Dodd, M. (2010). Upper extremity impairments in women with or without lymphedema following breast cancer treatment. Journal of Cancer Survivorship, 4(2), 167-178. doi:10.1007/s11764-010-0118-X

Stubblefield, M. D., \& Keole, N. (2014). Upper body pain and functional disorders in patients with breast cancer. Pm r, 6(2), 170-183. doi:10.1016/j.pmrj.2013.08.605 
Taghian, N. R., Miller, C. L., Jammallo, L. S., O'Toole, J., \& Skolny, M. N. (2014). Lymphedema following breast cancer treatment and impact on quality of life: A review. Critical Reviews in Oncology/Hematology, 92(3), 227-234. doi:10.1016/j.critrevonc.2014.06.004

Tamminga, S. J., de Boer, A. G., Verbeek, J. H., \& Frings-Dresen, M. H. (2012). Breast cancer survivors' views of factors that influence the return-to-work process--A qualitative study. Scandinavian Journal of Work, Environment \& Health, 38(2), 144-154.

Tan, F. L., Loh, S. Y., Su, T. T., Veloo, V. W., \& Ng, L. L. (2012). Return to work in multi-ethnic breast cancer survivors--A qualitative inquiry. Asian Pacific Journal of Cancer Prevention: Apjcp, 13(11), 5791-5797.

Tiedtke, C., de Rijk, A., Donceel, P., Christiaens, M. R., \& de Casterle, B. D. (2012). Survived but feeling vulnerable and insecure: A qualitative study of the mental preparation for RTW after breast cancer treatment. BMC Public Health, 12, 538.

Tiedtke, C., Donceel, P., Knops, L., Desiron, H., Dierckx de Casterle, B., \& de Rijk, A. (2012). Supporting return-to-work in the face of legislation: Stakeholders' experiences with return-to-work after breast cancer in Belgium. Journal of Occupational Rehabilitation, 22(2), 241-251.

Todd, B. L., Feuerstein, E. L., \& Feuerstein, M. (2011). When breast cancer survivors report cognitive problems at work. International Journal of Psychiatry in Medicine, 42(3), 279-294. 
Von Ah, D., Habermann, B., Carpenter, J. S., \& Schneider, B. L. (2013). Impact of perceived cognitive impairment in breast cancer survivors. European Journal of Oncology Nursing, 17(2), 236-241.

Winick, L., \& Robbins, G. F. (1977). Physical and psychologic readjustment after mastectomy: An evaluation of Memorial Hospitals' PMRG program. Cancer, 39(2), 478-486. 


\title{
CHAPTER THREE
}

\section{A NURSE'S TWENTY-FOUR-YEAR JOURNEY WITH BREAST CANCER-RELATED LYMPHEDEMA}

Manuscript Submitted: Sun Y., \& Armer J. M. (in review). A nurse’s twenty-four-year journey with breast cancer-related lymphedema.

\begin{abstract}
BACKGROUND: Lymphedema is one of the major complications for breast cancer treatment. The majority of women who developed breast cancer are in the active workforce. Therefore, occupational functioning and employment are issues of significant concern among women with breast cancer-related lymphedema (BCRL). We present a single-case study of a nurse with BCRL, as an exemplar to explore the 'return-to-work' phenomenon. METHODS: A sixty-minute, semi-structured interview was conducted with a selected single case ("Linda”), following a pre-interview survey. Themes and subconcepts were generated through constant comparison of evidence within the case.

RESULTS: Themes included: the feeling of being lost, fear and uncertainty due to the risk of infection, functional impairment, being limited yet not being limited, and experiencing different challenges with different jobs. Overall, returning to work with BCRL was a complex phenomenon involving interactions of the disease process, the work activity, the individual and an array of contextual factors. CONCLUSIONS: Linda's struggles, efforts, and adaptations at different career points were revealing and exemplified how individuals navigate the journey of returning to work with BCRL.
\end{abstract} Keywords: breast cancer, lymphedema, return to work 


\section{A NURSE'S TWENTY-FOUR-YEAR JOURNEY WITH BREAST CANCER- RELATED LYMPHEDEMA}

\section{Introduction}

The number of individuals who are living after cancer diagnoses and treatment has increased (American Cancer Society, 2013, 2014a). Breast cancer is the second most common cancer affecting women in United States with 3.1 million breast cancer survivors in the United States (American Cancer Society, 2014b). The majority of women who develop breast cancer are still in their employment years (Howlader et al., 2015), their vocational rehabilitation could raise significant concern. Employment not only affects financial resources, but also social networks. Studies have shown that the returnto-work rate, work ability, and performance are greatly decreased among breast cancer survivors, compared to healthy populations (Sun, Shigaki, \& Armer, 2017).

Lymphedema is one of the major complications that can follow breast cancer treatment. This condition is referred to as breast cancer-related lymphedema (BCRL) or secondary lymphedema (secondary to cancer treatment). Lymphedema occurs when fluid and protein accumulate in the extravascular interstitial spaces and it is associated with feelings of discomfort and heaviness, functional limitations, disfigurement, psychological distress, and an elevated risk of recurrent infection (American Cancer Society, 2014c). Lymphedema cannot yet be completely cured, and related symptoms and symptom distress may lead to poor quality of life (QOL) in the long-term (Ridner, 2005; Ridner et al., 2012). 
Negative work outcomes have been shown to be associated with BCRL (Boyages et al., 2016; Peugniez et al., 2011), especially among young survivors (Bifulco et al., 2012). However, little is known from the perspective of survivors and the specific effects of BCRL on their career life. In this paper, we present a single-case analysis with the aim of describing, from a personal perspective, the phenomenon of 'returning-to-work' with BCRL.

\section{Methods}

Yin’s (2014) case-study methodology was employed, the investigation of a phenomenon within its real-life context, especially when the boundaries between phenomenon (the case) and context are not clearly distinguishable (p.16). The case, “Linda” (pseudonym), was selected from a sample of 13 cases analyzed and reported elsewhere (Sun, Shigaki, \& Armer, In review). The participant completed an in-depth individual interview responding to questions about the how BCRL influenced her work experience, following a pre-interview survey that captured demographic, work-, and disease-related information. The participant was given the opportunity to share anything about her thoughts, feelings, and experiences with BCRL. The International Classification of Functioning, Disability, and Health (ICF, (World Health Organization, 2001)) was used to guide the development of interview questions and surveys. The ICF presents a holistic view of health outcomes by considering not only the disease-related factors, but also the effects of environmental and personal factors.

Linda was selected to be the subject of this single-case study because she had long (more than two decades) breast cancer survival time and history of BCRL, as well as 
multiple career changes. We felt these circumstances would provide opportunities to reveal the phenomenon with different contexts and the changes of the conditions over time. Linda also had an excellent understanding of BCRL, which allowed her to provide rich and detailed observation of how the disease process affected her. Both the case and the contextual conditions were examined. Constant-comparative data analysis was conducted within the single-case including: identifying and categorizing instances with similar properties that emerged from the data; comparing the properties with each set of categories; delimiting theoretical understanding from these categories, and writing the theory in the form of propositions, a model, or a narrative (Glaser \& Strauss, 1999).

\section{Results}

\section{Case Context}

Disease process. Linda is a 65-year-old Caucasian woman who has survived breast cancer for 27 years. She was married and had two young, school-aged children at the time of her initial breast cancer diagnosis. Her first breast cancer was treated with lumpectomy, removal of 20 lymph nodes, and external radiation to the right breast for 6 to 7 weeks. Linda underwent complete hysterectomy sixteen years after her initial breast cancer diagnosis, due to continuous bleeding. A second breast cancer then occurred twenty-four years after her initial diagnosis, at which point she underwent bilateral mastectomy with a prophylactic mastectomy (the left breast had lobular cancer in situ), one lymph node removal, and breast reconstruction procedures.

Linda developed lymphedema three years after her initial breast cancer diagnosis and treatment, when she was 39 years old. The symptoms and signs she reported related 
to lymphedema included: arm weakness, swelling, heaviness, redness, firmness, increased temperature, numbness, stiffness, aching, sleep problems, infection, lymphorrhea (weeping of lymphatic fluid), and difficulty with fit of clothes. She experienced repeated infections of the arm (cellulitis). Other co-morbid health conditions reported include: depression/anxiety, urinary incontinence, and hypothyroidism.

Work history. Linda was a registered nurse with a graduate degree. She resided near a medium-size city in the Midwestern United States. In her most recent jobs, she commuted 30 minutes to work from home.

Linda had a number of different jobs that capitalized on her nursing training over her career life. At the time of lymphedema diagnosis, she was working as a school nurse (three years). She saw 70-100 students a day in her office, which she reported as stressful. Her duties included one-on-one assessment and management of children who were sick; routine health screenings such as for hearing, vision, and scoliosis; management of students' immunization records; and providing health education for students and school staff. Linda changed jobs about a year later, and became a parent educator in a public health program targeting children 0-5 years of age for one year. In this position, she made home visits after work/school hours to work with parents and their children to maximize readiness for school. After that, she served as a nurse coordinator/consultant for three different public health programs over a decade. Most recently, before she retired, she worked as a nurse consultant/coordinator in two large quality assurance/improvement programs, for 11 years each. She worked full-time (40-hours-per-week) for her entire career. She had two-month sick leave when undergoing treatment for breast cancer, and occasionally took a few hours off during workdays for lymphedema clinic visits, and 
used several accumulated days of sick leave when under treatment for BCRL-related infection. She always had employer-sponsored medical insurance with good coverage.

\section{Themes}

\section{The Feeling of Being Lost}

Linda shared that her most difficult experience with BCRL was the struggle at the beginning, where she engaged in a long period of searching for a diagnosis and treatment for her lymphedema. She developed symptoms three years after her initial breast cancer diagnosis, when there was almost no information about lymphedema in the area where she was living. Her healthcare providers only recognized the presence of a problem after repeated episodes of infection. Each time, she was treated as if she were experiencing a single, discrete infection. She recalled that the doctors sent her antibiotics without any further examination or information. Even when the swelling from lymphedema became easily apparent, she felt ignored by all of her doctors: her surgeon, her medical oncologist, and her radiation oncologist.

Linda said, "So I went all over, to different doctors trying to get help, and they all turned me away. At that time, that was back in '93... because I've gone to all these different physicians and nobody would help or didn't know how to help." It took three years to finally learn that her diagnosis was BCRL and find a place someone who could treat it.

“It actually wasn't a 'diagnosis of lymphedema' at the time. They didn't treat lymphedema at (the time) when I was diagnosed, or when I went in for the cellulitis, they treated the infection, and then there was no other treatment 
available in this locale at that time. And then how I learned about lymphedema treatment was when I worked in [cancer screening], 'cause I worked with the whole state, and then I found out there were one or two lymphedema programs, and my arm was swollen and that's how I ended up getting treatment at that point."

During the years of searching, Linda was frustrated, helpless, angry, and felt like she was being ignored. “They didn't identify it and they left me to struggle to find my own answers and it took years to get the answers." She believed that the root cause of her struggles with her health and frustration was due to profound lack of awareness and resources for identifying and treating lymphedema and she felt the clinicians were disinterested in learning more about her condition (lymphedema). "If there had been adequate treatment at the beginning, outcomes would've been different." Linda felt she 'survived' lymphedema much the same way as she survived breast cancer. She perceived her journey as being filled with danger and challenges. "I used to say, the lymphedema used to remind me of how lucky I am to still be living, and I still say that."

\section{Fear and Uncertainty due to the Risk of Infection}

Linda's lymphedema was initially triggered by an infection in her arm that continued to recur and these recurrences became her biggest fear. She described them as "frightening," as she didn’t know how to handle these while watching the symptoms develop rapidly.

“When I get the infections, you know you get you're really sick, uh, like you get high fevers, your whole body aches. You can't.... I couldn't get..... I'd 
have to get treated before I could function again. You'd get worried because you'd start seeing the rash move across your body. Like, I've been traveling before when I've had lymphedema go out of control and it's really frightening because you don't know how to handle it."

Sometimes, the infection occurred at inopportune times, which could make the situation even worse. Linda recalled times when infection flared on the weekend or on a holiday, when antibiotic medication was hard to access, which resulted in her having to go to the emergency room repeatedly. She reported another episode, when the BCRLassociated cellulitis occurred early in a business trip and the antibiotic failed to control the condition. She became too sick to function and had to cancel the meeting mid-way through. Throughout her working years, management of infection induced by BCRL was the main reason for her use of sick leave.

\section{Functional Impairments Related to BCRL and Bandaging}

Linda reported that both the BCRL and the short-stretch bandaging used for reducing lymphedema-related swelling affected her functioning. On top of that, the bandaging itself made work difficult.

Reduced physical function. Linda recalled ways that BCRL has impeded her functioning. "I guess when I look back upon my career, carrying (things) is the biggest, one of the bigger things, that's always been the challenge as a result of lymphedema." She could not do as much lifting and carrying because of arm weakness, sensations of heaviness, and because she feared that these activities would cause even more swelling. 
However, carrying things was part of so many activities that this limitation affected her on a daily basis.

Bandaging is bothersome. Linda explained how difficult the bandaging (Photograph 3.1) had made her work and daily life. It limited her ability to use a computer keyboard and writing for taking notes; tasks that were essential for all of the jobs she held as a nurse. Linda described it like "wearing a boa constrictor on your arm." She said, "It's harder to do everything... it would interfere with almost my whole work day." She gave examples such as eating, going to bathroom, and driving, especially if the car did not have an armrest for support. Her bandaging also interfered directly with her work activities. One time when she went through the airport security with bandage wraps during her business trip, she was pulled out of the security line for a body search and asked to unwrap the bandages. Afterwards, she had to wrap her arm back up. She felt this was ironic, as it could be inferred that the security agents deemed her a threat, when she herself felt impaired.

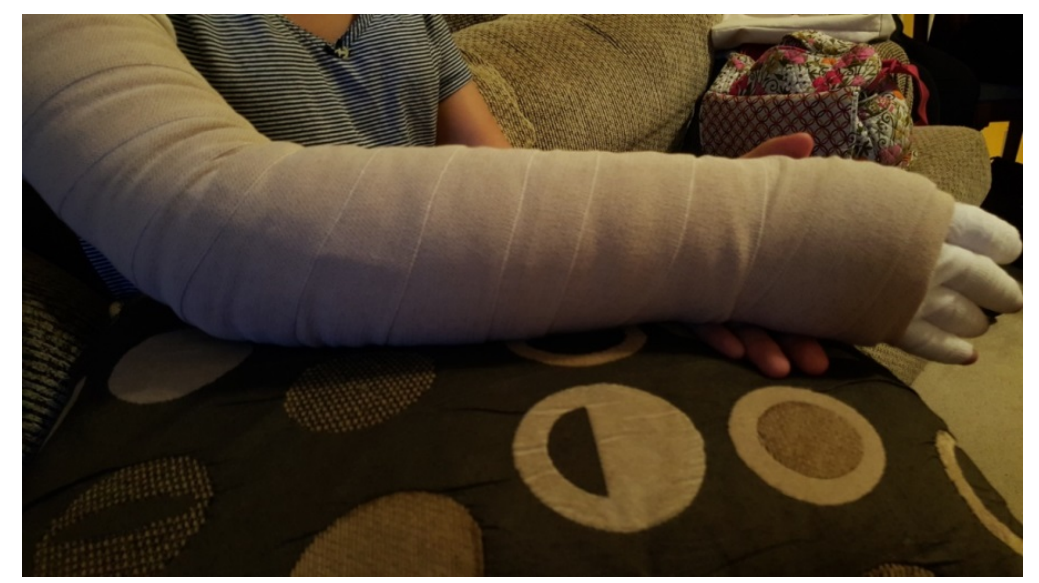

Photograph 3.1 Bandaging treatment for breast cancer related lymphedema 
In addition to affecting functionality, the bandaging also created considerable discomfort. Linda described, “When you're wearing them 24-hours-a-day, I feel like I'm gonna pull my hair out because they're so uncomfortable." The discomfort impacted her motivation to work because she was "just always agitated." At times she also wore compression sleeves and gauntlet (Photograph 3.2), but these also were uncomfortable and hot. This was especially problematic in the summer and during outdoor traveling, when she sweated more. Using a compression sleeve also was concerning as the top edge rolled down easily and the roll caused an area of constriction and decreased circulation, which could be potentially hazardous as well as uncomfortable.

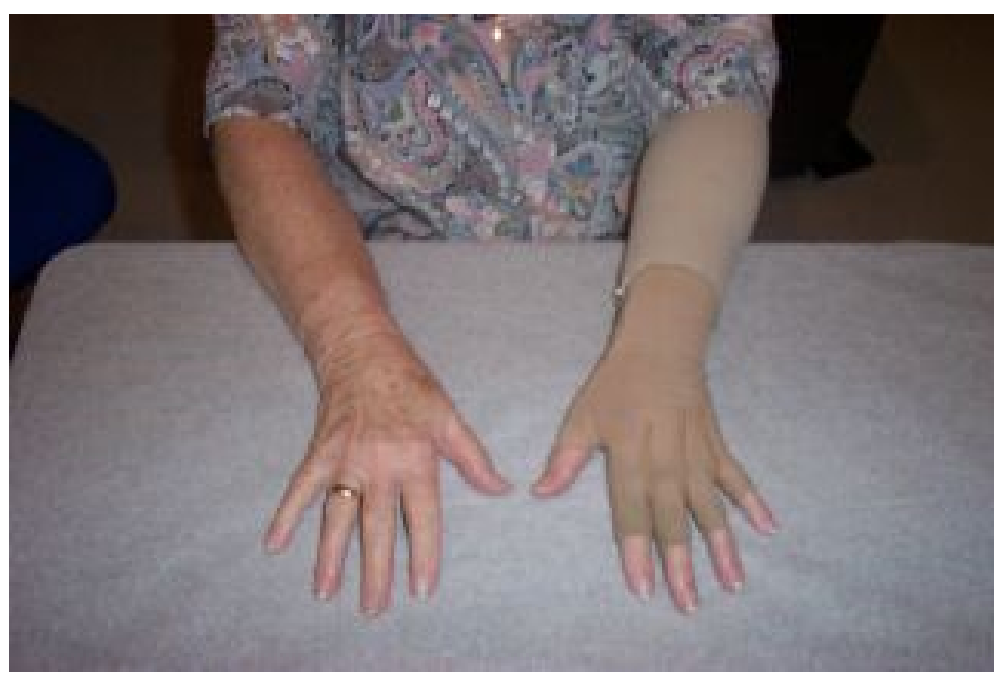

Photograph 3.2 Compression sleeve and gauntlet for breast cancer related lymphedema

Besides functional restrictions and discomfort, Linda felt the bandages and compression sleeves distracted from her job role. Such devices drew unwanted attention from others. She said, “When I'm trying to do certain things, like a presentation, it would be its bothersome. My role is to deliver a different message, not to deliver that I'm 
needy." From a process perspective, managing bandaging added time burden to her work life routine. While not visible to others, this was certainly an added and unwanted distraction for her. Linda had a busy career life, but bandaging became a necessary step added to her morning routine during the acute phase of BCRL.

Emotional distress. Linda's emotions were initially affected by her struggles with identifying BCRL. Once treatments were initiated, additional emotional struggles emerged. She felt discouraged because the treatments (e.g. bandaging) did not cure her BCRL and did not always even reliably control her symptoms, despite her compliance. "It always just seems to go back to a certain state... I would try to follow every single rule they'd give me about using the wrap all the time and having a sleep garment. I got a couple of the pumps that were supposed to be able to help, none of them really seem to control it.” As with many other chronic conditions, it was hard for her to maintain the motivation to adhere to treatment, when her efforts did not seem to correspond with improvement. "I'd give up on the wraps and say I'm just not gonna worry about it." Additionally, Linda did not like to have her bandaged arm to be visible by others and always tried to cover it. She felt it did not look good because of the bandaging and the drain related to lymphedema infection. She described herself as having always been selfconscious, and developing BCRL at a young adult age was upsetting and increased her negative body image. "I feel I got old early. I got lymphedema when I was in my 30's, so then it affected my clothing. It affected how I perceived myself. It made me feel old before my time."

\section{Being Limited, but not Being Limited}


Even though she shared many difficult experiences and restrictions related to her BCRL, Linda still worked full-time and experienced many points of growth in the path of her chosen career. Her success does not seem to be fully explained by simple motivation for financial income or a desire to be independent. Personal attributes also seemed to contribute to her striving to 'not be limited' in her work. This included an ability to take different perspectives and a sense of self-efficacy for developing coping strategies when challenges were faced.

Not perceiving herself as limited. Even though she experienced repeated infections that made her sick, and even though bandages and BCRL made everything hard to do, Linda said, "I don't consider it as a limiting thing, other than I consider it 'a pain at the neck' and a hassle." Her ability to take this perspective seemed to be an important factor in her ability to maintain her work objectives. Others with the same obstacles might feel too overwhelmed to continue working. On the other hand, she also said, “I don't consider as limiting me and my ability to work except for maybe heavy lifting. I've never had to do heavy lifting now... 'cause I did a lot of trainings and you'd have to take your materials with you, your computers and all of that, but I never had to lift like a merchandising way training materials." She perceived that the most essential parts of her jobs were her knowledge and expertise which she didn't think could be easily limited by lymphedema. While her ability to do certain tasks involving her arm (i.e., carrying things and typing) might be limited, she didn’t perceive them as essential elements of her work. Thus, the challenges faced may not be as predictive of work success as the self-limitations perceived by the individual. In Linda's case, the impact of BCRL was ameliorated by her appraisal. 
Developing coping strategies. An area of strength for Linda seemed to be her ability to adapt to the circumstances in which she found herself. She developed many strategies to overcome her functional limitations due to BCRL. For example, to address limitations in lifting and carrying, Linda started using "really good" roller bags which were easy to roll and sturdy. She learned to use voice-recognition technology for computer work to decrease the amount of keyboarding. She also adjusted her body mechanics and workstation set-up to make typing and writing easier. She started wearing shawls to cover her lymphedematous arm, for protective and aesthetic purposes. Linda developed strategies specifically for business travel. She packed more carefully for travel, trying to avoid extra, unnecessary weight. She was also able to work with her healthcare providers to obtain pre-emptive antibiotics to prevent infection and had compression sleeves ready for air travel. Over time, she built a working partnership with her primary physician, so that when infections occurred, she could have a quick response and avoid the hassle and delay of waiting for an appointment to receive treatment or an urgent care visit.

\section{Experiencing Different Challenges with Different Jobs}

Linda made multiple job changes in the years after she developed BCRL. Each change brought environmental change, as well as change in the specific work tasks associated with the job. At times, these changes were beneficial, but they also could present new challenges and/or barriers.

Linda had continued searching for years for information that would finally identify BCRL and potential treatments, even while continuing to work. Interestingly, she finally obtained this information when she changed jobs and began working with a 
program that served breast cancer survivors. She said, “That's where I got tied into the network of people who really manage breast cancer, so that's when I, myself, got more knowledge of what might be available (for lymphedema)."

The work activities as coordinator of the cancer screening program brought her both benefits and challenges as a survivor with BCRL, however. For this job, she had the opportunity to connect with different breast cancer treatment centers across the state, which provided her with access to valuable personal resources for BCRL treatment. On the other hand, the coordinator job role required frequent car and air travel, which was challenging. She recalled, "The training in [the program], that was the most carrying and driving I did ... I traveled by airplane, too, and air travel is hard when you're working on lymphedema."

Linda's work as a school nurse presented a different set of hazards. At this job, she was exposed to sick children every day, which increased her personal risk of contracting illness or infection. She believes it was her work in this environment that triggered the initial onset of lymphedema: "I think it was being in the school nurse's office. I must've been exposed to lots of stuff, I'm sure, and being around infection was a part of it and there was some."

In summary, as Linda’s work life changed, the types of challenge lymphedema brought also changed. Yet with each new challenge, Linda was able to evaluate the potential barriers and consider material and strategic resources for coping. 


\section{Discussion}

Linda expressed the feeling of being lost for a long time because of limited resources for BCRL, the fear of infection, and the struggles with functional impairments and different challenges with different jobs. After all of these, she still perceived herself not being limited for her work and shared her coping strategies along the way. We

discuss how all of these factors came together to influence Linda's working activities and shape the return-to-work experience.

\section{Interaction of the Person, BCRL and Work Activity}

We selected Linda for this case study because of her extensive experience with BCRL in the context of uninterrupted work history. Through interviewing, Linda illustrated for us how BCRL affected her return-to-work experience. Based on our findings with this single individual, we have created a map of the factors Linda described and their relationships (Figure 3.3). Given the dearth of information currently available about return to work among breast cancer survivors with lymphedema, this map can serve as a starting point for developing an understanding of the return-to-work experience of this population more generally.

Through analyzing Linda’s case, we found the return-to-work experience was built on a number of interactions between and among the work tasks, the BCRL condition, and the person. BCRL limited Linda's work activities by affecting a broad array of physical and emotional functions. The limitations were heightened when the functions did not match her work activities’ demands. Linda was limited in some physical tasks, such as lifting and carrying moderately large/heavy objects, keyboarding, and 
difficulties associated with travel. As a nurse, these physical requirements might not be essential for her job description, but were necessary for carrying out her daily work tasks. On the other hand, the clinical work also provided hazard to her BCRL condition with adding the incidence of infection. The program coordinator job involved much travel by driving and air flights, exacerbating her arm swelling. The path to work-related problems with BCRL can also be initiated by the treatments themselves, such as bandaging, which notably are on-going due to the chronicity of the BCRL. Both BCRL and its treatment (e.g. bandaging) interfered directly with Linda’s work tasks and indirectly through sick days associated with infection and treatment. BCRL also created inefficiencies, such as through unwanted attention/distraction, hassles in the airport, and the demands of daily self-management.

Linda demonstrated a high level of self-efficacy and perseverance with work tasks, e.g. being an early adopter of voice-recognition technology and developing a number of strategies and healthcare relationships to prevent mishap when traveling. While Linda was able to use procedural and instrumental coping adroitly, she also used internal coping strategies effectively. Foremost, she did not perceive herself to be incapacitated by her limitations. Rather, she viewed barriers as challenges that required problem-solving and adjustment. Even in her frustration with her healthcare providers, she did not feel compelled to stop working until a diagnosis was made and medical treatment prescribed. Rather, she continued with her chosen career as she searched. Ultimately, she found what she had been seeking, diagnosis and treatment, when she integrated her professional and personal priorities by choosing to work for an 
organization that served breast cancer survivors. Linda’s case showed that the individual's own action played an important role in adjusting to the return-to-work. 

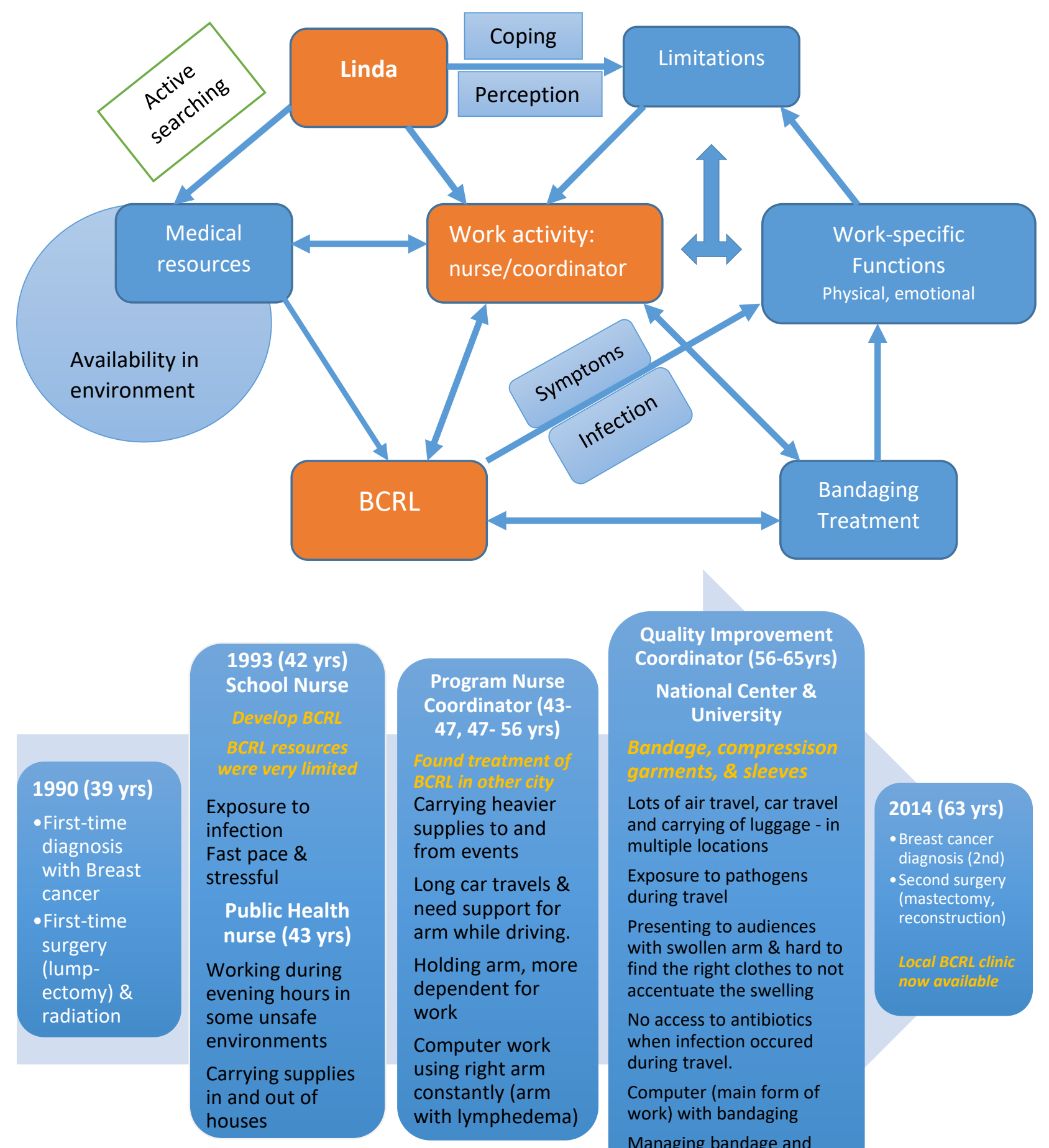

Program Nurse Coordinator (43-

47, 47- 56 yrs)

Found treatment of BCRL in other city

Carrying heavier supplies to and from events

Long car travels \& need support for arm while driving.

Holding arm, more dependent for work

Computer work using right arm constantly (arm with lymphedema)
Quality Improvement Coordinator (56-65yrs)

National Center \&

\section{University}

Bandage, compressison garments, \& sleeves

Lots of air travel, car travel and carrying of luggage - in multiple locations

Exposure to pathogens during travel

Presenting to audiences with swollen arm \& hard to find the right clothes to not accentuate the swelling

No access to antibiotics when infection occured during travel.

Computer (main form of work) with bandaging

Managing bandage and sleeves during travel

Figure 3.3 Linda's Journey with BCRL and Return-to-work 


\section{The Changes of the Person and the Outer World}

The information Linda provided is consistent with results from our published review on return-to-work among breast cancer survivors (Sun et al., 2017). In our review, individual factors (i.e. coping skills), work and related environmental factors (i.e. advisement from health professional), and societal and policy supports were identified as important to the return-to-work process. These factors interact in various ways to affect work outcomes, such as productivity. As Yin (Yin, 2014) has pointed out, understanding of the phenomenon should be done within its real-world context and yet there may not be evident boundaries between the phenomenon and context (Yin, 2014). We mapped the components from both Linda's environment(s) and from within Linda herself that could contribute to our understanding of returning-to-work (Figure 3.3).

Linda was a professional nurse and held a master's degree. She had substantial experience in healthcare, even at the time she developed breast cancer. Because of this, she likely had a different level of insight that may have motivated her to continue seeking information about BCRL and to be diligent with self-care, even at times when she experienced low motivation. During the interview, Linda's professional insight towards the problem was apparent as she identified problems within the health system and public health efforts. Not only did she discuss the ignorance of health providers, she also touched on legal issues related to asking about medical conditions by the employer. A person without a similar level of training and/or work experience might not be as wellinformed. We do not believe that her expertise negates the commonalities of her experience with other women with BCRL, especially with regard to navigating functional 
and interpersonal barriers at work or her emotional adjustment to having a serious chronic condition.

Moreover, unlike most breast cancer survivors, Linda had a second occurrence of breast cancer, and thus, went through cancer treatment twice. This also likely shaped her perspectives towards the phenomenon of BCRL-associated return-to-work. While we did not make a pointed comparison of Linda to "first-time survivors," we did observe at this point in her health trajectory, her resolve to return to work, as a means of seeking normalcy, and her focus on successes as opposed to focusing on anxieties. We must recognize and accept, however, that each survivor with BCRL is unique.

The changes of the outer world would have shaped Linda's experience of returning-to-work with BCRL in important ways. Linda initially developed lymphedema in early 90s. At this point in time and away from urban coastal areas, assessment and treatment for BCRL was very different from the present time. As she said, there were no lymphedema programs in her area and physicians turned her away; the local lymphedema program was developed years later. Public awareness and knowledge of BCRL was likewise, limited. Bandaging treatment and compression garments/sleeves were adopted years after Linda began to experience symptoms of lymphedema, and while use of these items provided her with better control of lymphedema, it also brought new challenges at work. Additionally, the treatment techniques for BCRL, guidelines for practice, and industry products likely have evolved since their introduction. Linda was able to compare the effectiveness of some practices and products to others, as well as her own efficacy with self-care, over time. 
Significantly, Linda herself has been changing. With age and experience her interpretation of her experiences with work-return in relation to BCRL has evolved. She was just retired and her children have grown up and have their own careers. Her career changed along the way, which was influential regarding her work experience and BCRL. She experienced changes in her tasks and duties both at home and at work, which brought new challenges and opportunities for exploring and coping with lymphedema management. She also developed other conditions such as hypothyroidism, depression, and urinary incontinence that have influenced her overall health and well-being, which required re-examination of her priorities to maintain health and work. In summary, Linda’s 24-year journey comprises all of these experiences and more, which have all contributed to her unique story.

We return to the fact that little is currently known about the challenges faced by breast cancer survivors who attempt to return to the workforce while also managing BCRL. In this paper, we have presented a single-case study, with the aim of better understanding the phenomenon of interest, using a personal perspective. Yin (2014) reminds us to contextualize such material, which leads to the conclusion that each person/phenomenon is unique. Even so, “Linda’s” experience provides us with a starting point for examining the phenomenon more broadly. Future work will focus on further developing the model platform introduced here, and work toward better understanding how survivors' desire to return to work can be best supported. 


\section{Conclusion}

Returning to work with BCRL represents a complicated phenomenon at the intersection of the individual, the disease processes, the work activities required, and an array of contextual factors. We have presented a case study that details the subject's experience over two decades, two episodes of cancer, multiple job changes, and significant changes in the healthcare environment. Our case example provides a personal perspective on how the lack of medical resource about BCRL can have a negative impact on health and well-being. Our case example also provides examples of perseverance and personal resiliency that helped her overcome BCRL-related barriers to return to work.

\section{Acknowledgements}

The authors thank the participant sharing her experience and perspectives. Funding support for the first author was provided by the Toni and Jim Sullivan Endowed Research Fund. 


\section{References}

American Cancer Society (2013). Cancer Facts \& Figures 2013. Retrieved from https://www.cancer.org/research/cancer-facts-statistics/all-cancer-factsfigures/cancer-facts-figures-2013.html

American Cancer Society (2014a). Cancer treatment \& survivorship facts \& figures 2014-2015. Retrieved from http://www.cancer.org/acs/groups/content/@research/documents/document/acspc042801.pdf

American Cancer Society (2014b). Cancer treatment \& survivorship facts \& figures 2014-2015. Retrieved from http://www.cancer.org/acs/groups/content/@research/documents/document/acspc042801.pdf

American Cancer Society (2014c). Lymphedema PDQ ${ }^{\circledR}$. Retrieved from https://www.cancer.org/treatment/treatments-and-side-effects/physical-sideeffects/lymphedema.html

Bifulco, G., De Rosa, N., Tornesello, M. L., Piccoli, R., Bertrando, A., Lavitola, G., . . . Nappi, C. (2012). Quality of life, lifestyle behavior and employment experience: A comparison between young and midlife survivors of gynecology early stage cancers. Gynecologic Oncology, 124(3), 444-451.

Boyages, J., Kalfa, S., Xu, Y., Koelmeyer, L., Mackie, H., Viveros, H., . . Gollan, P. (2016). Worse and worse off: The impact of lymphedema on work and career after breast cancer. SpringerPlus, 5(1), 1-8. doi:10.1186/s40064-016-2300-8 
Glaser, B. G., \& Strauss, A. L. (1999). The discovery of grounded theory strategies for qualitative research. Retrieved from http://www.sxf.uevora.pt/wpcontent/uploads/2013/03/Glaser_1967.pdf

Howlader, N., Noone, A. M., Krapcho, M., Garshell, J., Miller, D., Altekruse, S. F., . . . Cronin, K. A. (2015). SEER Cancer Statistics Review, 1975-2012. Available from based on November 2014 SEER data submission based on November 2014 SEER data submission Retrieved 2015, from National Cancer Institute http://seer.cancer.gov/csr/1975_2012

Peugniez, C., Fantoni, S., Leroyer, A., Skrzypczak, J., Duprey, M., \& Bonneterre, J. (2011). Return to work after treatment for breast cancer: Single center experience in a cohort of 273 patients. Bulletin du Cancer, 98(7), E69-79.

Ridner, S. H. (2005). Quality of life and a symptom cluster associated with breast cancer treatment-related lymphedema. Supportive Care in Cancer, 13(11), 904-911. doi:10.1007/s00520-005-0810-y

Ridner, S. H., Sinclair, V., Deng, J., Bonner, C. M., Kidd, N., \& Dietrich, M. S. (2012). Breast cancer survivors with lymphedema: Glimpses of their daily lives. Clin $J$ Oncol Nurs, 16(6), 609-614. doi:10.1188/12.CJON.609-614

Sun, Y., Shigaki, C. L., \& Armer, J. M. (2017). Return to work among breast cancer survivors: A literature review. Supportive Care in Cancer, 25(3), 709-718. doi:10.1007/s00520-016-3446-1

Sun, Y., Shigaki, C. L., \& Armer, J. M. (In review). The Influence of breast cancerrelated lymphedema on women's return-to-work. 
World Health Organization (2001) ICF: International classification of functioning, disability and health. Geneva: World Health Organization. Retrieved from http://psychiatr.ru/download/1313?view=name=CF_18.pdf

Yin, R. K. (2014). Case study research: Design and methods (5th ed.). Thousand Oaks, CA Sage. 


\section{CHAPTER FOUR RESEARCH DESIGN AND METHODS}

\section{Specific aims and research question}

The overall purpose of this multiple-case study was to describe how breast cancer-related lymphedema (BCRL) has influenced survivors’ work experience. The

research interest was centered on the phenomenon of "lymphedema" developed following breast cancer treatment specifically and the "work experience” in a competitiveintegrated environment, which would make this study a condition-context-specific exploration. Though the study focused on the clinical condition (lymphedema), the breast cancer survivor "being" was identified as the carrier of the interaction between BCRL and the work outcomes. Therefore, the specific aims were approached by fully exploring each individual being's journey and their shared experience.

Recent estimates suggest there are 15.5 million breast cancer survivors in the United States (Bluethmann, Mariotto, \& Rowland, 2016). The median age at the time of breast cancer diagnosis during 2008-2012 was 61.24 which implies that half of women who developed breast cancer were 61 years of age or younger and at the age for gainful employment (Howlader et al., 2015). Shih and colleagues (2009) studied working-age women who were treated for breast cancer and found that $10 \%$ of them suffered from BCRL requiring medical intervention and had significantly higher incidence of cellulitis or lymphangitis and medical costs compared to those who did not develop BCRL (Shih et al., 2009). Thus, for career women who survive breast cancer, BCRL is not only a clinical condition, but can become a chronic influence on their work life and socioeconomic status. 
Very limited numbers of studies have touched on the effect of BCRL on breast cancer survivors’ work. A recent online survey compared breast cancer survivors with and without lymphedema quantitatively in terms of their time off work. Results showed the detrimental effect of lymphedema on women's work and career over and above the initial impact of breast cancer in the long term (Boyages et al., 2016). Yet, we do not yet know "how and why" lymphedema has such an effect on breast cancer survivors' work life, even if it is true. Without knowing how lymphedema influences breast cancer survivors' work experience, we cannot provide effective rehabilitation services to breast cancer survivors who need help with restoring and retaining occupational life.

The primary specific aim of this study was to examine the ways that breast cancerrelated lymphedema (BCRL) influences the individual's work experience.

The secondary aim of this study was to investigate the influences of contextual factors (personal and environmental) on survivors with BCRL, as they return-to-work.

\section{Conceptual Framework}

The International Classification of Functioning, Disability, and Health (ICF) provided by the World Health Organization (WHO), was adopted to guide health-related research design and data analysis (World Health Organization, 2001a). The ICF is a basic framework that can help in understanding the problem of return to work for breast cancer survivors with lymphedema. The model explains how disease and disability are related. The ICF model identifies three levels of human function:1) the body; 2) the whole person; and 3) the whole environment. The body function level contains three domains of function and corresponding dysfunction: body functions and structures (impairments), activities (limitations), and participation (restriction). The body function refers to 
physiological functions. The body structures refer to the anatomical parts of body. The activity refers to the execution of a task. The participation refers to involvement in a life situation. The impairments refer to the problems in body functions or structures. The activity limitations refer to the difficulties an individual could have in the activities. The participation restriction refers to the problems an individual may experience in involvement in life situations (World Health Organization, 2001b)

The ICF model considers the influence of disease or disorders on an individual's participation in society. Diseases or disorders affect the triad of "body structure and function,” “activities,” and "participation,” which lead to either disability or no disability. The disability status depends on important context factors of both environmental origin, such as heavy physical work, and personal origin, such as personal ideas about disability (Jette, 2006; World Health Organization, 2001b). Regarding the former, a person can be affected by the environment, or actively change the environment. For example, job discrimination is possible for a breast cancer survivor with lymphedema to experience when applying for a job. This makes it more difficult to change work or start a new job after a period of not working. Regarding personal factors, a person with stronger willingness to work may be more likely to maintain the employment. These factors may be an important domain to explore when studying how BCRL has interacted with survivors’ work experiences.

The ICF was recommended by Duijts, Spelten, and Verbeek (2014) as a basic model to help understand "return-to-work as a heath behavior" in cancer patients. ICF examines how disease and disability are related. Compared to some medical models, ICF brings attention to environmental and personal factors in the rehabilitation process, 
instead of only focusing on physical functioning impairments (Schreuer, Rimmerman, \& Sachs, 2006). The environment could be the larger community (the society) and the individual's workplace. Working and living in the environment can create the interactions with other people. Each individual also has their own attributes that make them think, feel, and act differently. The interaction, attributes, and associated resource may potentially contribute to the survivor's experience of return-to-work.

Several models of occupational therapy for cancer survivors, such as Model of Human Occupation (MOHO) and Canadian Model of Occupational Performance (CMOP), have clear reference to the ICF as a frame of reference (Désiron, Donceel, de Rijk, \& Van Hoof, 2013). ICF has been frequently employed by studies examining work disability and return-to-work issues among diverse populations. Tamminga and colleagues (2012) used the ICF as a conceptual framework to guide a qualitative study to identify the barriers to return-to-work among breast cancer survivors. The ICF has been used to guide vocational rehabilitation research with focusing on the specific diseases. Based on a systematic review, De Croon et al. (2004) indicated that vocational rehabilitation programs for patients with rheumatoid arthritis have been introduced by seventeen research teams based on how ICF organizes the information. van der Valk et al. (2014) conducted a study on risk factors for work disability in patients with inflammatory bowel disease in the Netherlands. Moreover, ICF recognizes that the relationships between disease and function do not occur in the absolute but within specific contexts including personal and environmental factors.

Our published literature review (Sun et al., 2017) that examined return to work among breast cancer survivors shared a significant degree of conceptual similarity with 
the concepts in ICF. The relevant life situation "return-to-work" highly interacts with health and well-being, symptoms, and functioning (“the body” in ICF); individual characteristics (“the person”); work demands and work environment; and societal and cultural factors (together, “the whole environment”). An explanatory graph of how the ICF model can be used to help in understanding the phenomenon of lymphedema and how it interacts with breast cancer survivors’ work engagement follows (Figure 4.1). This model guided the exploration of the research aim and research questions by identifying the main biopsychosocial components involved. The outcomes construct a more practical model as reference for clinical practice and education.

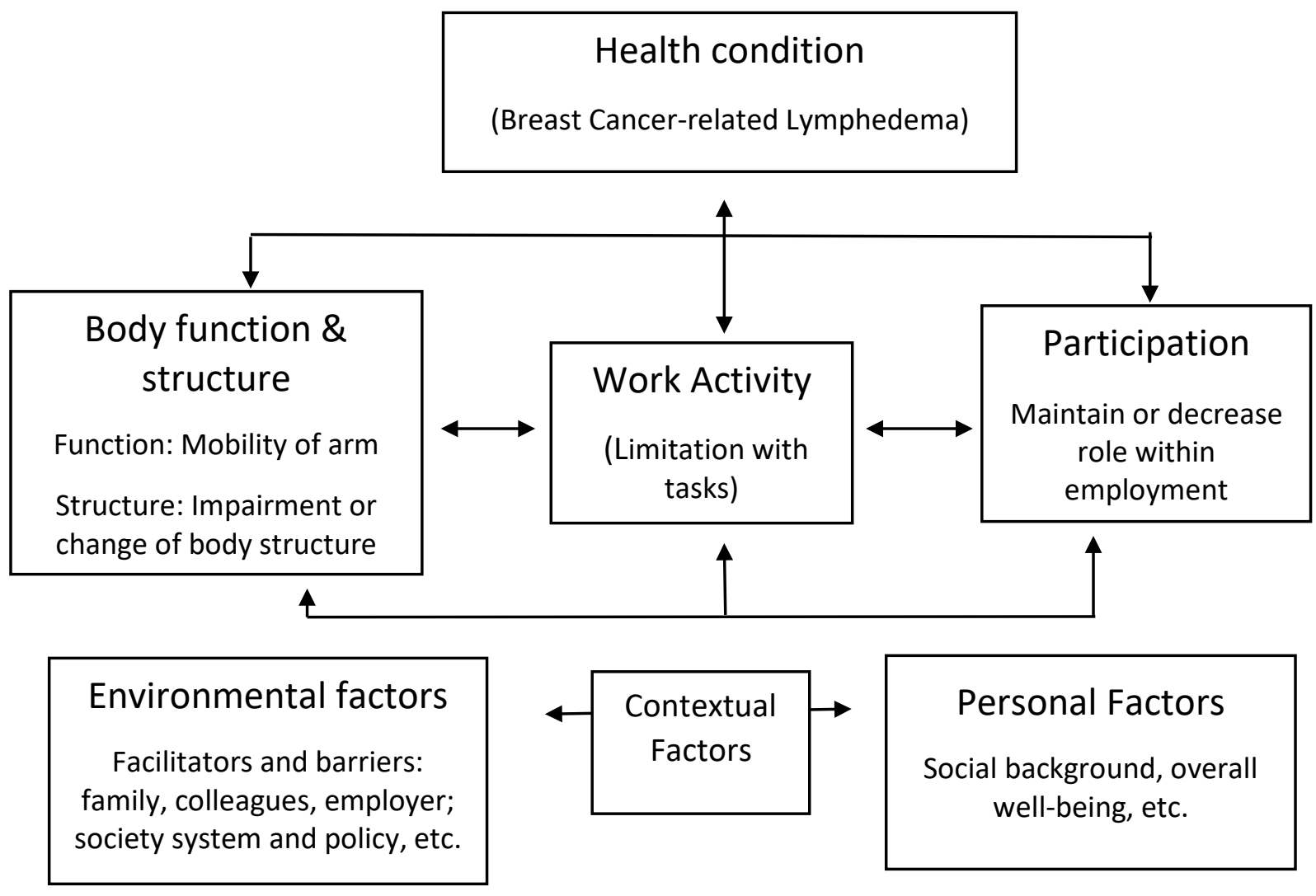

Figure 4.1 Phenomenon of "BCRL and work" explained by the International Classification of Functioning, Disability and Health (ICF) 


\section{Study Design and Methodology}

\section{Overview}

Yin’s (2014) multiple-case study methodology was employed to investigate the perceived effects of breast cancer-related lymphedema on survivors’ work experience and to explore the contribution of individual characteristics, environmental determinants, and other possible factors associated with the work experience while dealing with lymphedema. The interviews were conducted at quiet private sites selected by the participants. Breast cancer survivors who finished primary treatment (surgery, radiation) more than 12 months prior to study enrollment and were diagnosed with lymphedema, as well as having been employed in a competitive-integrated work environment at the time of diagnosis, were recruited from the central United States. Data were collected via survey and interview with the participants. Each case was analyzed individually and constant cross-case comparison and contrast assessments were made.

\section{Research Design}

\section{Methodological Approach}

A multiple-case study methodology drawing from Yin’s (2014) definition was employed. Case study has been defined differently by various methodologists (Merriam, 2009, p. 40). Here, we adopted Yin’s (2014) definition which referred to it as a research process and "empirical inquiry that investigates a contemporary phenomenon within its real-life context, especially when the boundaries between phenomenon and context are 
not clearly evident” (p.16). In line with this approach, the phenomenon (the "case") of interest and context is not distinguishable in the real world.

A case study is conducted as an empirical inquiry that: (a) "investigates a contemporary phenomenon in depth and within its real-world context," especially when (b) the "boundaries between phenomenon and context may not be clearly evident" (Yin, 2014, pg. 16); and featured as: a) large number of variables (this term has been broadly used in Yin's publication) of interest; b) in data-triangulating fashion; and c) "benefits from existing theoretical propositions for guiding data collection and analysis” (Yin, 2014, pg. 17). Yin (2014) has discussed that the case study method would best be suited with situations when research questions are trying to address "why" and "how;" behavioral events are rarely controlled by the researcher; and the study focuses on a contemporary phenomenon. The case study methodology serves the purpose well, as this study aimed to describe "in-depth” the current phenomenon that is “the survivors' return to work after developing BCRL," with a focus on asking "how" did BCRL influence survivors' work-return experience and what resources have been navigated by them and how they influenced their work-return during this process.

Research methodology is the design that shapes the choices of particular methods and the rationale for particular forms of the methods employed (Crotty, 1998, pp. 12-13). According to Yin (2014, p.17), case-study research embraces different epistemological orientations. The case- study methodology is articulated with constructivism by the researcher of this study, who believes: multiple realities are constructed through our lived experiences and interactions with others (ontology); reality is constructed in interaction between the knower (researcher) and the known (researched) and shaped by individual 
experience (epistemology); and there is a need for researchers to position themselves, since their own background may shape their interpretations flowing from their own personal, cultural, and historical experience, in order to interpret the meanings participants have (Andrews, 2012). The underpinning paradigm provides the rationale to carry out individual interviews using semi-structured questioning, guides data collection by prior-developed theoretical propositions, and employs researcher self-reflective journaling for minimizing bias.

Case definition: A case is considered as a phenomenon of some sort that occurs within a bounded context (Yin, 2014, pp. 15-17). Specifically, in this study:

- The "case” was the survivor(s) who had experienced 'return-to-work' while having lymphedema due to breast cancer treatment;

- In order to examine the different environmental factors, the enrollment of cases whose "work" was defined as “Competitive-Integrated Employment” by the Workforce Innovation and Opportunities Act (WIOA) (2016) was required. This refers to "the work" performed by a person with an impairment or health-related disability ("health impairment") within an integrated setting. It is used to distinguish work with typical productivity expectations and wages from other occupations such as those that may be done in a sheltered or volunteer setting, or may otherwise be unpaid (e.g. homemaker) or have reduced wages and/or productivity expectations (e.g. working for a relative who accepts a lower standard). In this case, Competitive refers to the employee (with lymphedema) having full or part-time work, at least paid minimum wage, and with wages and benefits and productivity expectations 
similar to those without lymphedema performing the same work. An integrated setting focuses on whether individuals with the health condition in question have the opportunity in their job positions to interact with persons without the same health condition. In this case, the studied individual with lymphedema may have had opportunity to interact with their "normal” nonlymphedema work peers. The interaction between individuals with lymphedema and the general public need not be face-to-face in order to meet the standard. Self-employed, home-based employees, and telecommuters may interact with the public through a variety of media, including telephone, facsimile, and computer (WIOA, 2016).

Rational for multiple-case design. Comparing to single-case design, the multiplecase design has advantages and disadvantages. The evidence from multiple cases is often considered more compelling, while it can also require extensive resources and time (Yin, 2014, p. 57).

The replication logic. The multiple cases are analogous to multiple experiments where "replication" logic is adopted. The "replication" means each individual case consisted of a "whole study" and each case’s conclusions indicating how and why a particular proposition was demonstrated (or not) was tested by replication with other cases (Yin, 2014, p. 59). The cases either functioned as "literal replications” which had similar predictions to answer the research questions or as "theoretical replications" that predicted contrasting results with anticipated reasons. In this study, both literal replications and theoretical replications were carried out. For example, a set of cases with exemplary findings to answer an evaluation question, such as "How have these 
lymphedema-related functional effects affected their work outcomes?” was expected to occur and account for literal replications of these findings from case to case (comprising a group, homogeneity). Meanwhile, theoretical repetitions resulted in choosing cases from different types of conditions and creating subgroups with literal replications within each subgroup. The findings from comparing and contrasting cases across the subgroups provided evidence on what factors may make the differences between women with good work re-entry experiences and women with poor work-return experiences. As replications in both literal and theoretical ways were desired, a multiple-case design was necessary. The initial set of propositions were assessed for support by the aggregated evidence from the selected cases. If the cases failed to support initial proposition, then revised propositions were tested by another set of cases (Yin, 2014, p. 62).

\section{Setting}

Data were collected in private with one-on-one interviews. One of the settings was at a conference room located on the campus of Midwestern public university. Some cases were scheduled after their oncology clinic visit in small Midwestern city; for their convenience, the consultation room of the breast cancer center was used. The respective rooms were reserved and prepared before each meeting with the participant to secure a private and comfortable environment. For potential participants who were not able to meet in person due to distance or other reasons, based on assessing the allowed means of communication and participants' preference, the interview was carried out by phone call or skype (Microsoft Skype @2017). One participant lived on the East Coast, US. For this data collection, a Skype interview was conducted and recorded by Ecamm Call Recorder 
for Skype (Ecamm Network @2017) software with audio-only feature. All other interviews were conducted in person.

\section{Participants and purposeful sampling}

Sample size. The total final sample size depended on how informative and predictable the potential cases were. The selection of the number of case replications was both a literal and theoretical decision in this study. The minimal cases needed for literal replication was 2-3 because the theory ("ICF") employed is straightforward and the issue at hand does not demand an excessive degree of certainty. Based on the propositions of the conceptual model, the research questions, and the initial findings of the five-case preliminary study conducted in 2015-2016, there were at least five anticipated potential aspects in relation to the work outcomes and experience; these needed to be theoretically replicated. Thus, the total number of cases needed for replications was projected to be around $10(2 * 5=10)$. Some cases were expected to be literal replications for several subgroups (theoretical replications), while some were believed to potentially lead to new discovery that we had not yet anticipated. The final sample size was determined during the research process when both replications were obtained and the data saturation criteria was met, meaning no new themes and patterns emerged (Polit \& Beck, 2012).

Screening Candidate Cases. The inclusion criteria were: 1) Diagnosed with lymphedema following breast cancer treatment; 2) Finished with primary cancer treatment and more than 12 months' post-surgery and -radiation; and 3) Employed or self-employed at the time of lymphedema diagnosis. For inclusion criteria 3), cases were “employed” within the definition of "Competitive-integrated employment” (Workforce 
Innovation and Opportunities Act (WIOA), 2016), as discussed above. This criterion was not necessary for all cases which means non-paying “occupations” (i.e. volunteer work, homemaker) and sheltered employment (i.e. sheltered workshops where people typically get paid for low-skill jobs, regardless of performance) would also be considered.

Purposeful sampling. As Yin (2014) stated, the goal of the screening procedure is to "be sure that you identify the final cases properly, prior to formal data collection” (p. 95). The principle is to choose cases which are likely to have the most available data and best fit the literal and theoretical replication design, as discussed above in the Design section. Additionally, we recruited the collective cases to employ maximum variation and represent diverse perspectives. In this case, extreme and deviant cases were included in the data collection. A one-phase approach was employed, in that researcher queried people knowledgeable about each candidate. The participants’ name was replaced with the job title and case ID assigned for each of them. Only the case ID and job title were used in the study report to indicate the specific individual data quoted.

Recruitment. Flyers (Appendix A) for patients and health providers, as well as facility staff, were disseminated in hospitals, community health centers, breast cancer survivor group events, and via emails to known survivors. The potential participants were recruited from support groups of cancer survivors and referral by enrolled participants (“snow-balling”) (Polit \& Beck, 2012, pp. 516-517), lymphedema therapists, and other clinicians. Survivors who were interested in participating and met the inclusion criteria were contacted and informed about the details of the study. Voluntary enrollment and informed consent for the study were clearly explained. A copy of the written consent (Appendix A) was given to each participant. Since the unpublished interview data from 
the pilot project conducted in 2015-2016 were used in conjunction with the data collected in this study, the participants in the early project were contacted for permission to use the information obtained and invited to provide survey and interview details not a part of the original pilot protocol. All five participants agreed to participate in the dissertation study and include their earlier data.

\section{Data collection}

The data collection method included a short structured survey for obtaining necessary demographic, clinical, and employment information and an initial one-hour semi-structured interview, with a possible 15-30 minutes’ follow-up interview for clarification focusing on the research questions.

Interview process. A 60-minute private, one-on-one, face-to-face interview were conducted with each participant by the researcher, following the amended the Institutional Review Board (IRB)-approved interview protocol (Appendix B). Some of the participants were invited to participate in a 15-to-30-minute follow-up individual interview, in case anything needed to be clarified and/or when further conversation was necessary for expanding some specific information from the initial interview. Each interview was double-recorded with digital recorders. Participants were informed about the recording during consent and before data collection began; this was explicitly stated on the informed consent form and was orally-informed during consent and before each interview. The researcher maintained an honest and transparent attitude and interest in the participant throughout the whole process. A descriptive summary was written after each 
interview to document any unusual or interesting observations during the interview, as well as to highlight information which might be informative for the following interviews.

Instruments. a) An interview protocol (Appendix B) was developed to guide the semistructured interviews to answer the research questions, using probes to gain details, as well as obtain unexpected, but meaningful, information from open-ended questions. The interview protocol was a revised and advanced version of the one used for the pilot project, which was developed based on the framework of ICF (Jette, 2006), the preliminary review for Return to Work among Breast Cancer Survivors (Sun, Shigaki, \& Armer, 2017), and the reflections on earlier interviews. The new interview protocol included the following categories: 1) work demographics covering work content, demands, and meaning to individual; 2) lymphedema-related changes covering structural changes, physical functional impairment, and emotional and interpersonal changes, etc.; 3) work-related outcomes covering engagement, retention, work ability, performance, and interrelationships, etc.; 5) environmental characteristics_covering micro-to macro-level, including: family support, friend support, and workplace policy; 6) final reflections on the experience: what they have learned and their outlook towards work in the future with lymphedema; and 7) open-ended question (about their experiences of having lymphedema while re-entering work after breast cancer treatment). The revised protocol was retested and timed to ensure its effectiveness for capturing the information, as well as the possibility to be finished within the planned time.

b) Demographic survey (Appendix C). The designed survey was to document the necessary information of participants' personal characteristics, including both $\underline{\text { individual }}$ demographics (date of birth, race /ethnicity, marital and relationship status, educational 
level, adequacy of financial resources for living, health insurance, basic occupational information, religion) and clinical characteristics [overall health and well-being, breast cancer treatment (surgery type, radiation, chemotherapy, medications, and complications), date of lymphedema diagnosis, and co-morbidities]. This survey contained 24 questions with estimated completion time of 6 to 10 minutes. Both paper and online Qualtrics (Qualtrics@2017. Provo Utah USA ) versions were available. Choice of version depended on the participant's preference, their internet accessibility, and computer skills (clicking with mouse and typing with keyboard). Preferably, the survey was sent to participants, completed, and returned to the researcher prior to the interview. This provided the researcher with some basic information and impressions about the individual interviewee ahead of the interview appointment, as well as making it be easy to follow-up anything unclear in the survey in the interview. However, the survey was administered by the researcher immediately before the interview, if the participant's literacy level was not compatible with independent completion or their preference was to do so. The survey findings helped better understand the "context” that the individual case belonged to and the distinctions they held. It also provided probes for cross-case comparison and sub-cases selection.

Researcher preparation. The researcher who collected the data had practiced the interview multiple times to know all the questions by memory and, at the same time, make sure it flowed a natural conversation, to the extent possible. Since researchers themselves function as instruments in qualitative data collection, one researcher conducted all the interviews to maintain the data collection in a consistent manner.

\section{Data management}


Data were carefully managed and stored in order to protect confidentiality of the participants. First, no identifiable information was collected during the interview sessions of this study. Second, only researchers associated with this project reviewed the recorded data. All digital recorders and files were stored in a secure locked filing cabinet. Digital audio files were saved in a folder on the researcher's computer with password protection. (No digital files were left on the digital recording device.) A back-up of the audio files was stored in a Box account and a digital data archive was placed in a secure back-up space at the Midwestern public university. No data were accessible to a third-party via a network connection. This was explicitly stated on the informed consent form. This eliminated the possibility of other parties identifying the participant based on voicerecognition. Finally, the identities of participants were held confidential. Data obtained were recorded through a code system in which each participant's information was linked to a number (Case ID), so that each participant could not be identified directly from the data. The list of participants' names, code numbers, addresses, and telephone numbers was stored in a locked file in the computer only accessible to the research team.

\section{Data analysis}

The interviews were transcribed verbatim and double-checked. Multiple organizing methods were involved in the overall analysis. Computer-based software program Dedoose (Dedoose Version 7.0.23, 2016), as well as manual organization and labeling, were used in this analysis. Software serves as a reliable assistant and reliable tool; the researcher studied the outputs to identify any meaningful emerging patterns (Yin, 2014, p. 192). The following steps were carried out. 
First, initial codes created. All transcripts were read through repeatedly for overall impression. Initial codes, including the research questions, suggested codes and other potential codes were determined during this process.

Second, initial code-tagging and marginal notation. The researcher underlined the portions of the transcripts related to the initial codes. A brief comment or notation summarizing the impressions of the data were made.

Third, data organization and deeper analysis. The data of each participant were organized in the following way (Dedoose software was used to label and export data in this step):

a) Within-case analysis. The data for each participant was reviewed. Categories and subcategories were generated from the initial codes, based on the theoretical framework and research question. The researcher looked for themes related to the question for each single participant. Categories or themes were confirmed and disconfirmed by looking at other pieces of data within this participant. As Yin refers to this process, it is analysis from the "ground up" (Yin, 2014). A constant-comparative data analysis was employed to categorize, refine, and induct data. Even though constantcomparative analysis has been popularly featured in grounded theory approach (Glaser \& Strauss, 1967, 1999), Yin (2014) has recommended similar techniques for the case-study method. Constant-comparative methods of coding data involves four steps: identifying and categorizing instances with similar properties that emerge from the data; comparing the properties with each set of categories; delimiting theoretical understanding from these categories; and writing the theory in the form of propositions, a model, or a narrative (Glaser \& Strauss, 1999). 
b) Across-case analysis. Once finishing within-case analysis for each participant, a comparison of the themes/findings across the different participants was conducted. It required the context of each case to be deeply explored, before finding patterns which transcended the cases.

Fourth, redefining and drawing themes. The emerged themes described categories of data that were identified across the cases. Themes were derived from the patterns and categories. Member-checking and debriefing were arranged.

\section{Mini Map}

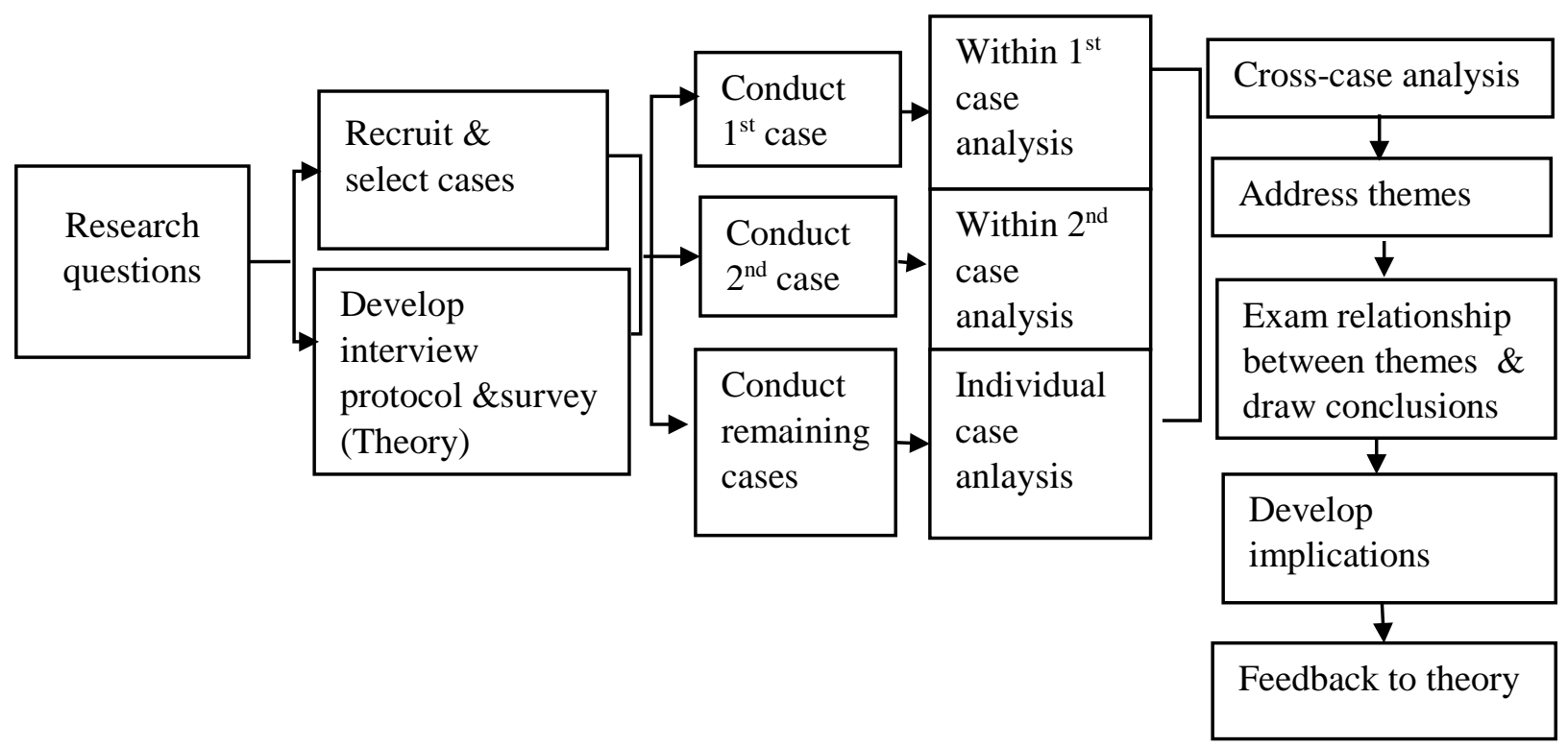

Figure 4.2 Mini map of this study

\section{Managing bias and ensuring rigor}

With diverse theoretical (epistemological, ontological) positions, divisions among qualitative researchers come into focus around "credibility” or "quality.” The most cited quality criteria by qualitative researchers is Lincoln and Guba’s (1985) criteria based on interpretive perspective (Crotty, 1998). The widely-known standard of trustworthiness by Lincoln and Guba (1985) is grounded in the approach of "transactional validity" which 
refers to qualitative research as an interactive process. As "transaction" implies, based on a series of "dialogues," each dimension can be problematic: between findings and participants (member-checking), between data sources (triangulation), and between different researchers (Cho \& Trent, 2006; Lincoln \& Guba, 1985). In order to reduce the manageable biases, first, the reflective journaling was maintained throughout the course of the study. Reflexivity involves "attending systematically and continually to the context of the knowledge, in particular, to the researcher's effect on the collection, analysis, and interpretation of data” (Polit \& Beck, 2012, p. 589). The journal documented the following content, but it was not limited to these items: 1) The researcher's personal values were clarified and the possible areas of bias were identified ahead of time and throughout the study; 2) The researcher made notes of how interests were highlighted; 3) The researcher recorded the possible role conflicts and any feelings that were identified as less neutrality during the interview conversation; 4) The researcher described the new and surprising findings in data collection and analysis, 6) The researcher recorded details about how the findings were written up and the findings were compared to the literature review.

Second, all interviews were conducted by one researcher. Since the researcher is considered an instrument in a qualitative study (Creswell \& Creswell, 2007), one interviewer reduced the variety of the "instrument," such as interview style. Third, the participant was invited to a follow-up interview additional to the initial interviews when the information in the first one was not clear. Additionally, a peer-debriefing session was employed. The methods experts and experienced researchers on this topic and a breast 
cancer survivor with lymphedema were invited to review the study design, procedures, and data to identify biases (Polit \& Beck, 2012).

Most important, a pilot case study was conducted to help refine the data collection "with respect to both the content of the data and the procedures to be followed" (Yin, 2014, p. 96). The pilot study was conducted in 2015 with five female survivors who developed BCRL. This pilot study was implemented after IRB approval. The cases chosen were those easy-to-access survivors with lymphedema who were known from local breast cancer support groups with personal contacts. The initial interview guide was drafted, data collected, and data were analyzed. The pilot study demonstrated the feasibility of the proposed study design and provided initial preliminary findings. The initial interviews suggested a revision of the initial interview protocol to better capture the information for the research questions. The pilot study helped to better estimate the number of participants to be recruited for data saturation, and also informed us of potential biases and missing data.

\section{Human Subjects Protection}

\section{Human Subjects Involvement, Characteristics, and Design}

The potential participants were recruited from local support groups of cancer survivors, referral by therapists or other clinicians, and referral by the enrolled survivors. The IRB-approved flyer was disseminated at local and regional area hospitals and clinics especially those sites with lymphedema rehabilitation services, and cancer survivor group meetings. Women who meet the inclusion criteria were informed about the details of the study, and an informed consent form in accordance with the University’s HS IRB- 
approved protocol was provided. The data collection (interview) was arranged based on the participant's and researcher's schedules. The data collection procedure followed the protocol delineated in the data collection section.

\section{Sources of Materials}

A semi-structured individual interview was conducted with working-age participants who had developed lymphedema after breast cancer treatment. Each participation included a 60-minute private interview, with each talking about their experiences of having lymphedema following breast cancer treatment while re-entering or returning to work. Participants were invited to a 15-to-30-minute follow-up interview, if information clarification or expansion of data of interest was needed.

The interviews were recorded with participants’ permission. Only assigned trained researchers in this project were allowed to access the recordings. Transcripts were saved in secured folders in a computer accessed with passwords. Case ID was used in transcripts, publications, and any other documents. Thus, participants would not be identifiable, unless they requested the preference of showing their real name in documents of the project.

\section{Potential Risks and Protecting from Potential Risks}

Even though there was no biological sample collected and no direct physical intervention involved, one must be cognizant of the possibilities that questions concerning psychosocial adjustment and difficulties with the chronic condition of lymphedema might cause emotional discomfort for the breast cancer survivors. The researcher gave vigilant attention to the possible cues of emotional discomfort during or 
after all the interviews. During each interview, the researcher reminded the participants that they did not need to answer any questions that they might feel uncomfortable with and informed them they might withdraw from the study at any time. This study was submitted to the Institutional Review Board for Research with Human Subjects in the Health Sciences section at the University of Missouri. Privacy was ensured: interviews were conducted in a setting with only the participant and researcher present; data obtained were recorded in a coded system in which each participant's identity was linked to a number, so that participants could not be identified from the dataset; each participant's name was matched to a code used to identify the audio, transcribed interview, and the notes taken in and following interview. The list of participants' name, code, address, and contacts were stored in a locked file in computer only accessible to the research team; data analysis was carried out and reported in such a way that individual identities cannot be revealed; all participants were informed that their words in the interview might be quoted in the research reports for illustration, without revealing their identities.

\section{Potential Benefits of the Proposed Research to Human Subjects and Others}

Each participant received a $\$ 20$ check for the initial 60-minute interview and a $\$ 15$ check for the follow-up interview, if necessary. Participants were provided written information of community services, information about breast cancer support groups, and other information and support, as needed. Participation might thus have served to raise people's awareness about the resources for coping with difficulties in their return to work.

\section{Importance of the Knowledge to be Gained}


Although approximately half of all women diagnosed with breast cancer are in their working years (American Cancer Society, 2013), research examining the experiences of young breast cancer survivors is very limited, compared to the elderly. The young survivors generally struggle with many issues, including employment, which are either not present or may be much less severe in the survivorship of older survivors. Employment is particularly a significant issue for young survivors; it represents part of the individual's life value, social function, and roles, and it highly relates to quality of life in cancer survivorship (Johnsson, Fornander, Rutqvist, \& Olsson, 2011).

Lymphedema is a key long-term cause of, or is related to, many top-listed factors associated with diminished QOL, such as arm impairment and symptoms, including pain, heaviness, fatigue, and psychological distress. Thus, we proposed lymphedema may significantly influence the return-to-work process. Survivors with lymphedema have talked about their challenges for resuming their work lives. By identifying in what ways lymphedema has challenged survivors’ work-return, we could help them better with occupational rehabilitation.

However, it was not previously clear whether their work lives were really affected by lymphedema as a whole, and how the lymphedema-reduced limitations played a role in carrying out their work task, and what were the possible other factors which were yet undiscovered related to lymphedema and causing work limitations. This study was designed and carried out to provide us true stories from survivors' perspectives on how and how much lymphedema influenced their work, as well as their journey of coping.

\section{Inclusion of Women}


Only female breast cancer survivors were included because they represent the majority (99\%) of the population of breast cancer patients. The focus was on women also because many differences exist in the job markets and societal roles between women and men and physiological differences may "muddy” the variables (lymphedema) and outcomes (barriers and impairment related to work) of main interest. As a minority in the population of breast cancer survivors, men indeed need to be studied in the future. Breast cancer survivors with lymphedema are not specifically included in the definition of vulnerable populations at the University’s IRB for Research with Human Subjects. 


\section{References}

Andrews, T. (2012). What is social constructionism. Grounded theory review, 11(1), 3946.

Bluethmann, S. M., Mariotto, A. B., \& Rowland, J. H. (2016). Anticipating the "Silver Tsunami": Prevalence Trajectories and Comorbidity Burden among Older Cancer Survivors in the United States. Cancer Epidemiology Biomarkers \& Prevention, 25(7), 1029-1036. doi:10.1158/1055-9965.Epi-16-0133

Cho, J., \& Trent, A. (2006). Validity in qualitative research revisited. Qualitative Research, 6(3), 319-340. doi:10.1177/1468794106065006

Creswell, J. W., \& Creswell, J. W. (2007). Qualitative inquiry \& research design : choosing among five approaches. Thousand Oaks: Sage Publications.

Crotty, M. (1998). The foundations of social research: Meaning and perspective in the research process. London; Thousand Oaks, California: Sage Publications.

De Croon, E., Sluiter, J., Nijssen, T., Dijkmans, B., Lankhorst, G., \& Frings-Dresen, M. (2004). Predictive factors of work disability in rheumatoid arthritis: A systematic literature review. Annals of the rheumatic diseases, 63(11), 1362-1367.

Dedoose Version 7.0.23. (2016). Web application for managing, analyzing, and presenting qualitative and mixed method research data. Retrieved from http://www.dedoose.com/)

Désiron, H. A. M., Donceel, P., de Rijk, A., \& Van Hoof, E. (2013). A conceptualpractice model for occupational therapy to facilitate return to work in breast cancer patients. Journal of Occupational Rehabilitation, 23(4), 516-526. doi:10.1007/s10926-013-9427-z 
Duijts, S., Spelten, E., \& Verbeek, J. (2014). Behavioral determinants of employment status in cancer patients. The handbook of behavioral medicine (Vols 1-2). (pp. 827-849): John Wiley \& Sons, Ltd.

Ecamm Network @2017. Retrieved from http://www.ecamm.com/mac/callrecorder/

Glaser, B. G., \& Strauss, A. L. (1967). The discovery of grounded theory: Strategies for qualitative research. Chicago: Aldine Pub. Co.

Glaser, B. G., \& Strauss, A. L. (1999). The discovery of grounded theory strategies for qualitative research. Retreived from http://www.sxf.uevora.pt/wpcontent/uploads/2013/03/Glaser_1967.pdf

Howlader, N., Noone, A. M., Krapcho, M., Garshell, J., Miller, D., Altekruse, S. F., . . . Cronin, K. A. (2015). SEER Cancer Statistics Review, 1975-2012. Available from based on November 2014 SEER data submission based on November 2014 SEER data submission Retrieved 2015, from National Cancer Institute http://seer.cancer.gov/csr/1975_2012

Jette, A. M. (2006). Toward a common language for function, disability, and health. Phys Ther, 86(5), 726-734.

Lincoln, Y. S., \& Guba, E. G. (1985). Naturalistic inquiry. Newbury Park, California: Sage.

Merriam, S. B. (2009). Qualitative research: A guide to design and implementation. Retrieved from http://public.eblib.com/choice/publicfullrecord.aspx?p=1662771 Microsoft Skype @2017. Retrieved from https://www.skype.com/en/ 
Polit, D. F., \& Beck, C. T. (2012). Nursing research: Generating and assessing evidence for nursing practice. Philadelphia: Wolters Kluwer Health/Lippincott Williams \& Wilkins.

Qualtrics@2017. Provo Utah USA (Producer). (2017). Retrieved from http://www.qualtrics.com/

Schreuer, N., Rimmerman, A., \& Sachs, D. (2006). Adjustment to severe disability: Constructing and examining a cognitive and occupational performance model. International Journal of Rehabilitation Research, 29(3), 201-207 207p.

Shih, Y. C., Xu, Y., Cormier, J. N., Giordano, S., Ridner, S. H., Buchholz, T. A., . . . Elting, L. S. (2009). Incidence, treatment costs, and complications of lymphedema after breast cancer among women of working age: A 2-year follow-up study. $J$ Clin Oncol, 27(12), 2007-2014. doi:10.1200/jco.2008.18.3517

Sun, Y., Shigaki, C. L., \& Armer, J. M. (2017). Return to work among breast cancer survivors: A literature review. Supportive Care in Cancer, 25(3), 709-718. doi:10.1007/s00520-016-3446-1

Tamminga, S. J., de Boer, A. G., Verbeek, J. H., \& Frings-Dresen, M. H. (2012). Breast cancer survivors' views of factors that influence the return-to-work process--A qualitative study. Scandinavian Journal of Work, Environment \& Health, 38(2), 144-154.

van der Valk, M. E., Mangen, M.-J. J., Leenders, M., Dijkstra, G., van Bodegraven, A. A., Fidder, H. H., . . . Romberg-Camps, M. J. (2014). Risk factors of work disability in patients with inflammatory bowel disease—A Dutch nationwide 
web-based survey: work disability in inflammatory bowel disease. Journal of Crohn's and Colitis, 8(7), 590-597.

Workforce Innovation and Opportunities Act (WIOA) (2016). REHABILITATION ACT

OF 1973 [As Amended Through P.L. 114-95, Enacted December 10, 2015]

Retrieved from https://legcounsel.house.gov/Comps/Rehabilitation Act Of

1973.pdf

World Health Organization (2001a). ICF: International classification of functioning, disability and health. Geneva: World Health Organization. Retrieved from http://psychiatr.ru/download/1313?view=name=CF_18.pdf

World Health Organization. (2001b). International classification of functioning, disability and health: ICF. Geneva: World Health Organization. Retrieved from http://psychiatr.ru/download/1313?view=name=CF_18.pdf

Yin, R. K. (2014). Case study research: Design and methods (5th ed.). Thousand Oaks, CA Sage. 


\title{
CHAPTER FIVE \\ THE INFLUENCE OF BREAST CANCER-RELATED \\ LYMPHEDEMA \\ ON WOMEN'S RETURN-TO-WORK
}

\author{
Manuscript Submitted: Sun, Y., Shigaki, C.L., \& Armer, J.M. (in review). The influences \\ of breast cancer-related lymphedema on women's return-to-work.
}

\begin{abstract}
PURPOSE: Breast cancer-related lymphedema (BCRL) is one of the major treatment complications for breast cancer patients who have undergone axillary lymph node dissection and radiation. As the majority of women who develop breast cancer are under the age of retirement, occupational functioning and employment are issues of concern for these patients. Although previous studies indicated the potential associations between BCRL and adverse work outcomes, this study is novel in exploring the ways that lymphedema affects their work. METHODS: A multiple-case study methodology drawn from Yin's (2014) definition was employed. Thirteen female breast cancer survivors who developed BCRL participated by completing a survey and a sixty-minute semi-structured interview. RESULTS: Four main themes emerged: 1) BCRL affects physical and emotional functioning associated with work; 2) Ongoing treatment for BCRL creates challenges for work; 3) Environmental factors affect the work experience; and 4) Personal factors play a key role in adjusting to return-to-work. CONCLUSION: Both BCRL and its treatment have direct and indirect effects on work, with environmental and personal factors also shaping the work-return experience. IMPLICATIONS: This study suggests that breast cancer survivors with BCRL face potential barriers when return to
\end{abstract}


work, and that gaps remain in the availability of supports that might facilitate workforce re-entry and maximize retention.

Keywords: Breast cancer, lymphedema, survivorship, return-to-work, occupational rehabilitation 
THE INFLUENCE OF BREAST CANCER-RELATED LYMPHEDEMA

ON WOMEN'S RETURN-TO-WORK

\section{Background}

Diagnosis and treatment of cancer have evolved in recent decades and, as a result, survival for persons with cancer continues to increase (American Cancer Society, 2018). As of January 2016, there were approximately 15.5 million cancer survivors in the United States (Bluethmann, Mariotto, \& Rowland, 2016). Breast cancer remains the second most common cancer affecting women in the United States, with a 5-year survival rate of 89.7\% (Howlader et al., 2016). Breast cancer is most frequently diagnosed in women who are under the age of retirement, between the ages of 55 - 64 years (Howlader et al., 2016). Despite medical advancements in treatment, knowledge of the functional status of cancer survivors in daily life, including employment functioning, remains limited (Richardson et al., 2011). According to Feuerstein’s review on work among general cancer survivors, cancer treatment and diagnosis can lead to negative work outcomes (e.g. work return, ability, performance, and sustainability) and multiple factors could contribute to these outcomes (e.g. physical function, health/well-being, work demands, work environment, policy, and economic factors) (Feuerstein et al., 2010). Our recent review on return-to-work among breast cancer survivors identified that personal factors, such as personality and coping, may also influence work-return outcomes. Breast cancer survivors may deal with treatment-specific problems such as upper extremity impairment and lymphedema (Sun, Shigaki, \& Armer, 2017). Because the majority of women who 
develop breast cancer are under the age of retirement, occupational functioning and employment are issues of significant concern for this population.

Lymphedema is one of the major treatment complications for breast cancer patients undergoing axillary lymph node dissection and radiation (Nguyen, Hoskin, Habermann, Cheville, \& Boughey, 2017; Warren et al., 2014; Zou et al., 2018) and it has become one of the greatest fears for survivors, second only to cancer reoccurrence (Bernas, Askew, Armer, \& Cormier, 2010). In the Western world, between 20 and 40 percent of women treated for breast cancer experience lymphedema, which can occur at any time, from immediately after treatment onward (Armer \& Stewart, 2010; Brennan \& Weitz, 1992). Lymphedema occurs when protein-rich fluid accumulates in the extravascular interstitial spaces and leads to swelling of the affected body part, most often the extremities, but also neck, face, abdomen, trunk and genitals (Földi, Földi, Strößenreuther, \& Kubik, 2012). The skin’s protective layer may be reduced, leading to disruption of the body's natural immune defense system. Because the excess fluid contains proteins and accumulated waste products, even minor cuts can rapidly lead to severe infection, including erysipelas and septicemia. Damage to tissue and vessels may lead to localized inflammation and systemic symptoms of fever, chills, headache, and even vomiting. If severe, acute sickness caused by BCRL-related infection may require hospitalization (Földi et al., 2012).

To date, lymphedema cannot be completely cured or prevented. Complete decongestive therapy (CDT) is considered the 'gold standard' of care for lymphedema, to reduce volume, control infection, manage fibrosis, and to improve functioning and overall quality of life (Zuther \& Norton, 2013). CDT is a two-phase system comprising 
an intensive phase and a maintenance phase. The intensive phase consists of daily treatment including a type of massage referred to as manual lymph drainage (MLD), application of compression bandaging (typically 23-of-24-hours a day, for up to six weeks), compression garments, remedial exercise, skincare, and education. Patients are typically required to visit therapists frequently during this interval. The maintenance phase focuses on a routine of self-management for lymphedema, in which survivors apply at home what they have learned in the intensive phase (Zuther \& Norton, 2013).

Studies have shown that lymphedema may be associated with multiple adverse work outcomes such as decreased work productivity (Boyages et al., 2016; Quinlan et al., 2009), delay in returning to work (Peugniez et al., 2011), reduced earnings (Babu, Swain, \& Rath, 2006), unemployment status (Bifulco et al., 2012; Moffatt et al., 2003), more time off from work (Babu et al., 2006; Bifulco et al., 2012; Boyages et al., 2016), and reduced work capacity (Babu et al., 2006; Quinlan et al., 2009). Despite the identified potential relationships between lymphedema and negative work outcomes, there is almost no published research that investigates the precise reasons for the association. The aim of this study was to address this gap by investigating survivors' perspectives regarding the ways in which BCRL influences their work. Because of the complexity of the phenomenon we wished to study, we used the International Classification of Functioning, Disability, and Health (ICF), (World Health Organization, 2001) as an organizing framework and general philosophy for our inquiry. The ICF is a scientific tool, published in 2001 by the WHO, which was developed to measure health and disability at both the individual and population levels. The unique contribution of the ICF lies in its recognition that health and disability do not occur in the absolute, a point that we wished 
to explore. As opposed to models for identifying health trends and statistics which focus on disease, the ICF considers the relationships between disease, disability, and function and acknowledges the role of personal factors, as they occur within specific contexts (e.g. activities, environments).

\section{Methods}

\section{Design}

We used a multiple-case study design drawn from Yin’s definition which inquiries about ongoing phenomenon (BCRL) within its real-life context (returning to work) and focuses on research questions throughout the data collection and analysis (Yin, 2014). We defined a "case” as a breast cancer survivor who developed lymphedema and who returned to competitive employment or self-employment, following breast cancer treatment.

\section{Participants and Setting}

Breast cancer survivors were eligible to participate if they: 1) were more than 12 months post-surgery and radiation treatment; 2) were subsequently diagnosed with lymphedema, and 3) were employed or self-employed at the time of developing lymphedema. Person who was unable to spoke English or Chinese efficiently were not included in this study. Potential participants were recruited from our university's Institutional Review Board (IRB)-approved database of known survivors as well as local hospitals, community health centers, breast cancer support groups, and survivors' events in a medium-size, Midwestern city. Interested individuals were informed about the details of the study and enrolled with written, informed consent. Data collection occurred in a 
private clinic or conference room setting. Participants who were unable to travel for the interview were given the option of interviewing over Skype (Microsoft Skype @2017), a video conferencing tool.

\section{Data Collection}

Data were collected between June and November 2017. A structured, investigator-developed data collection tool was administered to each participant, followed by a 60-minute, one-on-one interview. One participant also underwent a 15-30 minute follow-up interview to validate and enrich few specific ideas. The pre-interview data collection tool asked questions about demographic information (e.g. age, marital status, education level, adequacy of financial resources etc.), clinical characteristics (e.g. breast cancer treatment, lymphedema diagnosis, co-morbidities, etc.), and employment information (e.g. occupation, working hours, time off, insurance, etc.). The semistructured interview guide included questions regarding: 1) work content, demands, and meaning to individual; 2) lymphedema-related changes, including physical, emotional and interpersonal changes; 3) work-related outcomes, including engagement in work, job continuance, ability to do work tasks, performance, and workplace relationships; 4) work environment, including work-related social support; 5) reflections on personal experiences; and 6) having lymphedema after breast cancer treatment, in general. The interview were audio-recorded using digital recorder for in-person interviews and Ecamm Call Recorder for Skype software (Ecamm Network @2017) interview. A journal entry was written by the primary investigator after each interview to summarize and highlight details that might be informative for follow-up interviews and data analysis and to 
document any unusual or otherwise interesting observations during the data collection process.

\section{Data Management and Analysis}

Data were stored securely and access to the data was limited to the researchers and trained personnel associated with this study. All digital data were saved in a locked efolder on the researcher's computer. A coding system was used for participant data. Only researchers working with this projects were able to access the recorded data. Identifiable information on the audio were immediately removed after the transcript.

Audio-taped interviews were transcribed verbatim. Any identifying information that was provided by the participant in the course of the interview (i.e. names of persons and companies) was removed after transcription. Transcripts were subsequently read through for overall impression and initial coding-tagging. The transcripts then were imported into the computer-based software program Dedoose (Dedoose Version 7.0.23, 2016) for within-case and cross-case analysis. The work-related variables were examined before and after breast cancer and lymphedema diagnosis within each case and compared to other cases. The ICF framework was used during this process to conceptualize the factors identified and their relation to work outcomes. Merged themes and subthemes were confirmed and disconfirmed using constant-comparison of the data. All 13 transcripts and data collection tools were included in the data analysis.

\section{Findings}

\section{Case Demographic Characteristics}


Most participants lived in or near small metropolitan areas in the Midwest. All interviews were conducted in person, except one distant interview conducted via Skype. The age of participants ranged from 40-77 (mean 58 years) and the majority of participants were white. Education level and financial status tended to be reported as high. Social support also was self-reportedly high among the group (Table 5.1).

\section{Disease-related Characteristics}

All participants had undergone breast cancer surgery. Time-since-surgery ranged from 6.5 months to 27 years prior to enrollment in the study. (The 6-month post-surgery participant is an Institutional Review Board-approved alternative case who satisfied all other inclusion criteria except time post-surgery.) The majority had lymph node removal and mastectomy, lumpectomy, or both. More than half of them also had radiation and chemotherapy. At the time of the interview, the primary diagnosis of breast cancer ranged from 8 months to 27 years (median 5.3 years) prior. The initial diagnosis of lymphedema ranged from one month to 24.5 years (median 34 months) prior. The majority developed lymphedema on the side of their dominant limb. Most women recalled detecting lymphedema by themselves and they subsequently sought the medical diagnosis. About one-third of participants reported having depression and an equal number reported a change of health and well-being after developing lymphedema. The most frequently reported symptoms associated with lymphedema were heaviness ( $\mathrm{n}=10)$, upper extremity weakness ( $\mathrm{n}=6)$, aching $(\mathrm{n}=7)$, and sensation alteration $(\mathrm{n}=9)$ (e.g. numbness, firmness, stiffness) (Table 5.2).

\section{Employment Characteristics}


The participants' occupations in our sample included both sedentary jobs, such as office work, and more physically demanding jobs, such as natural sciences fieldwork and work in a grocery store. The majority of participants continued in their previous occupations after lymphedema diagnosis, except a grocery store food demonstrator who worked as cleaning staff before her lymphedema diagnosis. More than half reported no formal restrictions in terms of their work arrangements. In contrast, four women were restricted to light duty and two needed some workplace modification or modified work hours. Most participants did not take time off from work or took off only a few days in total for lymphedema treatment. The exception was an individual who took 5 months off from work from her cleaning duties after lymphedema diagnosis. All participants commuted to work within 5 to 20 minutes driving distance. A large majority (n=10) had employee or student-based health insurance, with full or deductible-only coverage for lymphedema treatment. Three paid for their insurance or lymphedema treatment on their own (Table 5.3). 
Table 5.1 Case Demographic Characteristics

\begin{tabular}{|c|c|c|c|c|c|c|c|c|}
\hline & $\begin{array}{l}\text { Case } \\
\text { ID }\end{array}$ & $\begin{array}{l}\text { Age } \\
\text { (yr) } \\
\text { (Q0) }\end{array}$ & $\begin{array}{l}\text { Race } \\
\text { (Q1) }\end{array}$ & $\begin{array}{l}\text { Education Level } \\
\text { (Q2) }\end{array}$ & $\begin{array}{l}\text { Marital } \\
\text { Status } \\
\text { (Q8) }\end{array}$ & $\begin{array}{l}\text { Household Size including } \\
\text { participant (Q13) }\end{array}$ & $\begin{array}{l}\text { Financial } \\
\text { Adequacy } \\
\text { (Q3) }\end{array}$ & $\begin{array}{l}\text { Degree of Social Support } \\
\text { (Q25) }\end{array}$ \\
\hline & 01 & 59 & White & Bachelor's Degree & Divorced & 1 & Extremely adequate & High \\
\hline & 02 & 63 & White & Associate's Degree & Divorced & 1 & Somewhat inadequate & Above average \\
\hline & 03 & 62 & White & Master's Degree & Married & 2 (spouse) & Extremely adequate & High \\
\hline & 04 & 77 & Black & High school diploma & Divorced & 3 (children) & Somewhat adequate & High \\
\hline & 05 & 40 & White & $\mathrm{PhD}$ & $\begin{array}{l}\text { Unmarried } \\
\text { In relationship }\end{array}$ & 2 (partner) & Extremely adequate & High \\
\hline & 06 & 65 & White & Master’s degree & Married & 4 (spouse \& children) & Extremely adequate & High \\
\hline & 07 & 66 & White & High school diploma & Divorced & 2 (children) & Extremely adequate & Above average \\
\hline & 08 & 62 & White & Bachelor's Degree & Married & 2 (spouse) & Extremely adequate & High \\
\hline & 09 & 68 & Black & Some college & Married & 3 (spouse \& child) & Somewhat adequate & High \\
\hline & 10 & 46 & White & Bachelor's Degree & Divorced & 3 (children) & Somewhat adequate & Average \\
\hline & 11 & 44 & White & Master's Degree & Divorced & 2 (child) & Somewhat adequate & Above average \\
\hline & 12 & 56 & White & Bachelor's Degree & Married & 3 (spouse \& child) & Extremely inadequate & Above average \\
\hline & 13 & 44 & White & Master's Degree & Single & 1 & Extremely adequate & High \\
\hline & \multicolumn{8}{|c|}{$\begin{array}{l}\text { Age was calculated by the date of interview and birthday. } \\
\text { Q25: High degree of social support: much support is either given or is available from family and friends. Above average degree of social support: more than } \\
\text { average support is given or potentially available from family and friends. Average degree of social support: compare to others, similar amount of support } \\
\text { from family and friends is given or potentially available. Below average degree of social support: while some support is available, it's not consistently } \\
\text { available. }\end{array}$} \\
\hline
\end{tabular}


Table 5.2 Case Disease-related Characteristics

\begin{tabular}{|c|c|c|c|c|c|c|c|c|}
\hline $\begin{array}{l}\text { Case } \\
\text { ID }\end{array}$ & $\begin{array}{l}\text { Overall health } \\
\text { well-being } \\
\text { before/after } \\
\text { lymphedema (LE) } \\
\text { (Q15) }\end{array}$ & $\begin{array}{l}\text { LE side } \\
\text { dominant/ } \\
\text { non- } \\
\text { dominant } \\
(Q 18,21)\end{array}$ & $\begin{array}{l}\text { How LE } \\
\text { was } \\
\text { detected } \\
(\mathbf{Q 1 9 )}\end{array}$ & $\begin{array}{l}\text { Duration of } \\
\text { LE/ } \\
\text { BC survival } \\
\text { time (Q20) }\end{array}$ & $\begin{array}{l}\text { LE symptoms } \\
\text { (Q22) }\end{array}$ & $\begin{array}{l}\text { Time post- } \\
\text { surgery/ } \\
\text { Radiation/ } \\
\text { chemo } \\
\text { (Q20) }\end{array}$ & $\begin{array}{l}\text { Type of surgery/ } \\
\text { Radiation/\# of } \\
\text { lymph nodes } \\
(\mathbf{Q} 23,24)\end{array}$ & $\begin{array}{l}\text { Other } \\
\text { Chronic } \\
\text { Health } \\
\text { Condition(s) } \\
\text { (Q16) }\end{array}$ \\
\hline 01 & $\begin{array}{l}\text { In good physical, } \\
\text { mental \& emotional } \\
\text { health (before \& } \\
\text { after) }\end{array}$ & $\begin{array}{l}\text { Right } \\
\text { Dominant }\end{array}$ & $\begin{array}{l}\text { Detected by } \\
\text { self and } \\
\text { sought } \\
\text { medical } \\
\text { diagnosis }\end{array}$ & $\begin{array}{l}\text { LE: } \\
5 \text { mos } \\
\text { BC: } \\
1 \text { yr }\end{array}$ & $\begin{array}{l}\text { Arm, hand } \\
\text { weakness, } \\
\text { swelling, } \\
\text { heaviness, } \\
\text { firmness/tightness, } \\
\text { numbness, stiffness, } \\
\text { aching }\end{array}$ & $\begin{array}{l}\text { Surgery: } \\
1 \mathrm{yr}\end{array}$ & $\begin{array}{l}\text { Mastectomy } \\
\text { Bilateral, } \\
\text { Reconstruction } \\
\text { No radiation }\end{array}$ & High cholesterol \\
\hline 02 & $\begin{array}{l}\text { Before: in good } \\
\text { physical, mental \& } \\
\text { emotional health } \\
\text { After: mild physical, } \\
\text { mental \& emotional } \\
\text { impairment }\end{array}$ & $\begin{array}{l}\text { Right } \\
\text { Dominant }\end{array}$ & $\begin{array}{l}\text { Referral by } \\
\text { nurse, } \\
\text { physical } \\
\text { therapist, } \\
\text { Or other } \\
\text { clinicians. } \\
\text { Involved in } \\
\text { research } \\
\text { projects on } \\
\text { lymphedema }\end{array}$ & $\begin{array}{l}\text { LE: } 4 \text { yrs } \\
\text { BC: } 4 \text { yrs } \\
\text { 5mos }\end{array}$ & $\begin{array}{l}\text { Arm weakness, } \\
\text { limited movement } \\
\text { (upper extremity), } \\
\text { swelling (under } \\
\text { arm), } \\
\text { heaviness, } \\
\text { firmness, } \\
\text { stiffness, aching } \\
\text { (upper arm), } \\
\text { sleep problem (LE) } \\
\text { ribs hurt in area of } \\
\text { radiation }\end{array}$ & $\begin{array}{l}\text { Surgery: } \\
3 \text { yrs } 6 \text { mos } \\
\text { Radiation: } \\
4 \text { yrs } 3 \text { mos }\end{array}$ & $\begin{array}{l}\text { Mastectomy } \\
\text { Bilateral, } \\
\text { Lymph node } \\
\text { removal (\#52) } \\
\text { External radiation to } \\
\text { breast and axilla } \\
(\# 25)\end{array}$ & $\begin{array}{l}\text { Depression, } \\
\text { sleep apnea }\end{array}$ \\
\hline 03 & $\begin{array}{l}\text { Mild physical, } \\
\text { mental \& emotional } \\
\text { impairment (before } \\
\text { \& after) }\end{array}$ & $\begin{array}{l}\text { Right } \\
\text { Dominant }\end{array}$ & $\begin{array}{l}\text { Detected by } \\
\text { self and } \\
\text { sought } \\
\text { medical } \\
\text { diagnosis }\end{array}$ & $\begin{array}{l}\text { LE: } 16 \text { yrs } \\
\text { BC: } 16 \text { yrs } \\
11 \text { mos }\end{array}$ & $\begin{array}{l}\text { Arm hand } \\
\text { weakness, right arm } \\
\text { fatigue, } \\
\text { swelling, } \\
\text { heaviness, } \\
\text { sleep problem } \\
\text { (due to night time } \\
\text { garment) }\end{array}$ & $\begin{array}{l}\text { Surgery: } \\
16 \text { yrs } 11 \text { mos } \\
\text { Radiation: } \\
16 \text { yrs } \\
\text { Chemo: } \\
16 \text { yrs } 5 \text { mos }\end{array}$ & $\begin{array}{l}\text { Lumpectomy } \\
\text { Lymph node } \\
\text { removal } \\
\text { External radiation to } \\
\text { breast (\#36) }\end{array}$ & $\begin{array}{l}\text { Hypothyroidism, } \\
\text { high cholesterol }\end{array}$ \\
\hline
\end{tabular}




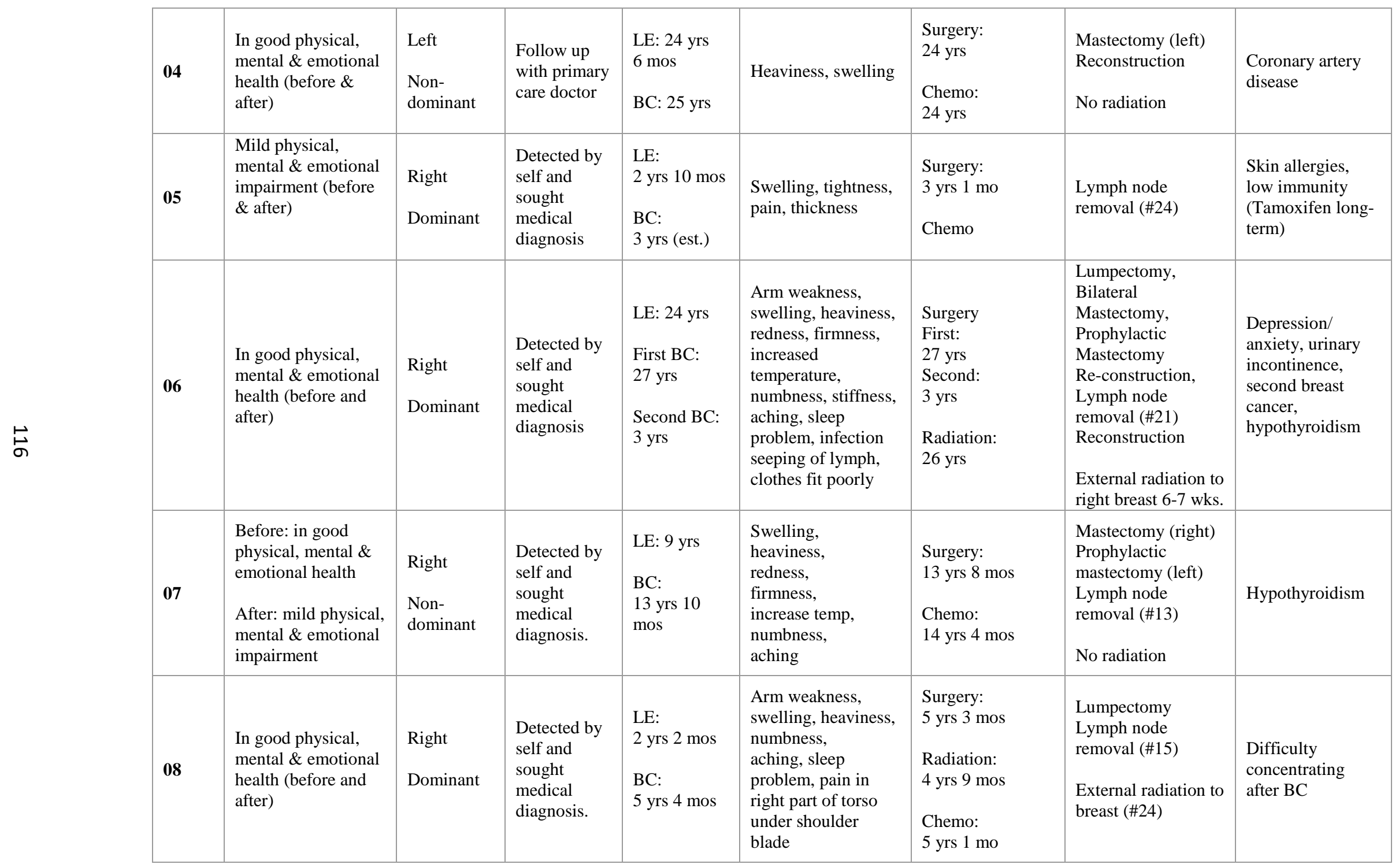




\begin{tabular}{|c|c|c|c|c|c|c|c|c|c|}
\hline & 09 & $\begin{array}{l}\text { Before: in good } \\
\text { physical, mental \& } \\
\text { emotional health } \\
\text { After: moderate } \\
\text { physical, mental \& } \\
\text { emotional } \\
\text { impairment }\end{array}$ & $\begin{array}{l}\text { Right } \\
\text { Dominant }\end{array}$ & $\begin{array}{l}\text { Follow-up } \\
\text { with } \\
\text { radiologist }\end{array}$ & $\begin{array}{l}\text { LE: } \\
6 \text { mos } \\
\text { BC: } \\
3 \text { yrs } 11 \text { mos }\end{array}$ & $\begin{array}{l}\text { Swelling, heaviness, } \\
\text { thickness, } \\
\text { tingling right hand }\end{array}$ & $\begin{array}{l}\text { Surgery: } \\
3 \text { yrs } 5 \text { mos } \\
\text { Radiation: } \\
3 \text { yrs } 5 \text { mos } \\
\text { Chemo: } \\
3 \text { yrs } 6 \text { mos }\end{array}$ & $\begin{array}{l}\text { Mastectomy both } \\
\text { Lymph node } \\
\text { removal } \\
\text { External radiation to } \\
\text { right chest wall\& } \\
\text { supraclavicular } \\
\text { fossa }\end{array}$ & $\begin{array}{l}\text { Tendonitis, } \\
\text { depression, } \\
\text { anxiety, } \\
\text { fatigue, } \\
\text { tingling right } \\
\text { hand, } \\
\text { vertigo }\end{array}$ \\
\hline & 10 & $\begin{array}{l}\text { Before: in good } \\
\text { physical, mental \& } \\
\text { emotional health. } \\
\text { After: moderate } \\
\text { physical, mental \& } \\
\text { emotional } \\
\text { impairment }\end{array}$ & $\begin{array}{l}\text { Both } \\
\text { Dominant }\end{array}$ & $\begin{array}{l}\text { Detected by } \\
\text { self and } \\
\text { sought } \\
\text { medical } \\
\text { diagnosis } \\
\text { Referral by } \\
\text { nurse, PT, } \\
\text { OT, or other } \\
\text { clinician }\end{array}$ & $\begin{array}{l}\text { LE: } \\
8 \text { yrs } 6 \text { mos } \\
\text { BC: } \\
9 \text { yrs }\end{array}$ & $\begin{array}{l}\text { Arm hand } \\
\text { weakness, } \\
\text { swelling, } \\
\text { heaviness, } \\
\text { fitness/tightness, } \\
\text { stiffness, } \\
\text { aching, } \\
\text { sleep problem } \\
\text { (leg ache) }\end{array}$ & $\begin{array}{l}\text { Surgery: } \\
8 \text { yrs } 10 \text { mos } \\
\text { Chemo: } \\
8 \text { yrs } 5 \text { mos }\end{array}$ & $\begin{array}{l}\text { Mastectomy } \\
\text { both }\end{array}$ & $\begin{array}{l}\text { Leg, body. truck, } \\
\text { face lymphedema }\end{array}$ \\
\hline \multirow[t]{2}{*}{$\mapsto$} & 11 & $\begin{array}{l}\text { In good physical, } \\
\text { mental \& emotional } \\
\text { health (before \& } \\
\text { after) }\end{array}$ & $\begin{array}{l}\text { Left } \\
\text { Non- } \\
\text { dominant }\end{array}$ & $\begin{array}{l}\text { Detected by } \\
\text { self and } \\
\text { referred by } \\
\text { specialty } \\
\text { (oncologist) }\end{array}$ & $\begin{array}{l}\text { LE: } \\
1 \text { yr } 4 \text { mos } \\
\text { BC: } \\
3 \text { yrs } 2 \text { mos }\end{array}$ & $\begin{array}{l}\text { Swelling } \\
\text { (throughout left } \\
\text { upper extremity), } \\
\text { firmness, } \\
\text { fibrosis }\end{array}$ & $\begin{array}{l}\text { Surgery: } \\
3 \text { yrs } 1 \text { mo } \\
\text { Radiation: } \\
2 \text { yrs } 7 \text { mos } \\
\text { Chemo: } 3 \text { yrs }\end{array}$ & $\begin{array}{l}\text { Mastectomy } \\
\text { Bilateral } \\
\text { Lymph node } \\
\text { removal }\end{array}$ & None \\
\hline & 12 & $\begin{array}{l}\text { Mild physical } \\
\text { impairment, } \\
\text { moderate emotional } \\
\text { impairment } \\
\text { (depression) } \\
\text { (before \& after) }\end{array}$ & $\begin{array}{l}\text { Left } \\
\text { Non- } \\
\text { Dominant }\end{array}$ & $\begin{array}{l}\text { Follow-up } \\
\text { with } \\
\text { Specialist } \\
\text { (oncologist) }\end{array}$ & $\begin{array}{l}\text { LE: } \\
1 \text { mo } \\
\text { BC: } \\
8 \text { mos }\end{array}$ & $\begin{array}{l}\text { Limited movement, } \\
\text { swelling, sleep } \\
\text { problem (hurting } \\
\text { when switch } \\
\text { position, bandage) }\end{array}$ & $\begin{array}{l}\text { Surgery: } \\
6.5 \text { mos } \\
\text { chemo: } 2 \text { mos }\end{array}$ & $\begin{array}{l}\text { Mastectomy } \\
\text { Bilateral, } \\
\text { Lymph node } \\
\text { removal (\#13) }\end{array}$ & $\begin{array}{l}\text { Arthritis, } \\
\text { asthma, } \\
\text { nephrolithiasis }\end{array}$ \\
\hline
\end{tabular}




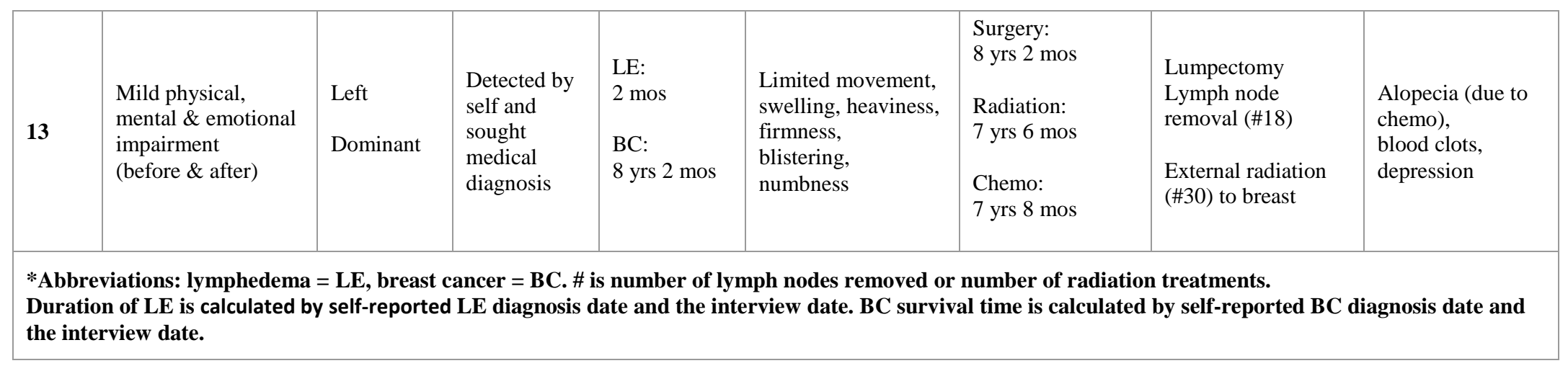


Table 5.3 Case Employment Characteristics

\begin{tabular}{|c|c|c|c|c|c|c|c|c|}
\hline $\begin{array}{l}\text { Case } \\
\text { ID }\end{array}$ & Occupation & $\begin{array}{l}\text { Employment } \\
\text { Status (Q7) }\end{array}$ & $\begin{array}{l}\text { Hours per wk } \\
\text { working (Q4); } \\
\text { Change since } \\
\text { breast cancer and } \\
\text { since LE }\end{array}$ & $\begin{array}{l}\text { Time off } \\
\text { between } \\
\text { BC and } \\
\text { RTW } \\
\text { (Q5) }\end{array}$ & $\begin{array}{l}\text { Time off } \\
\text { due to } \\
\text { LE } \\
\text { (Q6) }\end{array}$ & $\begin{array}{l}\text { Size of } \\
\text { business } \\
\text { \# persons } \\
\text { (Q8) }\end{array}$ & $\begin{array}{l}\text { Time to } \\
\text { commute } \\
\text { to work } \\
(\mathrm{Q} 10,11)\end{array}$ & $\begin{array}{l}\text { Health insurance } \\
\text { (Q14) }\end{array}$ \\
\hline 01 & $\begin{array}{l}\text { Insurance claim } \\
\text { representative }\end{array}$ & $\begin{array}{l}\text { Working full-time, } \\
\text { no restrictions }\end{array}$ & $\begin{array}{l}45 \text { hrs } \\
\text { no change }\end{array}$ & 4 wks & $\begin{array}{l}\text { Couple } \\
\text { hrs per wk } \\
\times 4 \text { wks }\end{array}$ & $\begin{array}{l}1000 \text { or } \\
\text { more }\end{array}$ & $\begin{array}{l}\text { Drive } \\
20 \text { min }\end{array}$ & Employer-based \\
\hline 02 & Food demonstrator & $\begin{array}{l}\text { Working, but } \\
\text { restricted to light } \\
\text { duty; working at } \\
\text { lower wage; fewer } \\
\text { hours than before LE }\end{array}$ & $\begin{array}{l}84 \text { hrs before BC } \\
0 \text { hrs after BC } \\
\text { 6-24/wk after LE }\end{array}$ & $9 \mathrm{mos}$ & $5 \mathrm{mos}$ & $100-499$ & $\begin{array}{l}\text { Drive } \\
20 \text { min }\end{array}$ & $\begin{array}{l}\text { Medicare (2015) } \\
\text { Medicaid (2017) }\end{array}$ \\
\hline 03 & Cytotechnologist & $\begin{array}{l}\text { Working full-time, } \\
\text { no restrictions }\end{array}$ & 40 hrs, no change & 4 wks & 2 days & $\begin{array}{l}1000 \text { or } \\
\text { more }\end{array}$ & $\begin{array}{l}\text { Drive } \\
5 \text { min }\end{array}$ & Employer-based \\
\hline 04 & Medical technician & $\begin{array}{l}\text { Working full-time, } \\
\text { no restriction with } \\
\text { assistance }\end{array}$ & 40 hrs, no change & 1 day & 0 & $\begin{array}{l}1000 \text { or } \\
\text { more }\end{array}$ & $\begin{array}{l}\text { Drive } \\
10 \mathrm{~min}\end{array}$ & $\begin{array}{l}\text { Employer-based } \\
\text { Medicare }\end{array}$ \\
\hline 05 & Wildlife biologist & $\begin{array}{l}\text { Working full-time, } \\
\text { restricted to light } \\
\text { duty }\end{array}$ & $\begin{array}{l}60 \text { hrs before BC } \\
15 \text { hrs after BC } \\
40 \text { hrs after LE }\end{array}$ & $\begin{array}{l}\text { Part-time } \\
15-20 \\
\text { hrs }\end{array}$ & $\begin{array}{l}3 \text { days } \\
\text { due to } \\
\text { infection }\end{array}$ & $\begin{array}{l}\text { Don’t } \\
\text { know }\end{array}$ & Walk 30 min & Student insurance \\
\hline 06 & Nurse & $\begin{array}{l}\text { Working full-time, } \\
\text { no restrictions or } \\
\text { modifications }\end{array}$ & 40 hrs, no change & $2 \operatorname{mos}$ & 5 days & $\begin{array}{l}100-499 \\
\& \\
1000 \text { or } \\
\text { more }\end{array}$ & $\begin{array}{l}\text { Drive } \\
30 \mathrm{~min}\end{array}$ & Employer-based \\
\hline 07 & $\begin{array}{l}\text { Customer service } \\
\text { representative }\end{array}$ & $\begin{array}{l}\text { Working full-time, } \\
\text { no restriction }\end{array}$ & 40 hrs, no change & 0 & 0 & $100-499$ & $\begin{array}{l}\text { Drive } \\
10 \text { min }\end{array}$ & $\begin{array}{l}\text { Employer-based } \\
\text { Full LE coverage }\end{array}$ \\
\hline 08 & Fitness instructor & $\begin{array}{l}\text { Working part-time, } \\
\text { no restriction } \\
\text { (Retired from } \\
\text { primary service job } \\
\text { due to BC treatment) }\end{array}$ & $\begin{array}{l}40 \text { hrs before BC } \\
15 \text { hrs after BC } \\
\text { (no change after } \\
\text { LE) }\end{array}$ & $1 \mathrm{wk}$ & 1 day & $1-19$ & $\begin{array}{l}\text { Drive } \\
15 \mathrm{~min}\end{array}$ & $\begin{array}{l}\text { Retiree Insurance from } \\
\text { former employer } \\
\text { Deductible } \\
\$ 3000\end{array}$ \\
\hline
\end{tabular}




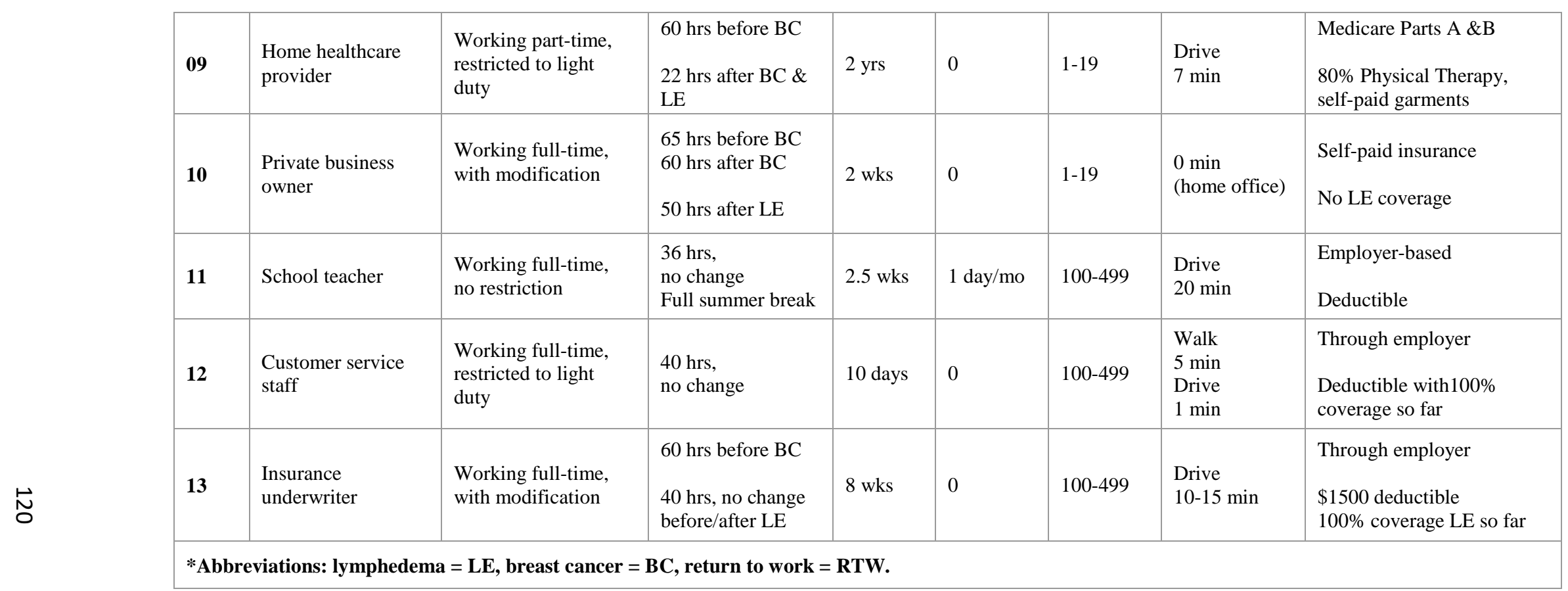




\section{Main Themes}

Four main themes emerged from our interviews: 1) BCRL affects physical and emotional functioning associated with work; 2) Ongoing treatment for BCRL creates challenges for work; 3) Environmental factors affect the work experience; and 4) Personal factors play a key role in adjusting to return-to-work.

\section{BCRL affects physical and emotional functioning associated with work}

Participants in this study reported both physical changes and emotional distress caused by lymphedema. Decreased physical function was especially likely when there were complications from an infection. The most frequently identified limitations included upper extremity strength and range of motion, endurance for carrying, bending, and decreased fine motor skills, such as would be required to pick up a pen (Cases 06, 08, 09, 12, 13). These concerns, which arose in the context of the interview, are consistent with survey data, including the report of upper extremity weakness, limited upper body movement, and upper extremity symptoms including altered sensation, heaviness, and aching.

The participants also reported long-term emotional stress and many participants considered this to be a greater problem than physical limitations in the long-term. As the customer service representative (07) said, “It's been 8 years... it probably affects you

more mentally, than physically.” The primary source of emotional stress included fear of BCRL-induced infection, which was especially pressing for participants who had experienced infection before. Participants who had experienced infection perceived a need to act more cautiously to avoid infection risks which, in turn, created a barrier to 
being able to act spontaneously at work. Selected quotations are provided below that demonstrate their fears related to infection-related concerns.

“That cellulitis experience really laid me up and financially it’s very expensive...It's hard not to just be able to be spontaneous and like, do things; that's the hardest part, is not being spontaneous, so I don't know how to not make it a drag... like a lot of my work that I've done in the past is, I'm outside and I'm in the elements; I'm digging in the dirt and getting scratched up and stuff. So to me, I feel like I need to be in a plastic bubble.” (Wildlife biologist 05)

"I've had two infections in the last year in my arm, where my arm, you know, got hot and beet red and I had to go to Urgent Care. So you do have to be more careful with it, and that was part of it, too, you know just having to watch: Am I gonna get a stick from one of my flowers or a thorn or something?” (Customer service representative 07)

"I think in the back (of my) mind I, I worry that I'm gonna get a cut on my hand. Or you know, something is gonna happen and it's going to get worse and then it's gonna get bigger and then it's never gonna... I get a little nervous because I'm worried something is going to happen to my arm.” (Fitness instructor 08)

Another major source of stress is that participants wanted to be perceived by coworkers as being just as capable and dependable, as they were prior to BCRL. However, because of their physical limitations, they perceived themselves as less productive than they were prior to BCRL. Additionally, they felt they were perceived as less dependable by their workplace peers, which was very frustrating and added to their sense of lost 
control. Frustrations related to their work performance cause by BCRL are depicted in selected quotes below.

"I'm pretty fast at my job and I'm one of the quickest underwriters. So to be in a situation where I can't function, based on something I can't control, is very frustrating.” (Insurance underwriter 13)

"I was always depended on to be there. If one of them, if somebody woke up sick and they knew I wasn't working or that I was working one of the other shifts, they would call me and switch shifts or something, and now it's like they're afraid to. Um, so, it feels like my life has changed to where I have no control... Being depended on. I like that they can depend on me." (Grocery store customer service representative 12)

As the participants note, the sense of lost control and emotional distress seemed to be driven by a tendency to compare their current abilities to their previous level of function and by the discouragement of being viewed by co-workers as less competent. In general, there was an overarching desire for life to be the same as before BCRL. Yet the realities of BCRL created barriers to normality.

\section{Ongoing treatment for BCRL creates challenges for work}

Returning to work while continuing treatments for BCRL increased the challenge. Survivors complained that bandages, compression garments, and sleeves could be more bothersome than BCRL itself and that the bandages could limit physical function and interfere with work activity more than BCRL alone. The garments and bandages were uncomfortable and distracted participants from their job. Less directly, using bandaging 
and garments added a time burden to participants' daily routine and affected their afterwork social life.

\subsection{Bandages compromise work activity}

Participants reported that upper extremity function was affected dramatically during the time of acute therapy, at which point most participants used some sort of compression bandaging. Multi-layer bandaging was the most cumbersome from the participants' perspective and was inconvenient for both office workers and workers with more physical jobs. The heaviness and bulkiness of the bandaging impeded upper body movements, such as raising the arm and keeping it raised, bending the arm, and fine motor movements. Work skills such as typing accuracy, writing in longhand, pushing objects (e.g. the cart at grocery store), and picking up small objects were dramatically affected.

In addition to being cumbersome for work tasks, participants also complained about discomfort (e.g. hot and restricting circulation) caused by garments which related to disturbance and reduced productivity at daily work. Warmth was the most bothersome feature, and discomfort increased the longer the garment was worn (Cases 06, 07, 11). The nurse (06) discussed travelling for business by car, in the summer: "The sleeve, they get really hot...It binds me and in the summer, it's worse because it's sweaty." Hot flashes, which may be experienced as a sequelae of cancer treatment, compounded the problem. The home healthcare provider (09) said, "It's just too hot... Since the surgery, I've had really bad hot flashes. So, with the hot flashes, it's hard for me to wear the bandages and the sleeve." Given that BCRL is a chronic and life-long treatment effect, discomfort from the side effects of treatment is also likely to be prolonged and, therefore, 
discouraging. Circulation problems (Cases 01, 05, 06, 13) were reported as a result of poorly-fitted garments or wearing the garment inappropriately. But problems with fit were not always easily remedied. For example, the wildlife biologist (05) said, "Sometimes feeling like my arm circulation is getting cut off because of the sleeve, because of the angle of how my arm is...My sleeve wasn't on right.” The insurance representative (01) said, "(The sleeves) ...hurt and makes the hands swell more.”

Bandage and garments also indirectly interfere with work activities. Many examples of interference were shared. For example, the fitness instructor (08) said: “I was teaching an aqua class, um, for arthritis sufferers. And, so I couldn't get in the water, obviously. So I had to teach the class, you know, from the outside of the pool." Another participant, who traveled for business purposes (Nurse 06), described being pulled out for a body search when she went through security at the airport with her bandaging. Also, for some work activities, it was necessary to maintain cleanliness, such as by wearing gloves, but this made some jobs more difficult. Examples included the cytotechnologist (03), whose job required wearing laboratory gloves every day. A participant whose job required high levels of hand hygiene found frequent hand washing difficult with hand bandages or compression gloves. The food demonstrator (02) mentioned, “It's hard to keep the glove (hand compression gloves) clean all day.” Also, participants described difficulty maintaining the bandages' good fit throughout the day. Making adjustments was described as inconvenient at work. For example, the grocery store customer service representative (12) said, “I've had to tighten it up three or four times at work. Now when I put it on, I start snug and when it starts getting loose, I tighten it up more and more and more." 
It is worth noting that even though there were many complaints, many

participants still admitted that the bandaging treatment alleviated the symptoms of BCRL and prevented exacerbation. Therefore, in some ways the bandages had a positive effect on their functioning at work.

“My skin itches because it's so swollen and it hurts because it's so swollen, but as long as I have these on it kind of keeps the swelling down and so it doesn't hurt, and I can get more done, it just makes my arm feel heavier." (Grocery store customer service representative 12)

“I wish I didn't have to wear all of that because I feel just - smothered, most of the times, but when I'm lifting, I feel so much better that I can have the bandages on because they do help me. I don't have to worry about if I'm going to pick up too much fluid... I don't have to worry about if maybe the arm is going to get swollen. It can't because I have the bandage which protects the arm." (Home healthcare provider 09)

\subsection{Bandages draw unwanted attention and distract from job role}

More generally, participants were frustrated at being the objects of attention in public because of their obvious bandages and compression sleeves. They disliked having to repeatedly explain about lymphedema and why they wore these garments at workplace and general public. The problem is compounded because it is a difficult thing to explain.

"I'm embarrassed when I have to wear it because someone's always asking me what's going on. I repeat it. I'm not fine with it because it is irritating at once, 
you know, people keep repeating the same thing. When I go anywhere, they ask me why I have the sleeve." (Home healthcare provider 09).

"It draws attention to it and it’s like, I don't wanna tell the story over...I have no problem telling people, but when it's, like, so much attention to it and you're, like, I've told this story, like, 100 times.” (Wildlife biologist 05)

"When I'm telling them about it, sometimes I feel frustrated because I can't tell them this is what's gonna happen; this is a way my life could be forever or it's gonna go away...And when I don't wear it, they may have a comment that you should handle (it), your arm is so swollen. So people even notice it, when I don't wear.” (Insurance representative 01)

For many participants, wearing bandages and sleeves caused a constant state of self-consciousness at work, which led to uncomfortable feelings in public and when interacting with people.

"You know having to wear that big wrapped arm, I was self-conscious about that and even when I had to wear my garment, I was at the beginning very selfconscious.” (Cytotechnologist 03)

The nurse (06) reported the bandages drew attention from the audience while she was giving presentations for work. This problem was shared by others, such as the school teacher (11): "I noticed sometimes when I point at the board or something, sometimes kids like, you know, it’s distracting to them."

\subsection{BCRL management affects work lifestyle}


Some aspects of lymphedema management created areas of frustration that were less directly related to work skills and productivity, but meaningful in the overall scheme of one's daily lifestyle while working. Examples started with the beginning of the workday, as donning the lymphedema bandages can be time-consuming and the bandages themselves can impede the morning routine as much as they impede work activities. For example, applying makeup and brushing/styling hair required raising the arm for long periods of time, which was difficult. These things increased the time burden for alreadybusy career women.

"It means that you have to get up earlier because it takes me about half an hour to wrap, to get it all wrapped, and get cleaned up. So you'd get up and you shower, and then I'd have to sit down figure out how to get my wrap on which is complicated.” (Nurse 06)

The women spoke about how the stress of wearing lymphedema treatment appliances had a negative effect on their after-work social life with their colleagues. The reasons they gave included unwanted attention and altered self-image, as well as discomfort and inconvenience.

"It prevents me from doing anything, because, first off, I don't want the attention and, second, it's cumbersome, so (I) don't want to be hot. I don't want to sweat in it. I don't want it to get wet. I don't want to be in the rain. I don't want anything ...I would've just went home, um, after I get off work. I got home and I just wrap it, and so it's very rare I will make plans after work right now." (Insurance underwriter 13) 
Women felt that the bandages/sleeves were unsightly. The compression garments did not look appealing and might not match their outfit. They might portray a "sick" image in public. For example, the fitness instructor (08) said, “I didn’t really wanna go out with all that wrapping either that much...Well, just because it looked silly.”

\section{Environmental factors affect the return-to-work experience with BCRL}

Participants in this study discussed a number of environmental factors negatively affecting their experience of returning to work. These included not only the work environment per se, but also a general lack of knowledge about lymphedema. On the positive side, a wide range of environmental supports was perceived, including informational and educational support, functional and practical supports in the workplace, and social support from various sources.

\subsection{Limited BCRL awareness and resources for patients pose barriers to work- return}

Almost all of the women talked about the lack of BCRL awareness by the public, which included their workplaces. Participants said that the general public largely did not know what BCRL is. Lack of knowledge among the general public made the survivors with BCRL feel conspicuous and misunderstood.

“I think that the general society ... because people, they don't think that, like, lymphedema is that big of a deal or that much of an issue ...I think the lack of understanding that people who go through cancer treatments ... especially, if they have new medical conditions because of their treatments...” (Private business owner 10) 
Participants expressed that this general lack of knowledge of BCRL resulted in the misunderstanding between them and their colleagues at times.

"In some ways it's hard because you look normal, but then people want you to do things like help them move furniture or help them dig a ditch. I have to be cautious about this, and they look at you, like, 'What are you, crazy?' ...so it's, like, until you really physically look ill, people don't really understand it." (05 Wildlife biologist)

Participants felt it was hard to gain support if the people around them did not understand their situation and what they had been through.

"People think that once you heal from your cancer treatments and your hair grows back, and all of that, they think that you are back to the old person you were before all this, and not understanding that all of that treatment and going through, all of that really changes a person and that a lot of the times they have long-term new health issues that interfere with their quality of life or their ability to function.” (Private business owner 10)

All participants reported receiving insufficient information and resources about BCRL, in general, let alone how this might affect work-life. Quite a few participants shared their difficult journey in searching for information about lymphedema and seeking diagnosis and treatment. This interview finding was consistent with the survey data that more than half of the individuals initially detected lymphedema themselves. Some women expressed unmet need for individualized support from the healthcare providers regarding work-return advices. They mentioned that lymphedema education at the clinic 
might still be too generalized and structured, and the information about occupational rehabilitation related to lymphedema was barely provided.

"I think the most information that I received about lymphedema was just in (a) brochure, the written information that was given to me. I just don't recall getting a lot of warning from my surgeon or from my oncologist, the people in the chemo room, radiation...” (Fitness instructor 08)

“When I talk to the doctor or somebody, I don't think they quite understand the nature of a lot of the work I've done.... like I can do more stuff indoors now.... like I can do a lot of computer programming and that kind of stuff, but I still wanna be able to go outside and be really physical with the earth." (Wildlife biologist 05)

"I think there's... it's too structured, what the information that is out there, and the information of how therapists, what they say to their people. If they fit into that box, you're all set, but if you don't fit into that box, you're kinda left there out all on yourself." (Private business owner 10)

\subsection{Social supports vary positively with work-return experience with BCRL}

Not all experiences were negative, however. Some participants shared about times that a clinician, family member, friend, or neighbor helped them with their difficulties. These supports were highly valued when they returned to work. Medical support and education from healthcare providers made it easier for participants to follow their treatment plan. In acute treatment of BCRL-induced infection, when antibiotics were needed immediately, supportive clinicians made a positive impact (Nurse 06), answering 
occasional questions (Customer service representative 07). Some clinicians provided compassionate listening when a participant just wanted to tell a health professional about their difficulties (Medical technician 04). Participants expressed that those supports from the clinicians made their lymphedema management easier while going back to work.

Others in the home environment had a largely positive impact on participants, as well. Married women often reported that their partners were helpful with bandages (Cases 03, 09, 08). In contrast, women living alone might not experience this support. For example, the private business owner (10) was single and experienced challenges in living with BCRL and working to support her family. Single women sometimes had support from their friends or parents (Insurance underwriter 13) who helped them get through the difficulties. Support from neighbors and communities also were mentioned as having a positive effect when participants returned to work (Cases 09, 12). A positive reinforcement from the people around them could be an emotional support to motivate and encourage those with BCRL. The fitness instructor (08) noted: “This morning one of the ladies in my fitness class...she told me, 'I can't believe how strong you are,' so I always get positive reinforcement from people.”

Participants provided examples of how people in the workplace provided practical and emotional support. The school teacher (11) noted: “I have a lot of friends that are teachers that would've, if I needed to leave, would cover my class and help me out." But not all survivors felt supported and some even felt threats to their job. As an example, the grocery store customer service representative (12) noted experiencing conflicting information from higher-ups. “The store manager, he’s always telling me to make sure and take care of myself. He tells me to put myself first, not to worry about it, not to worry 
about my position-it will be there. The other assistant managers, they're always helpful. They'll come up and be like, 'You're looking tired. You need to take an extra break,' or, 'Do you need to take an extra break?'” In contrast, she also recalled: “the HR person that had me in tears several times and kept telling me there was a chance that I was going to be terminated before all of this was over.”

In the workplace, participants said that having a flexible work schedule and sick leave was very helpful for lymphedema treatment, especially during the acute phase. It allowed them to go to medical appointments and also to manage lymphedema on a daily basis. Some participants, such as the customer service representative (07), had sufficient employer-based sick leave. The private business owner (10) could set her own schedule. The insurance claim representative (01) worked out an arrangement with her employers: "They would allow me that time off, but paid. They allowed me the flexibility to work, [to] just make it up."

Participants described impacts related to their healthcare insurance coverage which is one of the workplace financial supports for lymphedema management. Those who worked at a big company seemed more satisfied with their coverage: "I just had to pay a co-pay to go to the lymphedema clinic. But they covered $100 \%$ on the sleeves.” (Customer service representative 07). But not all participants had generous benefit plans. For example, the food demonstrator (02) shared that her insurance company only allowed her one lymphedema visit. Women expressed sufficient health insurance contributed to their adherence to lymphedema treatment while returning to work.

\section{Personal factors play a key role in adjusting to return-to-work}


A number of personal factors came up that were identified as helping participants as they returned to work. Broadly, these included personal motivation, having a level of comfort with seeking help, and having a positive attitude when facing challenges. Participants frequently identified areas of personal growth that occurred because of the adjustment process.

\subsection{Motivated to work}

Motivation was identified as an important individual determinant for returning-towork, even though the specific reasons for feeling motivated differed from individual to individual. Several women felt motivated by their enjoyment of their work and/or the sense of accomplishment that work provided (Case 01, 03, 04, 13). The insurance underwriter (13) conveyed this well by saying: "I like working. It's a place I can do something. When I do my job, part of what we do is safety-related, so I feel like I'm giving back to the community. Even when I had cancer, it was a place that kept my routine going. So I really enjoyed coming to work, doing something productive." She also appreciated the structure of work and the fact that it helped her to stay in a normalizing routine: “It's a part of what I do, like, I couldn't imagine not working. So it's very (much) a part of my day." This perspective was shared by others, especially participants who lived alone (e.g. Insurance claim representative 01).

Financial security also was identified as an important source of motivation. The food demonstrator (02) said: “I've been independent...I've always worked, I've always taken care of myself so I don't wanna stay home and sit and do nothing." Along similar lines, the insurance underwriter (13) commented: "I gotta work around it [effects of lymphedema], you know, and I don't think anyone else is responsible for my life but me." 
Although for many participants, financial need was a very concrete reality. "It's paying doctor bills and other bills so that we can live in a house and have a car." (Grocery store customer service representative 12) For at least one participant, the financial benefits of work allowed her to splurge: "I love money. And although me and my husband have a pretty good income coming in, I'm always wanting to make more money because I love to just buy things.” (Home healthcare provider 09)

\subsection{Comfort in seeking help}

Women in the study shared about their need to ask for help. While they seemed to think this was a good thing to do in the abstract, most indicated that they found it uncomfortable and disliked having to do it. This personal attribute could make a difference in overcoming difficulties at some points, as asking for help is one the coping strategies. The wildlife biologist (05) was among those who had to learn to ask others for help: “I think one of the biggest things I've learned is that I have to ask for help and I can't do everything on my own and that was a very big challenge for me because, like I said, I was very independent.”

Some women didn’t ask for help because they perceived that others were burdened by these requests. For example, the private business owner (10) said: “I don't really ask for help, but people also don't offer to help...Figure it out on your own, so you can stay connected to people.” The private business owner (10) went so far as to express concern that she might be judged negatively: "They just feel like breast cancer survivors who say they now have lymphedema are basically just wanting attention." In contrast, the medical technician (04) was comfortable seeking help and support and encouraged others to do so. She said, "I get help. You know, get someone to come and help you...and just... 
you know your limitations. You know that you're not gonna hurt yourself because it was ...I mean; I knew my handicap. It's like a person who had a handicap knew how far they could go."

\subsection{Positive attitudes towards challenges}

A number of individuals seemed to be able to maintain a positive outlook when difficulties arose and these positive attitudes helped them to cope with BCRL. The fitness instructor (08) was one such individual: "I think, just growing up, I was taught that you can either complain about your life situations or you can accept them, and find something positive out of whatever life throws your way." A positive attitude was presented in different forms. For example, the home healthcare provider (09) used a selfaffirming approach: "I just feel blessed because not a lot of people get along good like I do... I've come this far and done what I've done. So I feel very good about myself...and if I have to deal with lymphedema, that's just a little, small thing I'm going to have to deal with.” The fitness instructor (08) seemed to even experience a measure of pride in overcoming lymphedema: "I think people that know me and know that I wear this and the reasons why I wear it are proud of me."

An important resource for maintaining a positive frame of mind for many participants revolved around their spiritual habits and beliefs. The grocery store customer service representative (12) shared her perspective about God's role in her healing process: "I believe there is a God and I believe that He cares about us and that He's there for us when we need Him. I prayed a lot more during this, for strength to get through it.” The home healthcare provider (09) also used spiritual language when talking about her mental strengths: "I felt so fortunate. I felt blessed. I'm a very godly person, so 
I felt that I had all of this because of God. I don't leave Him out of the equation. He's always with me. The way I feel, you can do all things through Jesus Christ which strengthens you."

A final form of positive coping was the ability to put things into perspective. For example, the home healthcare provider (09) emphasized that she was able to do everything she did before, just with a greater level of discomfort. Some participants noted that BCRL was uncomfortable, but when compared to other events in their lives, it was manageable. This was the case for the medical technician (04) who observed: "It's not a disability to me yet. More disability was my heart to me."

\subsection{Coping strategies were developed along the way to work-return}

The participants in this study described a range of work-related coping strategies and mechanisms. For the most part, these were not innate, but rather learned through experience or developed in the face of necessity. Two facets of coping were time management and the development of adaptations to address their changing functional status.

As mentioned above, BCRL management added a time burden to the individual's daily routine and the women we interviewed described having to make space for BCRL management on their daily to-do list. Some examples included the insurance underwriter (13) who skipped lunch when she needed to do a self-management task, and the insurance representative (01) who tried to make her therapy appointments around her work schedule, in the morning or late afternoon. The fitness instructor (08) worked around a complicated schedule to apply her wrap, but also maximize her teaching: "I might go teach my class at eight using the sleeve, then come home and have him (spouse) 
help me wrap my arm well, for the rest of the day. For those classes, I just wore the sleeve. But then when I went to do my aqua class, I wrapped it. I would just do my instruction on the outside of the pool." The wildlife biologist (05) took a different perspective, prioritizing self-care over work: “(When I) have these appointments I have to go to, I just penciled it in... and (it has to) just be like, this is part of my job right now is, taking care of my health and because I treated it that way, it was so much easier to deal with that. It was just something that needed to be done.”

Women were faced with myriad functional challenges in the course of chronic BCRL and addressed these practically and creatively. For example, the nurse (06) had difficulty with lifting and typing, "I also started using roller bags, so I didn't have to carry as much, so that was an adaptation I made... I got something to put my arm on, so that I could hit the keyboard a little bit. So I got some tables and elevated my arm, so I could reach the keyboard a little better." They also reported being creative to cope with the unpleasant image of lymphedema garments in the workplace. One participant (Customer service representative 07) reported: "I got away from the brown (color) that looks medical. I've got some that are kind of fun colors. The gray, to me, doesn't look as medical as the, you know, everyone that has the beige."

In order to avoid work-related hazards that might have a negative impact on BCRL, such as heavy-duty tasks or infection exposure, some women adjusted their work activities, while others decided to change jobs altogether. For example, the grocery store food demonstrator (17) had quit her physically-demanding job as a house cleaner. The home healthcare provider (09) stopped accepting clients with mobility disorders who required assistance with transfers and switched instead to light-duty work, such as giving 
medications. Lymphedema inspired some women to incorporate BCRL advocacy in their work, in order to help others and increase awareness. The cytotechnologist (03) started a local support group. The private business owner (10) changed her business from interior design to lymphedema compression garments and keeps up with the newest innovations. The customer service representative (07) has taken her knowledge of BCRL and now focuses on providing education to patients and families in the clinic as a volunteer.

\section{Discussion}

The primary purpose of this study was to illustrate the ways BCRL influences individuals' experience of returning to work. Our findings have shown both BCRL and its treatment negatively influenced women’s physical, emotional, and interpersonal functions, and that this, in turn, had an impact on their work lives. On observation, the manifestation of physical impairment seemed similar across cases, while the manifestation of the emotional and interpersonal disturbances seemed more diverse. Based on participants' descriptions, physical impairment was comprised of decreased upper extremity mobility, strength, and fine motor coordination and was caused by BCRL, bandages, and/or BCRL-induced infection. The emotional and interpersonal effects were related to decreased satisfaction with one’s own work productivity, reduced spontaneity at work, undesired attention from others, and negative perceptions of body image. In some situations, BCRL and its treatment directly interfered with work activity (i.e. without a functional intermediary). For example, the bandages prevented the fitness instructor (08) from teaching the aqua class in the pool and created inconvenience to the nurse (06) when traveling by air. BCRL prevented the personal health care provider (09) from taking clients whose care required heavy lifting and prevented the field scientist 
(05) from working in the soil. The direct impact could also be considered as an indirect impact of BCRL on the individuals' functions since they are unable to work in a particular way.

The physical, emotional, and interpersonal factors reported by our sample seemed to interact with one another and collectively influence an individual's return-to-work experience. For example, the field scientist (05) had experienced significant physical dysfunction because of BCRL-related infections, which in turn caused chronic fear of potential future infection and related repercussions. Her fear made her increasingly cautious, preventing her from being spontaneous and fully functioning. Also, her negative body image caused her to be self-conscious and thus altered interpersonal function. Another participant, the private business owner (10), experienced emotional distress due to her decreased work productivity. Her distress also was fueled by questions of body image. Ultimately, she became more socially reserved.

Our findings are consistent with the ICF framework with respect to an individual's functioning being affected by their collective functions (as altered by BCRL and its treatment) and the context in which they must function. For our sample, this included the work task demands and the environment (e.g. accommodations, supports) in which those demands are made. For example, both the insurance underwriter (13) and grocery store customer service staff (12) were in the acute phase of lymphedema treatment at the time of interview. However, the insurance underwriter was doing light office work (e.g. typing and writing), while the grocery store customer service staff (12) performed tasks that were more physically demanding of the upper extremities (e.g. pushing/pulling grocery carts and operating the cash register). As such, the latter (12) 
found more restriction and difficulties in work activities (e.g. she couldn’t independently perform the tasks and required accommodation and others' help). In the case of the food demonstrator (02) who worked as cleaner before developing BCRL, her physical capacity could not reach the job requirements anymore and there was no easy way to make accommodations; thus, she had to give up the cleaner job completely. The collective functioning, specific work activities, and their means for BCRL management differed from person to person. Thus, survivors' return-to-work experiences are highly individualized, despite many common experiences in this sample.

Besides the direct and indirect effects on functions, more typically, participants reported more complex relationships between their experiences of BCRL and its impact on their work. Our findings highlighted the important role of the factors controlled by the individual in adjusting to work. Specifically, coping strategies and attitudes towards challenges seem to play key roles in adjusting to the outcomes of work-return. Novel to our study was the finding of BCRL-specific strategies - physical and emotional - that our participants used to facilitate their work. These were further individualized, depending on the personal concerns and available resources of each individual. Our work also shines a spotlight on the continuing limited awareness of BCRL among the general public and among some clinicians, which our participants identified as one of the major factors affecting their adjustment. While breast cancer survivorship has become much more familiar to the public, having benefited from decades-long public education and awareness campaigns, this is not the case for BCRL. Because of the limited understanding of BCRL by employers, work colleagues, and clients, our participants frequently reported their abilities as being either overestimated or underestimated. This 
had an impact on their ability to obtain appropriate support and confronted survivors with a decision as to whether or not to more actively seek support.

Besides the considerable agreement shared with the concepts and propositions of the ICF model in that functioning, work activity, contextual factors from the environment, and individual attributes, together, shaped the work experience of survivors with BCRL, our findings also raise questions for understanding the ICF model. Specifically, the concepts of "body function and structure" in the ICF are generally considered as physical changes. However, based on our findings, the emotional and interpersonal stressors caused by BCRL could be the most challenging aspects for some survivors. This seems cumbersome in the framework as one could consider emotional functioning as a matter of diagnosis (e.g. syndromes of depression, anxiety or adjustment disorder), a personal factor (e.g. insufficient coping), or environmental factor (e.g. the unpleasant curiosity of public). Moreover, the impact of the disease on work-return experience may include the effects of the treatment which could have both positive and negative influences.

Even with increasing public health awareness, lack of support (from workplace peers and supervisors, clinicians, or family) continues to be a potential barrier to returning to work for cancer survivors in general (Blinder et al., 2012; Carlsen et al., 2013; Fantoni et al., 2010; Hakanen \& Lindbohm, 2008; Mujahid et al., 2010). Support for returning to work among breast cancer survivors, as a specific sub-population, has not been well-studied. Given our results, and consistent with the more general cancer literature, at least some patients with BCRL seem highly motivated to overcome (or work around) such obstacles and return to the workforce (Ahn et al., 2009; Blinder et al., 2012; 
Carlsen et al., 2013; Tiedtke, de Rijk, Donceel, Christiaens, \& de Casterle, 2012). Personality factors, including positive attitude, as indicated by our findings and in other studies, are likely helpful (Sun, Shigaki, \& Armer, 2017), but motivation and attitude may not be enough. Hoving and colleagues (Hoving, Broekhuizen, \& Frings-Dresen, 2009) call for studies of interventions to include more attention, information, support, and advice on work issues, not only from healthcare professionals but also from employers - a recommendation which is consistent with the complexities of the ICF framework. Our findings suggest that important elements that interventions might address include: education about effective prevention measures for BCRL-related infections and the risk associated with BCRL to allow urgent antibiotic access; assessment and management of the functional impairment; examples of simple and low-cost job accommodations to consider (e.g. task changes, schedule changes, or adaptive equipment); evaluation of the negative effects of BCRL bandaging treatment on work functioning and potential adjustments; and education to increase the awareness of BCRL in the general public and clinicians. Other approaches might include preparing patients to respond to the interpersonal stressors associated with work, including how to discuss BCRL with peers and supervisors and how to effectively discuss needed work accommodations. Importantly, Short and colleagues (2005) have shown that when work issues are addressed as part of the treatment, work-return after cancer treatment is more successful.

While our study provided several novel and interesting findings, there are several factors that limit interpretation, exploration, and generalizability of the data. First, we purposefully recruited individuals who had been at least moderately successful in negotiating return-to-work to describe their perspectives and experiences. Our 
understanding of the phenomenon would be enhanced by obtaining interviews from survivors with BCRL who either did not want to go back to work, or who wanted to return but were unable to do so successfully. Perspectives from this angle would give us a better idea about which barriers are the most prohibitive and perhaps which coping strategies seem to be the most helpful. Additionally, we only obtained interviews with survivors. Future work to integrate the perspectives of employers, human resource personnel, disability experts, and/or work peers may be helpful in providing realistic intervention solutions. Finally, a limitation of this study is the restricted geographic range from which we recruited participants. Future research could include participants from more urban and more rural areas, as well as areas with differing climates, types of industry, and support resources.

\section{Conclusions}

Study participants perceived the experiences incurred from BCRL and its treatment as affecting the return-to-work process in a number of ways. Most concretely, they perceived effects manifested through impaired physical function, altering their work-life routine, and/or effects experienced on their psyche. The challenges they faced did not manifest singly and participants talked about these factors in a combined way. Participants also described influences (both positive and negative) occurring outside of themselves, which could facilitate or impede the return-to-work experience. These factors were woven into complex combinations that created each individual picture. The participants in this study all had returned to work and most had developed strategies to overcome or at least cope with the limitations and frustrations they perceived. Some strategies were very practical, e.g. discovering tools to aid functioning or adjusting work 
activities or roles to make the job more do-able. Others were more toward fortification of their internal states, e.g. joining support groups to exchange information or becoming advocates to help other people with BCRL. While sometimes difficult and sometimes costly on a number of levels, these participants perceived their efforts as important and return to work as rewarding.

\section{Implications for cancer survivors}

This study, which is among the first to closely explore the experience of returning-to-work after BCRL, moves the field of chronic cancer care forward by identifying areas where breast cancer survivors experience and overcome barriers, largely without empirically-informed support from their healthcare professionals. The study reveals many factors that impact an individual's return-to-work experience, varying from case-to-case. As such, the findings support the implication that both individualized patient-centered care and the availability of occupational rehabilitation services, even into the chronic phases of BCRL, would likely enhance return to work outcomes. While our finding that survivors can successfully return-to-work using personal and environmental coping and supports is encouraging, we did not interview survivors who did not return to work. Given the challenges reported by our sample, it would be reasonable to suspect that some (and perhaps many) survivors need more pointed assistance to tap these resources effectively. The information provided by survivors in this study regarding barriers, contextual factors, and coping strategies provides a starting point for future studies aiming to develop evidence-based assessment and intervention strategies to maximize returning to work. The complexity of individualizing care, which appears to be needed based on the multiple, interacting, and fluid factors that were observed, implies that an 
interdisciplinary approach may be the most beneficial approach to assessment and intervention. Psychologists, social workers, physical therapists, occupational therapists, nurses, physicians, and case managers, all represent disciplines that could potentially assist patients in meeting their occupational goals.

Our sample perceived that negative attention, unwelcome curiosity, and misunderstandings about lymphedema were fairly common among clinicians, as well as the general public, which became one of the baggiest barriers for survivors who were returning to work. The implication of this finding is that larger-scale efforts are needed to improve both education in the health professions and health literacy efforts aimed at the workforce (e.g. employers, managers, human resource providers, etc.). Moreover, BCRL and its treatment chronically impeded work and home life in frustrating ways. Innovative research is needed to improve BCRL treatment and innovative development of less cumbersome and more attractive products to manage lymphedema also are needed. In summary, in closely exploring the experience of returning-to-work after BCRL, this study shines a spotlight on the gap between the end of traditional medical care and the establishment of a productive and rewarding "new normal” for breast cancer survivors.

Acknowledgement This study was funded by the Toni and Jim Sullivan Endowed Research Fund for PhD Students. No resources from the Veterans Administration (e.g. monetary funding, material resources, paid time or unpaid time) were used in conducting this study.

Conflict of interest The authors declare that they have no conflict of interest. 
Ethical approval: "All procedures performed in studies involving human participants were in accordance with the ethical standards of the institutional research committee and with the 1964 Helsinki Declaration and its later amendments or comparable ethical standards.”

Informed consent: "Informed consent was obtained from all individual participants included in the study.” 


\section{References}

Ahn, E., Cho, J., Shin, D. W., Park, B. W., Ahn, S. H., Noh, D. Y., . . Yun, Y. H. (2009). Impact of breast cancer diagnosis and treatment on work-related life and factors affecting them. Breast Cancer Research \& Treatment, 116(3), 609-616.

American Cancer Society. (2018). Cancer Facts \& Figures 2018. Atlanta: GA. Retrieved from https://www.cancer.org/content/dam/cancer-org/research/cancer-facts-andstatistics/annual-cancer-facts-and-figures/2018/cancer-facts-and-figures-2018.pdf

Armer, J. M., \& Stewart, B. R. (2010). Post-breast cancer lymphedema: Incidence increases from 12 to 30 to 60 months. Lymphology, 43(3), 118-127.

Babu, B. V., Swain, B. K., \& Rath, K. (2006). Impact of chronic lymphatic filariasis on quantity and quality of productive work among weavers in an endemic village from India. Tropical Medicine \& International Health, 11(5), 712-717.

Bernas, M. J., Askew, R. L., Armer, J. M., \& Cormier, J. N. (2010). Lymphedema: How do we diagnose and reduce the risk of this dreaded complication of breast cancer treatment? Current Breast Cancer Reports, 2(1), 53-58. doi:10.1007/s12609-0100009-1

Bifulco, G., De Rosa, N., Tornesello, M. L., Piccoli, R., Bertrando, A., Lavitola, G., .. . Nappi, C. (2012). Quality of life, lifestyle behavior and employment experience: A comparison between young and midlife survivors of gynecology early stage cancers. Gynecologic Oncology, 124(3), 444-451.

Blinder, V. S., Murphy, M. M., Vahdat, L. T., Gold, H. T., de Melo-Martin, I., Hayes, M. K., . . . Mazumdar, M. (2012). Employment after a breast cancer diagnosis: A 
qualitative study of ethnically diverse urban women. Journal of Community Health, 37(4), 763-772.

Bluethmann, S. M., Mariotto, A. B., \& Rowland, J. H. (2016). Anticipating the "Silver Tsunami": Prevalence trajectories and comorbidity burden among older cancer survivors in the United States. Cancer Epidemiology Biomarkers \& Prevention, 25(7), 1029-1036. doi:10.1158/1055-9965.Epi-16-0133

Boyages, J., Kalfa, S., Xu, Y., Koelmeyer, L., Mackie, H., Viveros, H., . . G Gollan, P. (2016). Worse and worse off: The impact of lymphedema on work and career after breast cancer. SpringerPlus, 5(1), 1-8. doi:10.1186/s40064-016-2300-8

Brennan, M. J., \& Weitz, J. (1992). Lymphedema 30 years after radical mastectomy. American journal of physical medicine \& rehabilitation / Association of Academic Physiatrists, 71(1), 12-14.

Carlsen, K., Jensen, A. J., Rugulies, R., Christensen, J., Bidstrup, P. E., Johansen, C., . . . Dalton, S. O. (2013). Self-reported work ability in long-term breast cancer survivors: A population-based questionnaire study in Denmark. Acta Oncologica, 52(2), 423-429.

Dedoose Version 7.0.23. (2016). Web application for managing, analyzing, and presenting qualitative and mixed method research data. Retrieved from http://www.dedoose.com/

Ecamm Network (C2017. Retrieved from http://www.ecamm.com/mac/callrecorder/ 
Fantoni, S. Q., Peugniez, C., Duhamel, A., Skrzypczak, J., Frimat, P., \& Leroyer, A. (2010). Factors related to return to work by women with breast cancer in northern France. Journal of Occupational Rehabilitation, 20(1), 49-58.

Feuerstein, M., Todd, B. L., Moskowitz, M. C., Bruns, G. L., Stoler, M. R., Nassif, T., \& Yu, X. (2010). Work in cancer survivors: A model for practice and research. Journal of Cancer Survivorship, 4(4), 415-437.

Földi, M., Földi, E., Strößenreuther, C., \& Kubik, S. (2012). Földi's Textbook of Lymphology: For Physicians and Lymphedema Therapists. German: Elsevier Health Sciences Division.

Hakanen, J. J., \& Lindbohm, M. L. (2008). Work engagement among breast cancer survivors and the referents: The importance of optimism and social resources at work. Journal of Cancer Survivorship, 2(4), 283-295.

Hoving, J. L., Broekhuizen, M. L., \& Frings-Dresen, M. H. (2009). Return to work of breast cancer survivors: A systematic review of intervention studies. BMC Cancer, 9, 117.

Howlader, N., Noone, A. M., Krapcho, M., Miller, D., Bishop, K., Kosary, C. L., .. . Cronin, K. A. (2016). SEER Cancer Statistics Review, 1975-2014, National Cancer Institute. Retrieved from https://seer.cancer.gov/archive/csr/1975_2014

Microsoft Skype @2017. Retrieved from https://www.skype.com/en/ 
Moffatt, C. J., Franks, P. J., Doherty, D. C., Williams, A. F., Badger, C., Jeffs, E., . . . Mortimer, P. S. (2003). Lymphoedema: An underestimated health problem. Qjm, 96(10), 731-738.

Mujahid, M. S., Janz, N. K., Hawley, S. T., Griggs, J. J., Hamilton, A. S., \& Katz, S. J. (2010). The impact of sociodemographic, treatment, and work support on missed work after breast cancer diagnosis. Breast Cancer Research \& Treatment, 119(1), 213-220.

Nguyen, T. T., Hoskin, T. L., Habermann, E. B., Cheville, A. L., \& Boughey, J. C. (2017). Breast Cancer-Related Lymphedema Risk is Related to Multidisciplinary Treatment and Not Surgery Alone: Results from a Large Cohort Study. Ann Surg Oncol, 24(10), 2972-2980. doi:10.1245/s10434-017-5960-х

Peugniez, C., Fantoni, S., Leroyer, A., Skrzypczak, J., Duprey, M., \& Bonneterre, J. (2011). Return to work after treatment for breast cancer: Single center experience in a cohort of 273 patients. Bulletin du Cancer, 98(7), E69-79.

Quinlan, E., Thomas-MacLean, R., Hack, T., Kwan, W., Miedema, B., Tatemichi, S., .. . Tilley, A. (2009). The impact of breast cancer among Canadian women: Disability and productivity. Work: Journal of Prevention, Assessment \& Rehabilitation, 34(3), 285-296.

Richardson, A., Addington-Hall, J., Amir, Z., Foster, C., Stark, D., Armes, J., . . Sharpe, M. (2011). Knowledge, ignorance and priorities for research in key areas of cancer survivorship: Findings from a scoping review. British Journal of Cancer, 105(SUPPL. 1), S82-S94. 
Short, P. F., Vasey, J. J., \& Tunceli, K. (2005) Employment pathways in a large cohort of adult cancer survivors. Cancer, 103(6), 1292-1301. doi:10.1002/cncr.20912

Sun, Y., Shigaki, C. L., \& Armer, J. M. (2017). Return to work among breast cancer survivors: A literature review. Supportive Care in Cancer, 25(3), 709-718. doi:10.1007/s00520-016-3446-1

Tiedtke, C., de Rijk, A., Donceel, P., Christiaens, M. R., \& de Casterle, B. D. (2012). Survived but feeling vulnerable and insecure: a qualitative study of the mental preparation for RTW after breast cancer treatment. BMC Public Health, 12, 538.

Warren, L. E. G., Miller, C. L., Horick, N., Skolny, M. N., Jammallo, L. S., Sadek, B. T., . . Taghian, A. G. (2014). The Impact of Radiation Therapy on the Risk of Lymphedema After Treatment for Breast Cancer: A Prospective Cohort Study. International Journal of Radiation Oncology • Biology • Physics, 88(3), 565-571. doi:10.1016/j.ijrobp.2013.11.232

World Health Organization (2001). ICF: International classification of functioning, disability and health. Geneva: World Health Organization. Retrieved from http://psychiatr.ru/download/1313?view=name=CF_18.pdf

Yin, R. K. (2014). Case study research: Design and methods (5th ed.). Thousand Oaks, CA: Sage.

Zou, L., Liu, F.-h., Shen, P.-p., Hu, Y., Liu, X.-q., Xu, Y.-y., . . Tian, Y. (2018). The incidence and risk factors of related lymphedema for breast cancer survivors postoperation: A 2-year follow-up prospective cohort study. Breast Cancer. doi:10.1007/s12282-018-0830-3 
Zuther, J. E., \& Norton, S. (2013). Complete decongestive therapy. In lymphedema management: The comprehensive guide for practitioners (pp. 127). Stuttgart: Georg Thieme Verlag. 


\section{CHAPTER SIX CONCLUSION}

\section{Summary and Synthesis of Findings}

This dissertation incorporates three independent manuscripts presented in Chapters Two, Three, and Five. The published manuscript in Chapter Two is the preliminary work for the dissertation. It is a state-of-the-art review of the current literature regarding influential factors and outcomes associated with return-to-work among breast cancer survivors (Sun, Shigaki, \& Armer, 2017). Reduced work engagement and work ability were outcomes found in all studies. The influential factors contributing to the survivors' employment status and performance clustered as: symptoms and functioning, work demands and environment, individual characteristics, and societal and cultural factors. Within upper extremity symptoms and dysfunction, lymphedema specifically, has been identified as a significant variable related to poor work outcomes (Quinlan et al., 2009). It was this review where the importance of occupational rehabilitation among breast cancer survivors gave rise to my passions and concerns in this area and my later choice to focus my dissertation program in studying this complex problem.

The second manuscript is a single-case study, providing an in-depth and comprehensive examination of a nurse's experience of working while managing BCRL for more than two decades (Sun \& Armer, In review). Findings from this study emphasized the interactions between the BCRL disease process, the work activities required, the individual, and an array of contextual factors. The interviewee's experience 
provided material to form ideas about factors that may have a negative impact on effectiveness in the workplace, as well as factors that may help to overcome BCRLrelated barriers to return to work.

Chapter Five is the third manuscript, presenting the main results of this dissertation study (Sun, Shigaki, \& Armer, In review). This study uses a multiple-case study design and includes surveys and interviews with thirteen breast cancer survivors who had returned to work with lymphedema. Findings show that not only does BCRL have an effect on individuals' physical and emotional functioning, but the treatments for BCRL also can have adverse effects. Personal factors (e.g. adaptive or maladaptive coping) and environmental factors (e.g. presence or absence of workplace support) contribute to the return-to-work experience as facilitators or barriers. While the ICF model was used as a framework to discuss the main influences on return to work, study findings also suggested new perspectives towards understanding the ICF model (which is specifically discussed in Chapter Five). Themes generated from participants' responses provided material for recommending potential interventions to facilitate return-to-work.

The three manuscripts in this dissertation have built on one another sequentially. The literature review inspired research questions about how BCRL influences survivors' efforts to return to work. It provided a base of knowledge and demonstrated a gap in knowledge about the subpopulation of breast cancer survivors with BCRL and the returnto-work issue. Next, the single-case study selected a particular case, who had dealt with BCRL for decades and navigated multiple job changes. The particular individual likely had uncommon insight given her training as a nurse. Yet her journey was very reflective of the struggles and perspectives that breast cancer survivors with lymphedema might 
encounter. That is, her journey reflected the fact that health and disability do not occur in the absolute, but also in relationship with personal factors and within a specific context. To explore the identified gap in the literature, the third, multiple case study project was undertaken. Each case in the study is an experiment and with thirteen experiments, the multiple-case study produced compelling evidence with highly inductive themes about the complexity of returning to work while managing BCRL.

The findings of the three manuscripts cross-confirm and cross-check each other. There is no counter-indicative evidence that has been identified among the findings. The triangulations of evidence built on multiple resources: independent studies and literature review study, old studies and new studies, and within-case analysis and cross-case analysis. Breast cancer survivors with lymphedema are a special subgroup of breast cancer survivors. It is not surprising, therefore, that the findings have considerable overlap. Lymphedema and its treatment and the limitations of existing resources result in additional barriers compared to those faced by breast cancer survivors without lymphedema. It is those lymphedema-specific barriers that require specific attention and tailored options for intervention.

This dissertation study touched on an innovative topic. Studies for the return-towork issues in cancer survivorship are just gaining notice. Much knowledge about breast cancer-related lymphedema remains to be explored. However, many real-life stories imply a unique relationship between BCRL and work and are waiting to be discovered. Evidence from this body of work will contribute to both patient-centered care and evidence-based practice. 


\section{Significance of the Study}

This study is among the first to describe the personal experience of breast cancer survivors living with lymphedema, with specific emphasis on their work life. We got closer to the complex phenomenon through listening to each participant and comparing their perspectives and experiences. In addition to better understanding breast cancer survivors' needs and experiences, the findings of this study provide material to consider for interventions to reduce the struggles of coping with BCRL in the workplace since this study provides rich details to help explain the interactions and modulating factors that affect work experience among breast cancer survivors with LE. Findings also may guide clinical practice such as counseling services and education provided to survivors by nurses, physicians, rehabilitation therapists, psychological counselors, and others. This study strengthens the literature impacting long-range planning by government healthcare agencies and medical insurance companies, which are responsible for reimbursement policies for lymphedema care services. This study also may provide breast cancer survivors who have BCRL with information that supports mental preparation and coping skills for enhancing their work performance, as well as helping them find connection and empathy.

\section{Yin's Case Study Methodology}

Yin's (2014) case methodology focuses on the purpose of the study and reliance on the research questions. Re-design, re-analysis, and re-writing may be needed in order to answer the initial research questions. Yin's approach is different from the approach of some other case methodologists, such as Stake (1995), who focuses on data and recommends paying attention to what researchers consider worthy from the data to 
generate the meaningful conclusions. The authors' approaches are very different because they hold different views towards the reality of the world (Creswell \& Creswell, 2007).

Theory is very important in the design of the case study, according to Yin (2014), because it shapes the way we answer "how" and "why" questions in our research. For this study, we chose Yin’s (2014) approach which is question-driven and theory-guided. We had clear study purposes and questions. We carefully compared the theories and selected the ICF as the guide for developing the interview protocol and survey. The ICF's propositions suggested categories and initial concepts for data analysis in this study.

Yin (2014) used the criteria of "construct validity, internal validity, external validity” to evaluate the quality of a case study (p. 45). We used a survey to establish context for each case before the in-person interview. Multiple researchers reviewed the findings and the linkage of data evidence from both survey and interview to provide construct validity. We employed pattern-matching, explanation-building, and logic-model techniques to build internal validity. For example, we examined the pre-post (BCRL) patterns of each case's occupation, work hours, and limitations, and also examined each case in comparison to other cases (pattern-matching). A general explanation of how related factors led to different return-to-work experiences was built by drawing initial propositions from the ICF; comparing the findings from the initial cases against the propositions; and cross-validating with the findings from other cases (building explanation). The ICF helped by explaining how developing BCRL was associated with work participation (logic model). Using multiple cases (each one an 'experiment') provided replications in which each theme and subtheme was evidenced by more than one experiment. Within each case, the theory was used to explain and evaluate the 
evidence (external validity).

\section{Challenges and Limitations of the Dissertation Work}

The primary challenge of this study was participant recruitment. Many factors may have contributed this difficulty. The recruitment criteria were specific to include women who were working at the time of BCRL diagnosis and had finished breast cancer treatment more than 12 months prior. Additionally, recruitment occurred in a university town rather than a large urban area. These factors may have limited the potential subject pool. Also, the timeline set up for recruitment was comparably short and recruitment for this project started in the summer, when many individuals in this college town and university-based referring clinicians were on vacation.

The second set of challenges was related to data collection and interpretation. It is possible that some participants might not fully reveal their feelings and experiences to the researcher, as people do not necessarily like to talk about their weaknesses and negative experiences. Additionally, this multiple-case study produced a large amount of data. Summarizing the findings concisely was a significant challenge.

The main limitation of this study may be sample bias. Most of the participants enrolled in this study were highly educated, and education is a proxy for socioeconomic status. Only two of the 13 participants reported inadequate financial resource. The majority of participants also reported having a high level social support. This study may have lacked access to people with inadequate socioeconomic resources. Potential participants with fewer resources might not have known about the study or may not have had time to participate because they were busy working. The sample also lacked diversity 
regarding race, ethnicity, and geographic location. There might be disparity among socioeconomic groups in the larger population that we were unable to identify, with regards to work-return.

\section{Recommendations}

\section{Education}

Limited awareness and knowledge about BCRL among the general public and clinicians resulted in interpersonal distress among breast cancer survivors with lymphedema.

Education for the public. As discussed in an earlier section, lymphedema and treatment garments drew much unwanted attention from the public and created frustration on the part of the survivors and misunderstandings between them and others. This was mainly due to the lack of knowledge about BCRL among the general public. With greater knowledge and awareness, the negative attention and unwelcome curiosity might lessen. Education about BCRL could be integrated into existing breast cancer awareness campaigns. More people should be encouraged to play advocacy roles to make the government, professional schools (medicine, nursing, physical and occupational therapy, and public health), insurers, and others more informed about BCRL.

Education for health care providers. Quite a few participants shared their frustrations about their health providers' neglect with BCRL and lack of related service available, which led to delay of BCRL diagnosis and management. It may be necessary to incorporate BCRL knowledge into the healthcare provider's formal education and continuing education. This could take place through lectures, seminars, research presentations, student projects, and/or academic conferences. More funding should be 
granted to encourage the education of more specialty-trained lymphedema therapists among healthcare providers.

\section{Practice}

The findings from this dissertation indicated that the problems faced by each individual were unique and the situations had changed over time. The implementation of patientcentered care and long-term consultation would improve the management of lymphedmea and survivors' overall quality of life.

Patient-centered care. The findings shows that many factors could contribute to the individual's return-to-work experience, which varied from case to case. Participants often found the current clinical education of BCRL were too structured and not very helpful. Therefore, one of the biggest implications from this study is the emphasis on patient-centered care for occupational rehabilitation among survivors with BCRL. The complexity and specificity of each case would require a team with interdisciplinary expertise, which may include, but not be limited to, psychologists, social workers, physical and occupational therapists, nurses, physicians, and case managers, working collaboratively to help the patient meet her goal of occupational rehabilitation and workplace satisfaction. An individual's willingness or motivation to work, one of the most important factors to be assessed, should be respected. Also, other individual personal attributes should be taken into consideration, such as the comfort in seeking help, selfperceived limitations, and spiritual beliefs.

Long-term follow-up and consultation. The finding showed that individual's condition and the social context may change over time. The chronic nature of BCRL and the volatility of 
the contextual factors (personal and environmental) may require corresponding on-going and individualized clinical services. The findings of this study may be helpful in developing protocols to guide optimal assessment, management, and evaluation.

\section{Research}

This dissertation study is one of the initial studies on the short- and long-term influence of BCRL on survivors’ occupational functioning and experience. It suggests a number of gaps of knowledge which need to be filled.

\section{Research to improve occupational rehabilitation among survivors with BCRL.}

As discussed earlier, there is a very limited number of studies investigating the problem of return-to-work among survivors who developed lymphedema after breast cancer treatment. Moreover, there are very few intervention studies to help improve the returnto-work experience of breast cancer survivors. The systematic review of Hoving, Broekhuizen, and Frings-Dresen (2009) found only four interventional studies focusing on breast cancer survivors’ return-to-work from 1970 to 2007 (Fismen et al., 2000;

Maguire, Brooke, Tait, Thomas, \& Sellwood, 1983; Sachs et al., 1980; Winick \& Robbins, 1977). With the changes in health care, the age of these studies provides limited evidence for informing current health care practices. Moreover, return-to-work was not the primary focus for any of the studies, but rather "physical and social recovery." The only interventional study found focusing on return-to-work of breast cancer survivors after 2007 was conducted by Hubbard et al. (2013). This study utilized case management vocational rehabilitation services (Working Health Service [WHS]). The service was provided by case managers to enable work retention and based on an assessment of 
needs. The reported results did not statistically favor the intervention. Thus, interventions that improve return to work rates and sustained employment continue to be needed.

Research to improve treatment of BCRL. Innovative research to improve BCRL treatment at the practice level is in high demand. Our findings showed that BCRL treatment (bandaging, compression sleeves, etc.) was not yet satisfactory and caused physical, emotional, and interpersonal barriers to women's work and daily life. The complaints participants raised often were related to the complicated or time-consuming bandaging procedure, discomfort, and inconvenience of the treatments and bandages in daily activities. Navigating these barriers often lead to ineffective lymphedema control.

Findings from this study indicated that the discomfort of the garments and overall inconvenience in daily life and work made it difficult for patients to adhere to the BCRL treatment plans. Industry should collaborate with clinical practice closely to better design garments which are more comfortable and easier to use, while providing equivalent or enhanced BCRL management. Additionally, we may not understand as much about lymphedema and its relationship with cancer and other conditions as we think. The basic science of lymphedema such as genetics, biology background, physiopathology, and immunity would be fundamental to the treatment research of the future. Only with BCRL and underlying basic science being more fully understood, can more effective treatment be developed.

\section{Future directions}

The data collected from this study hold value for further secondary analysis. One of the potential future analyses could be looking at how breast cancer patients transition 
to survivors. Dealing with on-going cancer treatment complications such as lymphedema is part of the transition. The experience and outcomes associated with this transition may potentially predict the return-to-work experience. Secondly, during the interviews we found some women could not recall the problems and stressors they experienced early on in the course of returning to work while managing BCRL. We also sensed that the problems faced by women who were recently diagnosed with lymphedema were different from those experienced by women who had been working and managing BCRL for decades. Given the importance of work in quality of life, it would be very informative if the experience of sufficient number of survivors at different times in the trajectory can be compared and contrast or a longitudinal study could be conducted to follow the survivors’ return-to-work journey, starting at breast cancer diagnosis. Such evidence would provide valuable information for clinical and occupational rehabilitation services and also for human resource professionals.

Last, but not least, it would be well worth the effort to use the evidence from this study and possible future studies to improve clinical practice to better support breast cancer survivors who wish to return to work. This study provided detailed information that could inform clinical practice about the barriers patients' face in both the acute and maintenance phase of BCRL management. Improving clinical practice might mean doing a better job of educating patients, so they are more prepared to re-enter the work force. Or, it might mean doing a better job of educating clinicians to assess and address issues that may impede return to work. 


\section{References}

Creswell, J. W., \& Creswell, J. W. (2007). Qualitative inquiry \& research design: Choosing among five approaches. Thousand Oaks: Sage Publications.

Fismen, K., Osland, I. J., Fismen, E., Borge, L., Martinsen, E. W., Hjort, P., . . . Stanghelle, J. K. (2000). Rehabilitation of women with breast cancer. Tidsskr Nor Laegeforen, 120(23), 2749-2754.

Hoving, J. L., Broekhuizen, M. L., \& Frings-Dresen, M. H. (2009). Return to work of breast cancer survivors: A systematic review of intervention studies. BMC Cancer, 9, 117.

Hubbard, G., Gray, N. M., Ayansina, D., Evans, J. M., \& Kyle, R. G. (2013). Case management vocational rehabilitation for women with breast cancer after surgery: A feasibility study incorporating a pilot randomised controlled trial. Trials [Electronic Resource], 14, 175.

Maguire, P., Brooke, M., Tait, A., Thomas, C., \& Sellwood, R. (1983). The effect of counselling on physical disability and social recovery after mastectomy. Clin Oncol, 9(4), 319-324.

Quinlan, E., Thomas-MacLean, R., Hack, T., Kwan, W., Miedema, B., Tatemichi, S., .. . Tilley, A. (2009). The impact of breast cancer among Canadian women: Disability and productivity. Work: Journal of Prevention, Assessment \& Rehabilitation, 34(3), 285-296.

Sachs, S. H., Davis, J. M., Reynolds, S. A., Spagnola, M., Hall, P., \& Bloch, A. (1980). Postmastectomy rehabilitation in a community hospital. J Fam Pract, 11(3), 395401. 
Stake, R. E. (1995). The art of case study research. Thousand Oaks: Sage Publications.

Sun, Y., \& Armer, J. (In review). A Nurse’s Twenty-four-year Journey with Breast Cancer-related Lymphedema.

Sun, Y., Shigaki, C. L., \& Armer, J. M. (2017). Return to work among breast cancer survivors: A literature review. Supportive Care in Cancer, 25(3), 709-718. doi:10.1007/s00520-016-3446-1

Sun, Y., Shigaki, C. L., \& Armer, J. M. (In review). The Influence of breast cancerrelated lymphedema on women's return-to-work.

Winick, L., \& Robbins, G. F. (1977). Physical and psychologic readjustment after mastectomy: An evaluation of Memorial Hospitals' PMRG program. Cancer, 39(2), 478-486.

Yin, R. K. (2014). Case study research: design and methods (5th ed.). Thousand Oaks, CA Sage. 


\section{COMPREPHENSIVE REFERENCE LIST}

Abbott, B., \& Hauser, L. (1995). Realism, model theory, and linguistic semantics. Paper presented at the Annual Meeting Linguistics Society of America.

Ahn, E., Cho, J., Shin, D. W., Park, B. W., Ahn, S. H., Noh, D. Y., . . Yun, Y. H. (2009). Impact of breast cancer diagnosis and treatment on work-related life and factors affecting them. Breast Cancer Research \& Treatment, 116(3), 609-616.

American Cancer Society (2013). Breast Cancer Facts \& figures 2013-2014. Atlanta, GA. Retrieved from http://www.cancer.org/acs/groups/content/@research/documents/document/acspc042725.pdf

American Cancer Society (2013). Cancer Facts \& Figures 2013. Retrieved from https://www.cancer.org/research/cancer-facts-statistics/all-cancer-factsfigures/cancer-facts-figures-2013.html

American Cancer Society (2014). Cancer treatment \& survivorship facts \& figures 20142015. Retrieved from Atlanta, GA:

http://www.cancer.org/acs/groups/content/@research/documents/document/acspc042801.pdf

American Cancer Society (2015). Global Cancer Facts \& Figures 3rd Edition. Atlanta, GA. Retrieved from: https://www.cancer.org/content/dam/cancerorg/research/cancer-facts-and-statistics/global-cancer-facts-and-figures/globalcancer-facts-and-figures-3rd-edition.pdf

American Cancer Society (2018). Cancer Facts \& Figures 2018. Atlanta, GA. Retrieved from https://www.cancer.org/content/dam/cancer-org/research/cancer-facts-and- 
statistics/annual-cancer-facts-and-figures/2018/cancer-facts-and-figures-2018.pdf American Occupational Therapy Association (2011). Tips for living life to its fullest: Living with breast cancer.

Andrews, T. (2012). What is social constructionism. Grounded theory review, 11(1), 3946.

Anitei, M., Chraif, M., Vasile, C., \& Enache, R. G. (2012). The relationship between anxiety, depression and self-esteem in women with breast cancer after surgery. Procedia - Social and Behavioral Sciences, 33, 124-127. doi:http://dx.doi.org/10.1016/j.sbspro.2012.01.096

Armer, J. M., Radina, M. E., Porock, D., \& Culbertson, S. D. (2003). Predicting breast cancer-related lymphedema using self-reported symptoms. Nursing Research, 52(6), 370-379.

Armer, J. M., \& Stewart, B. R. (2010). Post-breast cancer lymphedema: incidence increases from 12 to 30 to 60 months. Lymphology, 43(3), 118-127.

Arroyo, J. M., \& Lopez, M. L. (2011). Psychological Problems Derived from Mastectomy: A Qualitative Study. International Journal of Surgical Oncology, Vol. 2011, 132461. doi:10.1155/2011/132461

Assis, M. R., Marx, A. G., Magna, L. A., \& Ferrigno, I. S. (2013). Late morbidity in upper limb function and quality of life in women after breast cancer surgery. Braz J Phys Ther, 17(3), 236-243.

Babu, B. V., Swain, B. K., \& Rath, K. (2006). Impact of chronic lymphatic filariasis on quantity and quality of productive work among weavers in an endemic village from India. Tropical Medicine \& International Health, 11(5), 712-717. 
Balak, F., Roelen, C. A., Koopmans, P. C., Ten Berge, E. E., \& Groothoff, J. W. (2008). Return to work after early-stage breast cancer: a cohort study into the effects of treatment and cancer-related symptoms. Journal of Occupational Rehabilitation, 18(3), 267-272.

Bernas, M. J., Askew, R. L., Armer, J. M., \& Cormier, J. N. (2010). Lymphedema: How do we diagnose and reduce the risk of this dreaded complication of breast cancer treatment? Current Breast Cancer Reports, 2(1), 53-58. doi:10.1007/s12609-0100009-1

Bifulco, G., De Rosa, N., Tornesello, M. L., Piccoli, R., Bertrando, A., Lavitola, G., . . . Nappi, C. (2012). Quality of life, lifestyle behavior and employment experience: A comparison between young and midlife survivors of gynecology early stage cancers. Gynecologic Oncology, 124(3), 444-451.

Blinder, V. S., Murphy, M. M., Vahdat, L. T., Gold, H. T., de Melo-Martin, I., Hayes, M. K., . . Mazumdar, M. (2012). Employment after a breast cancer diagnosis: A qualitative study of ethnically diverse urban women. Journal of Community Health, 37(4), 763-772.

Blinder, V. S., Patil, S., Thind, A., Diamant, A., Hudis, C. A., Basch, E., \& Maly, R. C. (2012). Return to work in low-income Latina and non-Latina white breast cancer survivors: A 3-year longitudinal study. Cancer, 118(6), 1664-1674.

Bluethmann, S. M., Mariotto, A. B., \& Rowland, J. H. (2016). Anticipating the "Silver Tsunami": Prevalence trajectories and comorbidity burden among older cancer survivors in the United States. Cancer Epidemiology Biomarkers \& Prevention, 25(7), 1029-1036. doi:10.1158/1055-9965.Epi-16-0133 
Boyages, J., Kalfa, S., Xu, Y., Koelmeyer, L., Mackie, H., Viveros, H., . . Gollan, P. (2016). Worse and worse off: The impact of lymphedema on work and career after breast cancer. SpringerPlus, 5(1), 1-8. doi:10.1186/s40064-016-2300-8

Boykoff, N., Moieni, M., \& Subramanian, S. K. (2009). Confronting chemobrain: An indepth look at survivors' reports of impact on work, social networks, and health care response. Journal of Cancer Survivorship, 3(4), 223-232.

Breckenridge, L. M., Bruns, G. L., Todd, B. L., \& Feuerstein, M. (2012). Cognitive limitations associated with tamoxifen and aromatase inhibitors in employed breast cancer survivors. Psycho-Oncology, 21(1), 43-53.

Brennan, M. J., \& Weitz, J. (1992). Lymphedema 30 years after radical mastectomy. American journal of physical medicine \& rehabilitation / Association of Academic Physiatrists, 71(1), 12-14.

Calvio, L., Peugeot, M., Bruns, G. L., Todd, B. L., \& Feuerstein, M. (2010). Measures of cognitive function and work in occupationally active breast cancer survivors. Journal of Occupational \& Environmental Medicine, 52(2), 219-227.

Carlsen, K., Jensen, A. J., Rugulies, R., Christensen, J., Bidstrup, P. E., Johansen, C., . . . Dalton, S. O. (2013). Self-reported work ability in long-term breast cancer survivors. A population-based questionnaire study in Denmark. Acta Oncologica, 52(2), 423-429.

Carter, B. J. (1994). Surviving breast cancer: A problematic work re-entry. Cancer Practice, 2(2), 135-140.

Chachaj, A., Malyszczak, K., Pyszel, K., Lukas, J., Tarkowski, R., Pudelko, M., . . . Szuba, A. (2010). Physical and psychological impairments of women with upper 
limb lymphedema following breast cancer treatment. Psychooncology, 19(3), 299305. doi:10.1002/pon.1573

Cheung, Y. T., Tan, E. H., \& Chan, A. (2012). An evaluation on the neuropsychological tests used in the assessment of postchemotherapy cognitive changes in breast cancer survivors. Supportive Care in Cancer, 20(7), 1361-1375.

Cho, J., \& Trent, A. (2006). Validity in qualitative research revisited. Qualitative Research, 6(3), 319-340. doi:10.1177/1468794106065006

Cormier, J. N., Askew, R. L., Mungovan, K. S., Xing, Y., Ross, M. I., \& Armer, J. A. (2010). Lymphedema beyond breast cancer: A systematic review and metaanalysis of cancer-related secondary lymphedema. Cancer, 6 (1), 5138-5149.

Creswell, J. W., \& Creswell, J. W. (2007). Qualitative inquiry \& research design: choosing among five approaches. Thousand Oaks: Sage Publications.

Crotty, M. (1998). The foundations of social research: meaning and perspective in the research process. London; Thousand Oaks, Calif.: Sage Publications.

Dawes, D. J., Meterissian, S., Goldberg, M., \& Mayo, N. E. (2008). Impact of lymphoedema on arm function and health-related quality of life in women following breast cancer surgery. J Rehabil Med, 40(8), 651-658. doi:10.2340/16501977-0232

De Croon, E., Sluiter, J., Nijssen, T., Dijkmans, B., Lankhorst, G., \& Frings-Dresen, M. (2004). Predictive factors of work disability in rheumatoid arthritis: A systematic literature review. Annals of the rheumatic diseases, 63(11), 1362-1367.

Dedoose Version 7.0.23. (2016). Web application for managing, analyzing, and presenting qualitative and mixed method research data. Retrieved from 
www.dedoose.com

Degnim, A. C., Miller, J., Hoskin, T. L., Boughey, J. C., Loprinzi, M., Thomsen, K., .. . Cheville, A. L. (2012). A prospective study of breast lymphedema: frequency, symptoms, and quality of life. Breast Cancer Research \& Treatment, 134(3), 915922. doi:http://dx.doi.org/10.1007/s10549-012-2004-x

Désiron, H. A. M., Donceel, P., de Rijk, A., \& Van Hoof, E. (2013). A conceptualpractice model for occupational therapy to facilitate return to work in breast cancer patients. Journal of Occupational Rehabilitation, 23(4), 516-526. doi:10.1007/s10926-013-9427-z

Devoogdt, N., Van Kampen, M., Christiaens, M. R., Troosters, T., Piot, W., Beets, N., . . . Gosselink, R. (2011). Short- and long-term recovery of upper limb function after axillary lymph node dissection. European Journal of Cancer Care, 20(1), 77-86. doi:10.1111/j.1365-2354.2009.01141.x

Duijts, S., Spelten, E., \& Verbeek, J. (2014). Behavioral determinants of employment status in cancer patients. In The Handbook of Behavioral Medicine (pp. 825-849): John Wiley \& Sons, Ltd.

Ecamm Network @2017. Retrieved from http://www.ecamm.com/mac/callrecorder

Fantoni, S. Q., Peugniez, C., Duhamel, A., Skrzypczak, J., Frimat, P., \& Leroyer, A. (2010). Factors related to return to work by women with breast cancer in northern France. Journal of Occupational Rehabilitation, 20(1), 49-58.

Feuerstein, M., Todd, B. L., Moskowitz, M. C., Bruns, G. L., Stoler, M. R., Nassif, T., \& Yu, X. (2010). Work in cancer survivors: A model for practice and research. Journal of Cancer Survivorship, 4(4), 415-437. 
Fismen, K., Osland, I. J., Fismen, E., Borge, L., Martinsen, E. W., Hjort, P., . . . Stanghelle, J. K. (2000). Rehabilitation of women with breast cancer. Tidsskr Nor Laegeforen, 120(23), 2749-2754.

Földi, M., Földi, E., Strößenreuther, C., \& Kubik, S. (2012). Földi's Textbook of Lymphology: For Physicians and Lymphedema Therapists: Elsevier - Health Sciences Division.

Fu, M. R., \& Rosedale, M. (2009). Breast cancer survivors' experiences of lymphedemarelated symptoms. Journal of Pain \& Symptom Management, 38(6), 849-859. doi:http://dx.doi.org/10.1016/j.jpainsymman.2009.04.030

Glaser, B. G., \& Strauss, A. L. (1967). The discovery of grounded theory: strategies for qualitative research. Chicago: Aldine Pub. Co.

Glaser, B. G., \& Strauss, A. L. (1999). The discovery of grounded theory strategies for qualitative research. Retrieved from http://www.sxf.uevora.pt/wpcontent/uploads/2013/03/Glaser_1967.pdf

Gupta, P., Sturdee, D. W., Palin, S. L., Majumder, K., Fear, R., Marshall, T., \& Paterson, I. (2006). Menopausal symptoms in women treated for breast cancer: The prevalence and severity of symptoms and their perceived effects on quality of life. Climacteric, 9(1), 49-58. doi:10.1080/13697130500487224

Hakanen, J. J., \& Lindbohm, M. L. (2008). Work engagement among breast cancer survivors and the referents: The importance of optimism and social resources at work. Journal of Cancer Survivorship, 2(4), 283-295.

Hansen, J. A., Feuerstein, M., Calvio, L. C., \& Olsen, C. H. (2008). Breast cancer survivors at work. Journal of Occupational \& Environmental Medicine, 50(7), 
777-784.

Hauglann, B., Benth, J. S., Fossa, S. D., \& Dahl, A. A. (2012). A cohort study of permanently reduced work ability in breast cancer patients. Journal of Cancer Survivorship, 6(3), 345-356.

Hayes, S. C., Janda, M., Cornish, B., Battistutta, D., \& Newman, B. (2008).

Lymphedema after breast cancer: Incidence, risk factors, and effect on upper body function. Journal of Clinical Oncology, 26(21), 3536-3542.

Hayes, S. C., Rye, S., Battistutta, D., DiSipio, T., \& Newman, B. (2010). Upper-body morbidity following breast cancer treatment is common, may persist longer-term and adversely influences quality of life. Health and Quality of Life Outcomes, 8. doi:10.1186/1477-7525-8-92

Hayes, S. C., Rye, S., Battistutta, D., \& Newman, B. (2010). Prevalence of upper-body symptoms following breast cancer and its relationship with upper-body function and lymphedema. Lymphology, 43(4), 178-187.

Henry, N. L., \& Griggs, J. J. (2009). Complexities of adjuvant endocrine therapy in young premenopausal women. Oncology (Williston Park), 23(6), 482, 487.

Hormes, J. M., Bryan, C., Lytle, L. A., Gross, C. R., Ahmed, R. L., Troxel, A. B., \& Schmitz, K. H. (2010). Impact of lymphedema and arm symptoms on quality of life in breast cancer survivors. Lymphology, 43(1), 1-13.

Hoving, J. L., Broekhuizen, M. L., \& Frings-Dresen, M. H. (2009). Return to work of breast cancer survivors: a systematic review of intervention studies. BMC Cancer, 9, 117.

Howard-Anderson, J., Ganz, P. A., Bower, J. E., \& Stanton, A. L. (2012). Quality of life, 
fertility concerns, and behavioral health outcomes in younger breast cancer survivors: A systematic review. Journal of the National Cancer Institute, 104(5), 386-405.

Howlader, N., Noone, A. M., Krapcho, M., Garshell, J., Miller, D., Altekruse, S. F., . . . Cronin, K. A. (2015). SEER Cancer Statistics Review. Retrieved 2015, from National Cancer Institute http://seer.cancer.gov/csr/1975_2012

Howlader, N., Noone, A. M., Krapcho, M., Garshell, J., Miller, D., Altekruse, S. F., . . . Cronin, K. A. (2015). SEER Cancer Statistics Review, 1975-2012. Available from based on November 2014 SEER data submission based on November 2014 SEER data submission Retrieved 2015, from National Cancer Institute http://seer.cancer.gov/csr/1975_2012

Howlader, N., Noone, A. M., Krapcho, M., Miller, D., Bishop, K., Kosary, C. L., . . . Cronin, K. A. (2016). SEER Cancer Statistics Review, 1975-2014, National Cancer Institute. Retrieved from https://seer.cancer.gov/csr/1975_2014

Hubbard, G., Gray, N. M., Ayansina, D., Evans, J. M., \& Kyle, R. G. (2013). Case management vocational rehabilitation for women with breast cancer after surgery: A feasibility study incorporating a pilot randomized controlled trial. Trials [Electronic Resource], 14, 175.

Jette, A. M. (2006). Toward a common language for function, disability, and health. Phys Ther, 86(5), 726-734.

Johnsson, A., Fornander, T., Rutqvist, L. E., \& Olsson, M. (2011). Work status and life changes in the first year after breast cancer diagnosis. Work, 38(4), 337-346.

Johnsson, A., Fornander, T., Rutqvist, L. E., Vaez, M., Alexanderson, K., \& Olsson, M. 
(2009). Predictors of return to work ten months after primary breast cancer surgery. Acta Oncologica, 48(1), 93-98.

Lavigne, J. E., Griggs, J. J., Tu, X. M., \& Lerner, D. J. (2008). Hot flashes, fatigue, treatment exposures and work productivity in breast cancer survivors. Journal of Cancer Survivorship, 2(4), 296-302.

Lerner, D., Amick Iii, B. C., Rogers, W. H., Malspeis, S., Bungay, K., \& Cynn, D. (2001). The work limitations questionnaire. Medical Care, 39(1), 72-82.

Lewis, P. E., Sheng, M., Rhodes, M. M., Jackson, K. E., \& Schover, L. R. (2012). Psychosocial concerns of young African American breast cancer survivors. Journal of Psychosocial Oncology, 30(2), 168-184.

Lincoln, Y. S., \& Guba, E. G. (1985). Naturalistic inquiry. Newbury Park, California: Sage.

Maguire, P., Brooke, M., Tait, A., Thomas, C., \& Sellwood, R. (1983). The effect of counselling on physical disability and social recovery after mastectomy. Clin Oncol, 9(4), 319-324.

Mehnert, A., de Boer, A., \& Feuerstein, M. (2013). Employment challenges for cancer survivors. Cancer, 119(11, Suppl), 2151-2159. doi:10.1002/cncr.28067

Merriam, S. B. (2009). Qualitative research: A guide to design and implementation. Retrieved from http://public.eblib.com/choice/publicfullrecord.aspx?p=1662771 Microsoft Skype @2017. Retrieved from https://www.skype.com/en/ Moffatt, C. J., Franks, P. J., Doherty, D. C., Williams, A. F., Badger, C., Jeffs, E., . . Mortimer, P. S. (2003). Lymphoedema: An underestimated health problem. Qjm, 96(10), 731-738. 
Molina Villaverde, R., Feliu Batlle, J., Villalba Yllan, A., Jimenez Gordo, A. M., Redondo Sanchez, A., San Jose Valiente, B., \& Gonzalez Baron, M. (2008). Employment in a cohort of breast cancer patients. Occupational Medicine (Oxford), 58(7), 509-511.

Mortimer, J., \& Behrendt, C. E. (2013). Severe menopausal symptoms are widespread among survivors of breast cancer treatment regardless of time since diagnosis. $J$ Palliat Med, 16(9), 1130-1134. doi:10.1089/jpm.2012.0585

Mujahid, M. S., Janz, N. K., Hawley, S. T., Griggs, J. J., Hamilton, A. S., \& Katz, S. J. (2010). The impact of sociodemographic, treatment, and work support on missed work after breast cancer diagnosis. Breast Cancer Research \& Treatment, 119(1), 213-220.

Munir, F., Burrows, J., Yarker, J., Kalawsky, K., \& Bains, M. (2010). Women's perceptions of chemotherapy-induced cognitive side effects on work ability: A focus group study. Journal of Clinical Nursing, 19(9-10), 1362-1370.

Nguyen, T. T., Hoskin, T. L., Habermann, E. B., Cheville, A. L., \& Boughey, J. C. (2017). Breast Cancer-Related Lymphedema Risk is Related to Multidisciplinary Treatment and Not Surgery Alone: Results from a Large Cohort Study. Annals of Surgical Oncology, 24(10), 2972-2980. doi:10.1245/s10434-017-5960-х

Norman, S. A., Localio, A. R., Potashnik, S. L., Simoes Torpey, H. A., Kallan, M. J., Weber, A. L., . . . Solin, L. J. (2009). Lymphedema in breast cancer survivors: Incidence, degree, time course, treatment, and symptoms. J Clin Oncol, 27(3), 390-397. doi:10.1200/jco.2008.17.9291

Oberst, K., Bradley, C. J., Gardiner, J. C., Schenk, M., \& Given, C. W. (2010). Work task 
disability in employed breast and prostate cancer patients. Journal of Cancer Survivorship, 4(4), 322-330.

Ottati, A., \& Feuerstein, M. (2013). Brief self-report measure of work-related cognitive limitations in breast cancer survivors. Journal of Cancer Survivorship, 7(2), 262273.

Peppercorn, J. (2009). Breast cancer in women under 40. Oncology (Williston Park), 23(6), 465-474.

Petersson, L. M., Wennman-Larsen, A., Nilsson, M., Olsson, M., \& Alexanderson, K. (2011). Work situation and sickness absence in the initial period after breast cancer surgery. Acta Oncologica, 50(2), 282-288.

Peugniez, C., Fantoni, S., Leroyer, A., Skrzypczak, J., Duprey, M., \& Bonneterre, J. (2011). Return to work after treatment for breast cancer: single center experience in a cohort of 273 patients. Bulletin du Cancer, 98(7), E69-79.

Polit, D. F., \& Beck, C. T. (2012). Nursing research: Generating and assessing evidence for nursing practice. Philadelphia: Wolters Kluwer Health/Lippincott Williams \& Wilkins.

Przezdziecki, A., Sherman, K. A., Baillie, A., Taylor, A., Foley, E., \& Stalgis-Bilinski, K. (2013). My changed body: Breast cancer, body image, distress and selfcompassion. Psychooncology, 22(8), 1872-1879. doi:10.1002/pon.3230

Pyszel, A., Malyszczak, K., Pyszel, K., Andrzejak, R., \& Szuba, A. (2006). Disability, psychological distress and quality of life in breast cancer survivors with arm lymphedema. Lymphology, 39(4), 185-192.

Qualtrics@2017. Provo Utah USA (Producer). (2017). Retrieved from 
http://www.qualtrics.com

Quinlan, E., Thomas-MacLean, R., Hack, T., Kwan, W., Miedema, B., Tatemichi, S., . . . Tilley, A. (2009). The impact of breast cancer among Canadian women: Disability and productivity. Work: Journal of Prevention, Assessment \& Rehabilitation, 34(3), 285-296.

Rebegea, L., Firescu, D., Dumitru, M., \& Anghel, R. (2015). The incidence and risk factors for occurrence of arm lymphedema after treatment of breast cancer. Chirurgia (Bucur), 110(1), 33-37.

Richardson, A., Addington-Hall, J., Amir, Z., Foster, C., Stark, D., Armes, J., . . Sharpe, M. (2011). Knowledge, ignorance and priorities for research in key areas of cancer survivorship: Findings from a scoping review. British Journal of Cancer, 105(SUPPL. 1), S82-S94.

Ridner, S. H. (2005). Quality of life and a symptom cluster associated with breast cancer treatment-related lymphedema. Supportive Care in Cancer, 13(11), 904-911. doi:10.1007/s00520-005-0810-y

Ridner, S. H., Sinclair, V., Deng, J., Bonner, C. M., Kidd, N., \& Dietrich, M. S. (2012). Breast cancer survivors with lymphedema: Glimpses of their daily lives. Clinical Journal of Oncology Nursing, 16(6), 609-614. doi:10.1188/12.CJON.609-614

Sachs, S. H., Davis, J. M., Reynolds, S. A., Spagnola, M., Hall, P., \& Bloch, A. (1980). Postmastectomy rehabilitation in a community hospital. J Fam Pract, 11(3), 395401.

Schmalenberger, S., Gessert, C. E., Giebenhain, J. E., \& Starr, L. D. (2012). Livelihood vs. life: The occupational well-being of women musician survivors of breast 
cancer. Medical Problems of Performing Artists, 27(1), 15-20.

Schmalenberger, S., Gessert, C. E., Giebenhain, J. E., \& Starr, L. D. (2012). Working after breast cancer treatment: Lessons from musicians. Medical Problems of Performing Artists, 27(4), 175-180.

Schreuer, N., Rimmerman, A., \& Sachs, D. (2006). Adjustment to severe disability: Constructing and examining a cognitive and occupational performance model. International Journal of Rehabilitation Research, 29(3), 201-207 207p.

Sclafani, L. M., \& Baron, R. H. (2008). Sentinel lymph node biopsy and axillary dissection: Added morbidity of the arm, shoulder and chest wall after mastectomy and reconstruction. Cancer Journal, 14(4), 216-222.

Shih, Y. C., Xu, Y., Cormier, J. N., Giordano, S., Ridner, S. H., Buchholz, T. A., . . . Elting, L. S. (2009). Incidence, treatment costs, and complications of lymphedema after breast cancer among women of working age: A 2-year follow-up study. $J$ Clin Oncol, 27(12), 2007-2014. doi:10.1200/jco.2008.18.3517

Short, P. F., Vasey Jj Fau - Tunceli, K., \& Tunceli, K. Employment pathways in a large cohort of adult cancer survivors. (0008-543X (Print)).

Smith, D. F. (1975). The functions of work. Omega, 3(4), 383-393. doi:https://doi.org/10.1016/0305-0483(75)90002-X

Smoot, B., Wong, J., Cooper, B., Wanek, L., Topp, K., Byl, N., \& Dodd, M. (2010). Upper extremity impairments in women with or without lymphedema following breast cancer treatment. Journal of Cancer Survivorship, 4(2), 167-178. doi:10.1007/s11764-010-0118-x

Stake, R. E. (1995). The art of case study research. Thousand Oaks: Sage Publications. 
Stubblefield, M. D., \& Keole, N. (2014). Upper body pain and functional disorders in patients with breast cancer. Pm r, 6(2), 170-183. doi:10.1016/j.pmrj.2013.08.605

Sun, Y., \& Armer, J. (In review). A Nurse’s Twenty-four-year Journey with Breast Cancer-related Lymphedema.

Sun, Y., Armer, J., \& Shigaki, C. L. (In review). The Influence of breast cancer-related lymphedema on women's return-to-work.

Sun, Y., Shigaki, C. L., \& Armer, J. M. (2017). Return to work among breast cancer survivors: A literature review. Supportive Care in Cancer, 25(3), 709-718. doi:10.1007/s00520-016-3446-1

Taghian, N. R., Miller, C. L., Jammallo, L. S., O'Toole, J., \& Skolny, M. N. (2014). Lymphedema following breast cancer treatment and impact on quality of life: A review. Critical Reviews in Oncology/Hematology, 92(3), 227-234. doi:10.1016/j.critrevonc.2014.06.004

Tamminga, S. J., de Boer, A. G., Verbeek, J. H., \& Frings-Dresen, M. H. (2012). Breast cancer survivors' views of factors that influence the return-to-work process--A qualitative study. Scandinavian Journal of Work, Environment \& Health, 38(2), 144-154.

Tan, F. L., Loh, S. Y., Su, T. T., Veloo, V. W., \& Ng, L. L. (2012). Return to work in multi-ethnic breast cancer survivors--A qualitative inquiry. Asian Pacific Journal of Cancer Prevention: Apjcp, 13(11), 5791-5797.

Tiedtke, C., de Rijk, A., Donceel, P., Christiaens, M. R., \& de Casterle, B. D. (2012). Survived but feeling vulnerable and insecure: A qualitative study of the mental preparation for RTW after breast cancer treatment. BMC Public Health, 12, 538. 
Tiedtke, C., Donceel, P., Knops, L., Desiron, H., Dierckx de Casterle, B., \& de Rijk, A. (2012). Supporting return-to-work in the face of legislation: Stakeholders' experiences with return-to-work after breast cancer in Belgium. Journal of Occupational Rehabilitation, 22(2), 241-251.

Todd, B. L., Feuerstein, E. L., \& Feuerstein, M. (2011). When breast cancer survivors report cognitive problems at work. International Journal of Psychiatry in Medicine, 42(3), 279-294.

Tsauo, J. Y., Hung, H. C., Tsai, H. J., \& Huang, C. S. (2011). Can ICF model for patients with breast-cancer-related lymphedema predict quality of life? Supportive Care in Cancer, 19(5), 599-604. doi:http://dx.doi.org/10.1007/s00520-010-0857-2

van der Valk, M. E., Mangen, M.-J. J., Leenders, M., Dijkstra, G., van Bodegraven, A. A., Fidder, H. H., . . . Romberg-Camps, M. J. (2014). Risk factors of work disability in patients with inflammatory bowel disease-A Dutch nationwide web-based survey: Work disability in inflammatory bowel disease. Journal of Crohn's and Colitis, 8(7), 590-597.

Von Ah, D., Habermann, B., Carpenter, J. S., \& Schneider, B. L. (2013). Impact of perceived cognitive impairment in breast cancer survivors. European Journal of Oncology Nursing, 17(2), 236-241.

Warren, L. E. G., Miller, C. L., Horick, N., Skolny, M. N., Jammallo, L. S., Sadek, B. T., . . Taghian, A. G. (2014). The Impact of Radiation Therapy on the Risk of Lymphedema After Treatment for Breast Cancer: A Prospective Cohort Study. International Journal of Radiation Oncology • Biology • Physics, 88(3), 565-571. doi:10.1016/j.ijrobp.2013.11.232 
Winick, L., \& Robbins, G. F. (1977). Physical and psychologic readjustment after mastectomy: An evaluation of Memorial Hospitals' PMRG program. Cancer, 39(2), 478-486.

Workforce Innovation and Opportunities Act (WIOA) (2016). REHABILITATION ACT OF 1973 [As Amended Through P.L. 114-95, Enacted December 10, 2015]. Retrieved from https://legcounsel.house.gov/Comps/Rehabilitation\%20Act\%20Of\%201973.pdf

World Health Organization. (2001). ICF: International classification of functioning, disability and health. In. Geneva: World Health Organization.

World Health Organization. (2001). International classification of functioning, disability and health: ICF. Geneva: World Health Organization.

Yang, E. J., Ahn, S., Kim, E. K., Kang, E., Park, Y., Lim, J. Y., \& Kim, S. W. (2016). Use of a prospective surveillance model to prevent breast cancer treatment-related lymphedema: A single-center experience. Breast Cancer Res Treat, 160(2), 269276. doi:10.1007/s10549-016-3993-7

Yang, E. J., Kang, E., Kim, S. W., \& Lim, J. Y. (2015). Discrepant trajectories of impairment, activity, and participation related to upper-Limb function in patients with breast cancer. Arch Phys Med Rehabil, 96(12), 2161-2168. doi:10.1016/j.apmr.2015.08.426

Yin, R. K. (2014). Case study research: Design and methods. In (5th ed.). Thousand Oaks, CA: Sage.

Zou, L., Liu, F.-h., Shen, P.-p., Hu, Y., Liu, X.-q., Xu, Y.-y., . . Tian, Y. (2018). The incidence and risk factors of related lymphedema for breast cancer survivors post- 
operation: A 2-year follow-up prospective cohort study. Breast Cancer. doi:10.1007/s12282-018-0830-3

Zuther, J. E., \& Norton, S. (2013). Complete Decongestive Therapy. In Lymphedema Management: The Comprehensive Guide for Practitioners (pp. 127). Stuttgart: Georg Thieme Verlag. 


\title{
APPENDIX A \\ Consent Form and Flyers
}

\section{CONSENT FORM TO PARTICIPATE IN A RESEARCH STUDY}

\author{
Researcher's Name(s): Yuanlu Sun, Dr. Jane Armer \\ Project Title: The Impact of Breast Cancer-related Lymphedema on Survivors' \\ Return to Work \\ INTRODUCTION
}

This consent may contain words that you do not understand. Please ask the investigator or the study staff to explain any words or information that you do not clearly understand.

You are being asked to participate in a research study. This research is being conducted to investigate breast cancer survivors' perception of the effects of breast cancer-related lymphedema on survivors' work ability, performance, experience and other work-related outcomes. When you are invited to participate in research, you have the right to be informed about the study procedures so that you can decide whether you want to consent to participation. This form may contain words that you do not know. Please ask the researcher to explain any words or information that you do not understand.

You have the right to know what you will be asked to do so that you can decide whether or not to be in the study. Your participation is voluntary. You do not have to be in the study if you do not want to. You may refuse to be in the study and nothing will happen. If you do not want to continue to be in the study, you may stop at any time without penalty or loss of benefits to which you are otherwise entitled. You can skip any questions you feel uncomfortable with.

\section{WHY IS THIS STUDY BEING DONE?}

The goal of the proposed study is to investigate breast cancer survivors' perception of the effects of breast cancer-related lymphedema on their work experience including work ability, performance, experience, and other work-related outcomes.

\section{HOW MANY PEOPLE WILL BE IN THE STUDY?}

About 15 people will take part in this study in the United States.

\section{WHAT AM I BEING ASKED TO DO?}

- Fill in a survey including demographic, occupational, and medical information either online or paperback (estimated 10 minutes). 
- Participate in a 60-minute face-to-face interview talking about your experience by answering semi-structured questions. If in-person meeting is not available, a distance interview will be carried by software such as Skype, Facetime or phone call depending on your internet accessibility and preference.

- 15-30 min unstructured follow-up interview, if necessary, to help researcher confirm the initial findings.

- You can skip any questions you feel uncomfortable with.

\section{HOW LONG WILL I BE IN THE STUDY?}

Your participation will include filling in a survey requiring an estimated 10 minutes prior to participation in a 60-minute private interview and talking about your experience of having lymphedema while re-entering or returning to your work after breast cancer treatment. You will be invited to participate in a 15-to-30-minute follow-up interview, if necessary. You may stop participating in the study at any time. Your decision to withdraw from the study will not in any way affect your medical care and/or benefits.

\section{WHAT ARE THE RISKS OF BEING IN THE STUDY?}

There are no known risks related to this study.

\section{WHAT ARE THE COSTS OF BEING IN THE STUDY?}

There is no cost to you to participate in the study.

\section{WHAT OTHER OPTIONS ARE THERE?}

You also have the option of not participating in this study, and you will not be penalized for your decision.

\section{CONFIDENTIALITY}

- The data resulting from your participation may be made available to other researchers in the future for research purposes not detailed within this consent form. In these cases, the data will contain no identifying information.

- The results of this study may be published in a book or journal or used for teaching purposes. However, your name or other identifiers will not be used in any publication or teaching materials without your specific permission.

- Only researchers working with this project will review the recorded data.

- Any potential identifying information on the audio will immediately be removed after the interview

- If video call is employed, only audio will be recorded for transcription.

\section{WILL I BE COMPENSATED FOR PARTICIPATING IN THE STUDY?}

You will receive a $\$ 20$ check for the initial 60-minute interview; and a $\$ 15$ check for the follow-up interview, if necessary.

WHO DO I CONTACT IF I HAVE QUESTIONS ABOUT THE STUDY? 
Please contact Dr. Jane Armer, co-Principal Investigator and Academic Advisor, if you have questions about the research. Additionally, you may ask questions, voice concerns, or report complaints to the research team.

\section{WHOM DO I CALL IF I HAVE QUESTIONS, CONCERNS, OR COMPLAINTS, OR PROBLEMS ABOUT THE RESEARCH?}

If you have any questions regarding your rights as a participant in this research and/or concerns about the study, or if you feel under any pressure to enroll or to continue to participate in this study, you may contact the University of Missouri Health Sciences Institutional Review Board (which is a group of people who review the research studies to protect participants’ rights) at (573) 882-3181 and irb@missouri.edu.

A copy of this Informed Consent form will be given to you before you participate in the research. 


\section{M}

\section{PARTICIPANTS NEEDED FOR STUDY !}

We are looking for women diagnosed with lymphedema following breast cancer to take part in a study on Impact of Lymphedema on Return to Work

Are you :

1. Diagnosed with lymphedema following breast cancer treatment;

2. Finished with primary cancer treatment and more than $\mathbf{1 2}$ months' post-surgery and radiation;

3. Employed or self-employed at the time of lymphedema diagnosis.
If you decide to participate: We will arrange a 60-min private interview with you to talk about your experience of having lymphedema whiling returning to work after breast cancer treatment. You will be asked to fill in a 6 to 10 -minute survey including your demographic, occupational, and medical information.

Each participant is endowed with $\$ 20$ for each interview.

For more information, please contact: A pril (Yuanlu) Sun, RN, BSN, CLT

University of Missouri

Sinclair School of Nursing

Mizzou North 408

Columbia, MO 65211

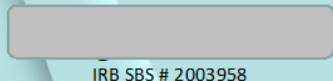

IRB SBS \# 2003958

\section{는}

PLEASE HELP US RECRUIT PARTICIPANTS

We are looking for women diagnosed with lymphedema

following breast cancer to take part in a study on Impact of Lymphedema on Return to Work

Do you have patients who are:

1. Diagnosed with lymphedema following breast cancer

treatment;

2. Finished with primary cancer

treatment and more than 12 months' post-surgery and radiation;

3. Employed or self-employed at time of lymphedema diagnosis.
Please refer her to us if she is

interested in our study: We will arrange a $\mathbf{6 0}$-min private interview with her to talk about her experience of having lymphedema whiling re-entering work after breast cancer treatment. She will be asked to fill in a 6 to 10-minute survey with work-related information before the interview.

Each participant is endowed with $\$ 20$ for each interview.

For more information, please contact:

April (Yuanlu) Sun, RN, CLT

University of Missouri

Sinclair School of Nursing

Mizzou North 408

Columbia, MO 65211

IRB SBS \# 2003958 


\section{APPENDIX B \\ Interview Protocol}

\section{The Influence of Breast Cancer-related Lymphedema on Survivors’ Return to Work}

Researchers: Yuanlu Sun, Jane M. Armer

The interview is a semi-structured interview consisting of the following questions: Work demographics

- What does work/employment mean to you? (define, describe)

- What kind of work do you do (have you done)?

- How long have you worked in these fields?

- Tell me about a typical day at work for you, around the time you were diagnosed with breast cancer.

- How do you describe your work?

o What type of job(s) are/were you doing (describe the job content and tasks):

- Before diagnosis with breast cancer?

- Before diagnosis with lymphedema?

- After diagnosis with lymphedema?

- What are the reasons if you work part-time?

o What are/were the physical/functional/activity demands:

- Before diagnosis with breast cancer?

- Before diagnosis with lymphedema?

- After diagnosis with lymphedema?

- Describe why you were off work due to breast cancer treatment

- Describe why you were off work due to lymphedema (How does lymphedema affect your working time?)

\section{Lymphedema-related Changes}

- Tell me about a typical day at work for you after you developed lymphedema and how this has been different than before you were diagnosed.

- What changes do you experience from lymphedema physically?

- What changes do you experience from lymphedema emotionally/psychologically?

- What changes do you experience from lymphedema interpersonally (family, friends, neighbors)? Interpersonal Changes in Work

o How does it feel to talk about lymphedema to the people you work with? 
o How do you feel your relationships with people at work have been affected by your lymphedema?

o What are your colleagues' attitudes after they came to know you have lymphedema?

o What support, if any, have your colleagues given to you?

o What interpersonal challenges have you experienced in the work place since experiencing lymphedema?

o How do you feel your company/work place treated/supported you after you developed lymphedema?

o What ways of coping help you deal with the interpersonal challenges?

o What ways of coping have not worked for you in dealing with the interpersonal challenges?

\section{$\underline{\text { Work-related Outcomes }}$}

- Please give me some specific examples of how lymphedema is affecting you in your work or how it has affected you in the past. (Please tell me if you have/had a disability that prevents you from accepting any kind of work or caused layoff from a job after diagnosis with breast cancer and lymphedema.)

- How has lymphedema affected you in the work place in the following areas:

o How does lymphedema affect your ability to carry out physical tasks?

o How does lymphedema affect your self confidence and self-esteem?

o How does lymphedema affect your mental focus and emotional well-being?

o How do you feel lymphedema has affected your work productivity?

- How do you feel people in your work place evaluate your productivity, compared to before you had lymphedema (if you stayed in the same job)?

o How do you think the changes caused by lymphedema affect your ability to meet work demands?

- How do you feel people in your work place think about changes in your ability to meet work demands due to lymphedema?

- How have you coped with meeting work place demands after experiencing lymphedema?

o What ways of coping have worked for you in coping with work place demands?

o What ways of coping have not worked for you in meeting work place demands?

\section{Environmental Characteristics}

- How do you feel society considers women who are breast cancer survivors with lymphedema?

- What social support resources have been available to you?

o How was information on lymphedema been made available to you? 
o What have the clinicians (PT, physician, nurses etc.) advised and supported you for return to work after you were diagnosed with lymphedema?

o How has your family supported you, if they have, after you developed lymphedema and returned to work?

o How have your community/neighborhood/friends supported you, if they have, after you developed lymphedema and returned to work? In what ways have they helped you?

\section{Final reflections on the experience}

- What have you learned from the experience of having lymphedema during these past months/years? If you were to advise newly-diagnosed patients with breast cancer-related lymphedema, what suggestions/advice would you give to them?

- How do the situations and difficulties you may be experiencing now compare to the beginning of your lymphedema experience?

- What changes in your outlook toward work have you experienced after having lymphedema? How do you think about your future with lymphedema? How do you think lymphedema may change in the future? How do you foresee lymphedema may change your life?

Is there anything else you would like to tell me about your experience with lymphedema in the work place that we have not discussed? 


\title{
APPENDIX C \\ Demographic Data Collection Tool
}

\author{
BCRL_RTW Demographic Data Collection Tool
}

The following questions will give you opportunity to tell us more about you. Answer all questions you understand. Do not answer questions that have any words you do not understand. Circle any words you do not know.

Participant ID \#

Date of taking this survey

Date of Birth

Q1 Choose one or more races that you consider yourself to be:

$\square$ White

$\square$ Black or African American

$\square$ American Indian or Alaska Native

$\square$ Asian

$\square$ Native Hawaiian or Pacific Islander

$\square$ Other

Q2 What is the highest level of school you have completed or the highest degree you have received?

Less than high school degree

$\square$ High school graduate (high school diploma or equivalent including GED)

$\square$ Some college but no degree

$\square$ Associate degree in college (2-year)

$\square$ Bachelor's degree in college (4-year)

$\square$ Master's degree

$\square$ Doctoral degree

$\square$ Professional degree (JD, MD) 
Q3 How would you describe your financial resources, as far as being adequate for your needs and the needs of your household?

$\square$ Extremely adequate

$\square$ Somewhat adequate

$\square$ Neither adequate nor inadequate

$\square$ Somewhat inadequate

$\square$ Extremely inadequate

Q4 How many hours do/did you work per week on average?

- Before diagnosis of breast cancer? hours

- After breast cancer diagnosis but before diagnosis of lymphedema? hours

- Since diagnosis of lymphedema? hours

Q5 How long were you or have you been off from work due to breast cancer treatment? (circle: days/months/years).

Q6 How long were you or have you been off from work due to lymphedema? (circle: days/months/years).

Q7 Please choose your employment status after you developed lymphedema, and select all statements describes you in the subcategories.

$\square$ Working (paid employee, or self-employed)

$\square$ Working full-time, no restrictions or modifications

$\square$ Working part-time, no restrictions or modifications

$\square$ Working but restricted to "light duty" (e.g. cannot lift 10 pounds)

$\square$ Working at lower wage, fewer hours than before diagnosis

$\square$ Working at lower skilled job than before diagnosis

$\square$ Working (other): 


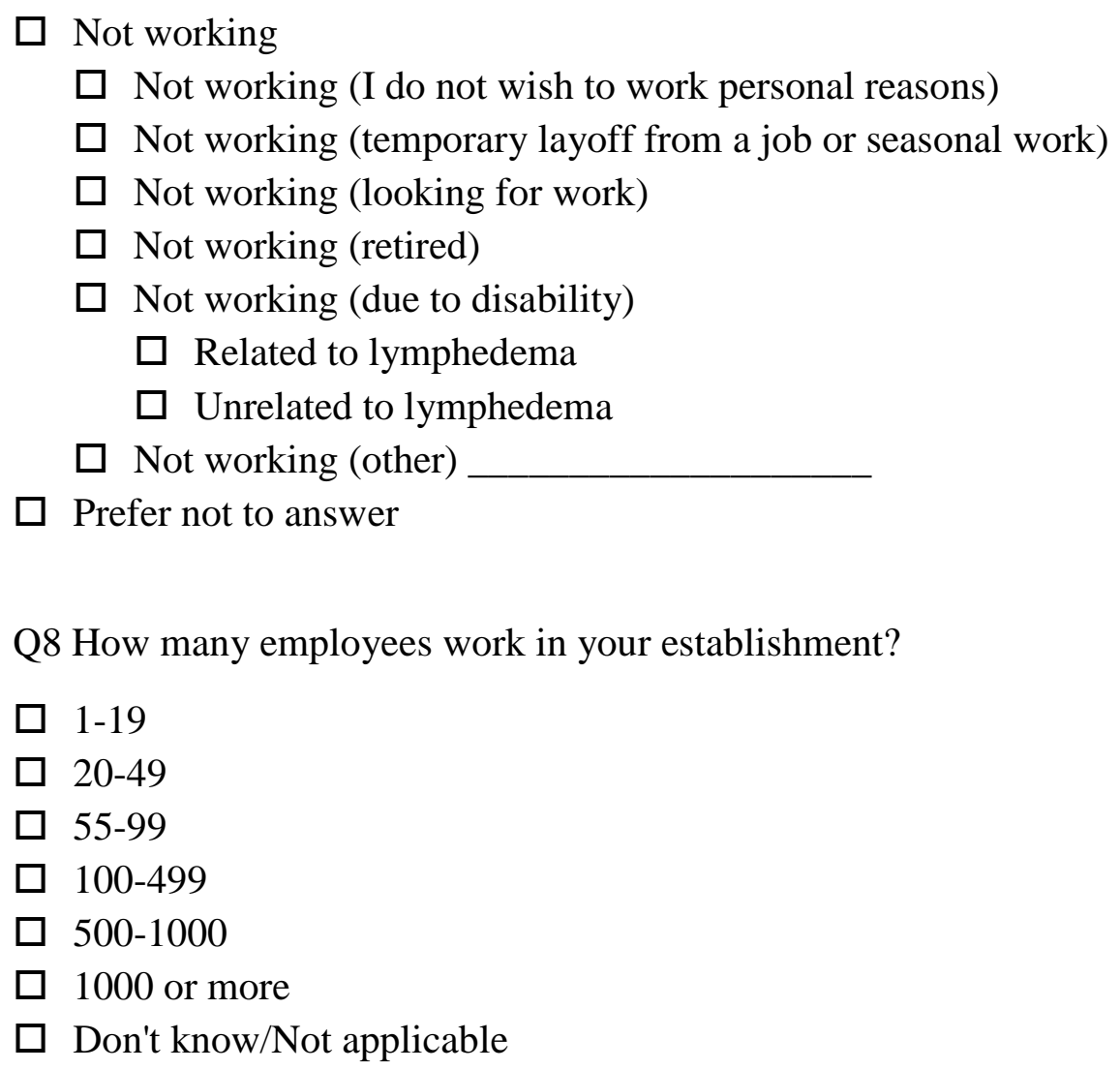


Q9 What was/is your occupation(s) Please indicate if they are before (B) or after (A) your lymphedema diagnosis on the line following your choices (select all that apply).

Managers (chief executives, legislators, etc.)

$\square$ Professionals (engineering, healthcare providers, teaching, business, softerware developers, data analysts, legal and cultural, etc.)

$\square$ Technicians and associate professionals

$\square$ Clerical support workers (general keyboard, customer service, material recording, etc.)

$\square$ Service and sales workers (travel attendants, cooks, childcare and teachers' aides, personal care, etc.)

$\square$ Skilled agricultural, forestry and fishery workers

$\square$ Craft and related trades workers (building, metal, machinery trades, food processing, wood working)

$\square$ Plant and machine operators, and assemblers (stationary/mobile plant operators, drivers)

$\square$ Elementary occupations (cleaners, agricultural forestry and fishery laborers, street sakes, etc.)

$\square$ Armed forces occupations

$\square$ Retired

$\square$ Unemployed

$\square$ others

Q10 How did/do you commute to work daily since diagnosis of lymphedema (select all that apply)?

$\square$ Walk

$\square$ Drive

$\square$ Take public transportation

$\square$ Ride with others/assist by others

$\square$ Others

Q11 How long does it take to commute to work (in minutes) each day in average? At the time of lymphedema diagnosis currently if different 
Q12 What was your marital and relationship status at the time of your lymphedema diagnosis?

Married

$\square$ Widowed

$\square$ Divorced

$\square$ Separated

$\square$ Never Married

Q13 How many persons have been in your household SINCE your diagnosis of lymphedema?

Q14 How do you describe your health insurance SINCE your breast cancer and lymphedema diagnosis? (Select all that apply). Please indicate the date (mm/yy-mm/yy) on the line following each of your choice.

Private

Through employer

Catastrophic coverage only

Through Affordable Care Act

$\square$ Medicare

$\square$ Medicaid

$\square$ Other(s), Please explain

Q15 How do you describe your overall health and well-being? Please indicate if they are before (B) or after (A) your lymphedema diagnosis on the line following your choices.

$\square$ In good physical, mental or emotional health. (No significant illnesses or disabilities. Only routine medical care such as annual checkups required.)

$\square$ Mildly physically, mental or emotional impaired. (You have only minor illnesses and/or disabilities which might benefit from medical treatment or corrective measures.)

$\square$ Moderately physically, mental or emotional impaired. (You have one or more diseases or disabilities which are either painful or which require substantial medical treatment.)

$\square$ Severely physically, mental or emotional impaired. (You have one or more illnesses or disabilities which are either severely painful or life threatening, or which require extensive medical treatment.)

$\square$ Totally physically, mental or emotional impaired. (Confined to bed and requiring fulltime medical assistance or nursing care to maintain vital bodily functions.) 
Q16 What other chronic diseases/health conditions do you have? [See the doctor for or take medicine for?] Please type the information on the line below.

Q17 Did you have lymphedema before the breast cancer?

$\square$ Yes. Please describe

$\square$ No

Q 18 Which side of your body was treated for breast cancer?

$\square$ Left

$\square$ Right

$\square$ Both

Q19 How did you initially know/suspect that you had developed lymphedema or something was wrong with your extremity? (Select all that apply)

$\square$ Referral by nurse, physical therapist, occupational therapist, or other clinicians.

$\square$ Follow up with primary care doctor(s)

$\square$ Follow up with specialist(s)

$\square$ Involved in research projects on lymphedema and survivorship

$\square$ Detected by self and sought medical diagnosis

$\square$ Others, please describe

Q20 Breast cancer treatment

Date of diagnosis with breast cancer

Date of surgery

Date of last radiation

Date of last chemotherapy

Date of lymphedema diagnosis

Date of other treatment complications 
Q21 Is your side affected by lymphedema your dominant extremity (including the hand, the arm, axilla and shoulder)?

$\square$ Yes

$\square$ No

Q 22 Have you experienced any symptoms below or any other symptoms or discomfort since you were diagnosed with lymphedema? Please describe the location, since when and any thoughts about the causes. (Select all that apply)

$\square$ Weakness of arm, hand.

$\square$ Limited movement of shoulder, elbow, wrist, fingers, etc.?

$\square$ Swelling

$\square$ Heaviness

$\square$ Redness

$\square$ Firmness/tightness

$\square$ Blistering

$\square$ Increased temperature in arm

$\square$ Numbness

$\square$ Stiffness

$\square$ Aching

$\square$ Sleep problem through the night because of the discomfort through the night.

$\square$ Other symptoms and discomfort 
Q23 Type of surgery for treatment of breast cancer (select all that apply)

Lumpectomy

$\square$ Mastectomy (left)

$\square$ Mastectomy (right)

$\square$ Mastectomy (both

$\square$ Prophylactic mastectomy

$\square$ Lymph node removal (Number of nodes, if known

$\square$ Prophylactic ovary removal

$\square$ Cryotherapy

$\square$ Reconstruction

$\square$ Others

$\square$ I am not sure.

$\square$ I have not had surgery.

Q24 Type of Radiation (Select all that apply).

External (CIRCLE the treatment sites: to breast, to axilla, to ovaries; Number of treatments, if known

$\square$ Internal (also called "brachytherapy")

$\square$ I am not sure.

$\square$ I have not had radiation.

Q25 Please tell about the amount of social support you receive from your family, friends, etc? When you have the need to talk to someone or go on outings with friends and/or relatives, do you feel there is someone who fulfills these needs?

$\square$ High degree of social support. (Much support is either given or is available, if needed, from family and friends.)

$\square$ Above average degree of social support. (Given or potentially available from family and friends.)

$\square$ Average degree of social support from family and friends is given or potentially available.

Below average degree of social support. (While some support is available, it's not consistently available)

No support or potential support is available from either family or friends.

Q26 What other health and employment information which we have not asked about would you like to provide. 
Thank you for your time. 


\section{APPENDIX D \\ License for Reuse of Published Manuscript (Chapter Two)}

\section{SPRINGER NATURE LICENSE \\ TERMS AND CONDITIONS}

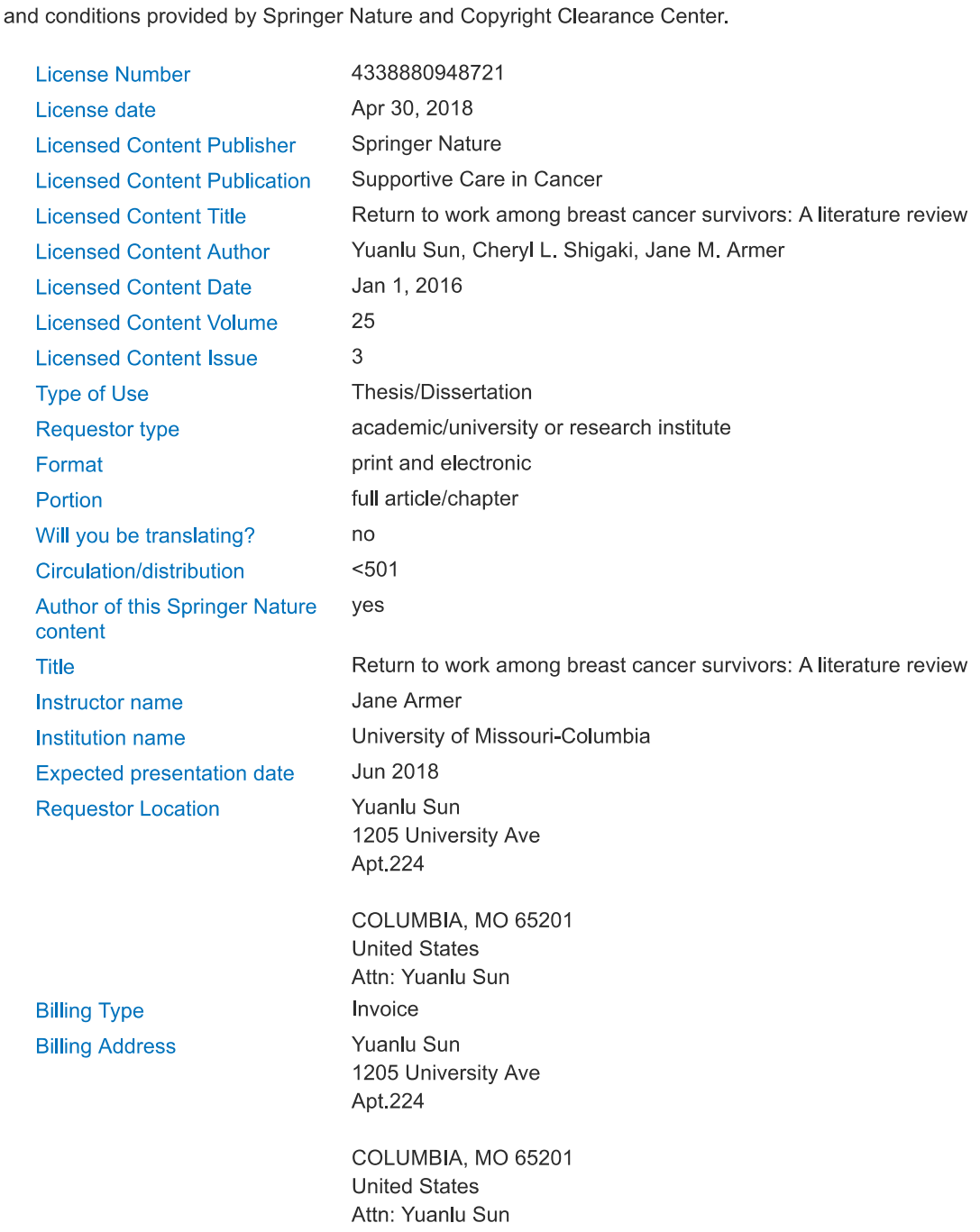


Total

0.00 USD

Terms and Conditions

\section{Springer Nature Terms and Conditions for RightsLink Permissions}

Springer Customer Service Centre GmbH (the Licensor) hereby grants you a non-exclusive, world-wide licence to reproduce the material and for the purpose and requirements specified in the attached copy of your order form, and for no other use, subject to the conditions below:

1. The Licensor warrants that it has, to the best of its knowledge, the rights to license reuse of this material. However, you should ensure that the material you are requesting is original to the Licensor and does not carry the copyright of another entity (as credited in the published version).

If the credit line on any part of the material you have requested indicates that it was reprinted or adapted with permission from another source, then you should also seek permission from that source to reuse the material.

2. Where print only permission has been granted for a fee, separate permission must be obtained for any additional electronic re-use.

3. Permission granted free of charge for material in print is also usually granted for any electronic version of that work, provided that the material is incidental to your work as a whole and that the electronic version is essentially equivalent to, or substitutes for, the print version.

4. A licence for 'post on a website' is valid for 12 months from the licence date. This licence does not cover use of full text articles on websites.

5. Where 'reuse in a dissertation/thesis' has been selected the following terms apply: Print rights for up to 100 copies, electronic rights for use only on a personal website or institutional repository as defined by the Sherpa guideline (www.sherpa.ac.uk/romeo/).

6. Permission granted for books and journals is granted for the lifetime of the first edition and does not apply to second and subsequent editions (except where the first edition permission was granted free of charge or for signatories to the STM Permissions Guidelines http://www.stm-assoc.org/copyright-legal-affairs/permissions/permissions-guidelines/), and does not apply for editions in other languages unless additional translation rights have been granted separately in the licence.

7. Rights for additional components such as custom editions and derivatives require additional permission and may be subject to an additional fee. Please apply to Journalpermissions@springernature.com/bookpermissions@springernature.com for these rights.

8. The Licensor's permission must be acknowledged next to the licensed material in print. In electronic form, this acknowledgement must be visible at the same time as the figures/tables/illustrations or abstract, and must be hyperlinked to the journal/book's homepage. Our required acknowledgement format is in the Appendix below.

9. Use of the material for incidental promotional use, minor editing privileges (this does not include cropping, adapting, omitting material or any other changes that affect the meaning, intention or moral rights of the author) and copies for the disabled are permitted under this licence.

10. Minor adaptations of single figures (changes of format, colour and style) do not require the Licensor's approval. However, the adaptation should be credited as shown in Appendix below.

\section{Appendix - Acknowledgements:}

\section{For Journal Content:}


Reprinted by permission from [the Licensor]: [Journal Publisher (e.g. Nature/Springer/Palgrave)] [JOURNAL NAME] [REFERENCE CITATION (Article name, Author(s) Name), [COPYRIGHT] (year of publication)

For Advance Online Publication papers:

Reprinted by permission from [the Licensor]: [Journal Publisher (e.g. Nature/Springer/Palgrave)] [JOURNAL NAME] [REFERENCE CITATION (Article name, Author(s) Name), [COPYRIGHT] (year of publication), advance online publication, day month year (doi: 10.1038/sj.[JOURNAL ACRONYM].)

For Adaptations/Translations:

Adapted/Translated by permission from [the Licensor]: [Journal Publisher (e.g. Nature/Springer/Palgrave)] [JOURNAL NAME] [REFERENCE CITATION (Article name, Author(s) Name), [COPYRIGHT] (year of publication)

Note: For any republication from the British Journal of Cancer, the following credit line style applies:

Reprinted/adapted/translated by permission from [the Licensor]: on behalf of Cancer Research UK: : [Journal Publisher (e.g. Nature/Springer/Palgrave)] [JOURNAL NAME] [REFERENCE CITATION (Article name, Author(s) Name), [COPYRIGHT] (year of publication)

For Advance Online Publication papers:

Reprinted by permission from The [the Licensor]: on behalf of Cancer Research UK: [Journal Publisher (e.g. Nature/Springer/Palgrave)] [JOURNAL NAME] [REFERENCE CITATION (Article name, Author(s) Name), [COPYRIGHT] (year of publication), advance online publication, day month year (doi: 10.1038/sj.[JOURNAL ACRONYM])

For Book content:

Reprinted/adapted by permission from [the Licensor]: [Book Publisher (e.g. Palgrave Macmillan, Springer etc) [Book Title] by [Book author(s)] [COPYRIGHT] (year of publication)

Other Conditions:

Version 1.0

Questions? customercare@copyright.com or +1-855-239-3415 (toll free in the US) or +1-978-646-2777. 


\section{APPENDIX E}

\section{Supplementary Table for Chapter Two}

\begin{tabular}{|c|c|c|c|c|c|c|}
\hline Author \& Year & Objectives & $\begin{array}{l}\text { Study design/data } \\
\text { collection }\end{array}$ & Sample/ Country & Outcomes/variables & Findings & Conclusion/implication \\
\hline \multicolumn{7}{|l|}{ Qualitative studies } \\
\hline $\begin{array}{l}\text { Blinder, Murphy, } \\
\text { et al. (2012) }\end{array}$ & $\begin{array}{l}\text { Explore the } \\
\text { experience of } \\
\text { RTW in } \\
\text { immigrant and } \\
\text { minority } \\
\text { survivors. }\end{array}$ & $\begin{array}{l}\text { Exploratory qualitative } \\
\text { study } \\
\text { Ethnically cohesive } 6 \\
\text { focus groups. } \\
\text { Audio- and video- } \\
\text { recorded, transcribed, } \\
\text { thematically coded. }\end{array}$ & $\begin{array}{l}23 \text { urban female } \\
\text { BCS: African- } \\
\text { American (3), } \\
\text { African-Caribbean } \\
\text { (5), Chinese (5), } \\
\text { Filipina (4), Latina } \\
\text { (3), non-Latina } \\
\text { white (3). } \\
\text { U.S. }\end{array}$ & $\begin{array}{l}\text { Outcomes: return to } \\
\text { work } \\
\text { Variables: Individual } \\
\text { Ethnicity, work } \\
\text { environment (employer } \\
\text { support: schedule } \\
\text { flexibility, medical } \\
\text { confidentiality, } \\
\text { normalcy). Few } \\
\text { differences between } \\
\text { ethnic groups., } \\
\text { experience of RTW. }\end{array}$ & $\begin{array}{l}7 \text { themes: normalcy, } \\
\text { acceptance, identity, } \\
\text { appearance, privacy, lack } \\
\text { of flexibility at work, } \\
\text { employer support. } \\
\text { Normalcy is common in } \\
\text { each group; Acceptance } \\
\text { of diagnosis is common } \\
\text { in Chinese; Appearance } \\
\text { in all except Chinese } \\
\text { (who are related to } \\
\text { privacy). }\end{array}$ & $\begin{array}{l}\text { Improving support } \\
\text { services to and clinical } \\
\text { management of employed } \\
\text { BCS women was } \\
\text { important }\end{array}$ \\
\hline $\begin{array}{l}\text { Boykoff, Moieni, } \\
\text { and Subramanian } \\
\text { (2009) }\end{array}$ & $\begin{array}{l}\text { Documented } \\
\text { the effects of } \\
\text { Chemo-brain } \\
\text { on BCS' } \\
\text { professional } \\
\text { life. }\end{array}$ & $\begin{array}{l}\text { Qualitative: } \\
\text { phenomenology } \\
\text { Focus group and in- } \\
\text { depth interview. }\end{array}$ & $\begin{array}{l}74 \text { white and } \\
\text { African American } \\
\text { BCS in CA who } \\
\text { experienced post- } \\
\text { treatment side } \\
\text { effects. }\end{array}$ & $\begin{array}{l}\text { Outcome: personal and } \\
\text { professional work } \\
\text { difficulties. } \\
\text { Variables: Cognitive } \\
\text { function }\end{array}$ & $\begin{array}{l}\text { Cognitive impairment } \\
\text { was reported by many } \\
\text { BCS as the most } \\
\text { troublesome symptoms } \\
\text { which diminished the } \\
\text { quality of life (QoL) }\end{array}$ & $\begin{array}{l}\text { Cognitive impairment has } \\
\text { negative effects on many } \\
\text { BCS’ professional life. }\end{array}$ \\
\hline
\end{tabular}




\begin{tabular}{|c|c|c|c|c|c|c|}
\hline Author \& Year & Objectives & $\begin{array}{l}\text { Study design/data } \\
\text { collection }\end{array}$ & Sample/ Country & Outcomes/variables & Findings & Conclusion/implication \\
\hline $\begin{array}{l}\text { Munir, Burrows, } \\
\text { Yarker, } \\
\text { Kalawsky, and } \\
\text { Bains (2010) }\end{array}$ & $\begin{array}{l}\text { Investigate the } \\
\text { awareness of } \\
\text { chemo- } \\
\text { induced } \\
\text { cognitive } \\
\text { change and the } \\
\text { perceptions of } \\
\text { the influences } \\
\text { the change } \\
\text { make on work } \\
\text { ability. }\end{array}$ & $\begin{array}{l}\text { Qualitative study: } \\
\text { phenomenology } \\
\text { Semi-structured } \\
\text { interviews with two } \\
\text { focus groups ( } \mathrm{n}=6, \mathrm{n} \\
=7 \text { ). } \\
\text { 25-item Cognitive } \\
\text { Failures Questionnaire }\end{array}$ & $\begin{array}{l}\text { 13 BCS (6 support } \\
\text { group, } 7 \text { other) } \\
\text { Mean age: } 48.8 \text { yr } \\
\text { at study, } 43.3 \text { at } \\
\text { diagnosis. }\end{array}$ & $\begin{array}{l}\text { Outcomes: return to } \\
\text { work, work ability } \\
\text { Variables: cognitive } \\
\text { functions (awareness, } \\
\text { actual function). }\end{array}$ & $\begin{array}{l}4 \text { themes: (1) awareness } \\
\text { of cognitive changes } \\
\text { during and following } \\
\text { chemo; (2) cognitive } \\
\text { ability and confidence } \\
\text { RTW; (3) impact of } \\
\text { cognitive changes on } \\
\text { work ability, } \\
\text { (4) cognitive side effects } \\
\text { of chemo info. }\end{array}$ & $\begin{array}{l}\text { RTW and work ability } \\
\text { were affected by chemo- } \\
\text { induced cognitive } \\
\text { impairment. } \\
\text { Specifically: actual } \\
\text { cognitive ability, } \\
\text { awareness of cognitive } \\
\text { failures, subsequent } \\
\text { impact on confidence. }\end{array}$ \\
\hline $\begin{array}{l}\text { Tamminga, de } \\
\text { Boer, Verbeek, } \\
\text { \& Frings-Dresen } \\
\text { (2012) }\end{array}$ & $\begin{array}{l}\text { *Explore the } \\
\text { barriers and } \\
\text { facilitators that } \\
\text { affect RTW. } \\
\text { *And } \\
\text { important } \\
\text { factors during } \\
\text { initial and post } \\
\text { RTW. } \\
\text { *Identify } \\
\text { possible } \\
\text { solution. }\end{array}$ & $\begin{array}{l}\text { Qualitative study: } \\
\text { approach unsure } \\
\text { semi-structured } \\
\text { interviews }\end{array}$ & $\begin{array}{l}12 \text { breast cancer } \\
\text { survivors } \\
\text { Mean age: } 42 \text { yrs } \\
\text { (SD=7) } \\
\text { All Dutch culture } \\
\text { background. }\end{array}$ & $\begin{array}{l}\text { Outcomes: RTW } \\
\text { Variables: Work } \\
\text { environment } \\
\text { (supervisors' support, } \\
\text { importance of work), } \\
\text { work demands (physical, } \\
\text { psycho), Function } \\
\text { (physical/psychological } \\
\text { side-effects), Individual } \\
\text { Characteristics } \\
\text { (temperament and } \\
\text { personality functions, } \\
\text { "job lock", coping skill), } \\
\text { societal factors (family }\end{array}$ & $\begin{array}{l}\text { Initial phase of RTW key } \\
\text { concern: physical- } \\
\text { psychological side- } \\
\text { effects. Post-RTW: } \\
\text { deficit knowledge of } \\
\text { work environment. } \\
\text { Solution: guidance from } \\
\text { health professionals. } \\
\text { Information for } \\
\text { supervisors and } \\
\text { colleagues. }\end{array}$ & $\begin{array}{l}\text { Individual specific } \\
\text { barriers and facilitators at } \\
\text { different time points } \\
\text { should be examined. } \\
\text { Guidance from } \\
\text { professionals and } \\
\text { information for colleagues } \\
\text { will help. }\end{array}$ \\
\hline
\end{tabular}




\begin{tabular}{|c|c|c|c|c|c|c|}
\hline Author \& Year & Objectives & $\begin{array}{l}\text { Study design/data } \\
\text { collection }\end{array}$ & Sample/ Country & Outcomes/variables & Findings & Conclusion/implication \\
\hline & & & & $\begin{array}{l}\text { and healthcare } \\
\text { professionals’ support). }\end{array}$ & & \\
\hline $\begin{array}{l}\text { Tan, Loh, Su, } \\
\text { Veloo, \& Ng } \\
\text { (2012) }\end{array}$ & $\begin{array}{l}\text { Explore the } \\
\text { barriers and } \\
\text { facilitators that } \\
\text { affect RTW. }\end{array}$ & $\begin{array}{l}\text { Qualitative study: } \\
\text { Thematic analysis } \\
\text { using constant- } \\
\text { comparative method } \\
\text { (grounded theory), and } \\
\text { data management } \\
\text { aided by Vivo-9 } \\
\text { Semi-structured } \\
\text { interview: six focus } \\
\text { groups (6-8 survivors } \\
\text { each, stratified } \\
\text { according to ethnic } \\
\text { and RTW status) }\end{array}$ & $\begin{array}{l}40 \text { employed } \\
\text { multiethnic breast } \\
\text { cancer survivors } \\
\text { Age range: non- } \\
\text { RTW 40-58 yrs, } \\
\text { RTW 21-54 yrs }\end{array}$ & $\begin{array}{l}\text { Outcomes: Return to } \\
\text { work } \\
\text { Influential factors: } \\
\text { function (physical and } \\
\text { emotional), Work } \\
\text { environment, work } \\
\text { demands, economic } \\
\text { status, social culture } \\
\text { influence. }\end{array}$ & $\begin{array}{l}\text { Barriers: physical and } \\
\text { psychological effects of } \\
\text { treatment and worry of } \\
\text { environmental hazards, } \\
\text { high physical job } \\
\text { demands, negative } \\
\text { thoughts, over protective } \\
\text { family. } \\
\text { Facilitators: social } \\
\text { support, employer } \\
\text { support, pursuing } \\
\text { financial independence. }\end{array}$ & $\begin{array}{l}\text { Occupational } \\
\text { rehabilitation consultation } \\
\text { should be provided by } \\
\text { health professionals. } \\
\text { Prognostic factors may } \\
\text { guide clinical efforts to } \\
\text { restore occupational } \\
\text { function for survivors' } \\
\text { desired work, } \\
\text { productivity, and well- } \\
\text { being. }\end{array}$ \\
\hline $\begin{array}{l}\text { Tiedtke, de Rijk, } \\
\text { Donceel, } \\
\text { Christiaens, \& de } \\
\text { Casterle (2012) }\end{array}$ & $\begin{array}{l}\text { Explore the } \\
\text { considerations } \\
\text { of return to } \\
\text { work, and how } \\
\text { they relate to } \\
\text { social } \\
\text { environment. }\end{array}$ & $\begin{array}{l}\text { Qualitative study: } \\
\text { ground theory } \\
\text { (QUAGOL): Constant } \\
\text { data comparison and } \\
\text { interactive team } \\
\text { dialogue about } \\
\text { reflections and }\end{array}$ & $\begin{array}{l}22 \text { breast cancer } \\
\text { employees } \\
\text { Mean age } 46 \\
1-3 \text { yrs post- } \\
\text { surgery }\end{array}$ & $\begin{array}{l}\text { Outcomes: Return to } \\
\text { work } \\
\text { Influential factors: work } \\
\text { environment, individual } \\
\text { psycho/personality; and } \\
\text { economic characteristics }\end{array}$ & $\begin{array}{l}\text { Four considerations prior } \\
\text { to RTW: 1) wish to keep } \\
\text { job; 2) is it worth the } \\
\text { effort; 3) capacity; 4) } \\
\text { acceptability in working } \\
\text { place (Uncertainty and } \\
\text { vulnerability). }\end{array}$ & $\begin{array}{l}\text { Social environment } \\
\text { (people in the work place) } \\
\text { can have positive or } \\
\text { negative influences on the } \\
\text { survivors' vulnerability } \\
\text { during mental preparation } \\
\text { for RTW }\end{array}$ \\
\hline
\end{tabular}

In-depth interviews $\quad$ Belgium 


\begin{tabular}{|c|c|c|c|c|c|c|}
\hline Author \& Year & Objectives & $\begin{array}{l}\text { Study design/data } \\
\text { collection }\end{array}$ & Sample/ Country & Outcomes/variables & Findings & Conclusion/implication \\
\hline $\begin{array}{l}\text { Tiedtke, } \\
\text { Donceel, et al. } \\
\text { (2012) }\end{array}$ & $\begin{array}{l}\text { Explore the } \\
\text { relationship } \\
\text { between public } \\
\text { health policy } \\
\text { and practice } \\
\text { regarding } \\
\text { RTW among } \\
\text { BCS. }\end{array}$ & $\begin{array}{l}\text { Qualitative study: } \\
\text { Focus group Interview } \\
3 \text { groups included a } \\
\text { variety of physician } \\
\text { specialties, employers } \\
\text { and consumer } \\
\text { advocates } \\
\text { Thematic analysis, } \\
\text { consistent comparison. }\end{array}$ & $\begin{array}{l}27 \text { participants: } 4 \\
\text { treating physicians, } \\
6 \text { employers, } 3 \\
\text { social security } \\
\text { physicians, } 4 \\
\text { occupational } \\
\text { physicians, } 5 \\
\text { survivors, } 4 \\
\text { representatives of } \\
\text { patient. }\end{array}$ & $\begin{array}{l}\text { Outcomes: RTW } \\
\text { Variables: Health } \\
\text { professional support, } \\
\text { Function, work } \\
\text { environment (support) }\end{array}$ & $\begin{array}{l}\text { 1) BCS felt ill-informed } \\
\text { about RTW options and } \\
\text { experienced supportive } \\
\text { or discriminatory } \\
\text { attitudes from } \\
\text { colleagues; 2) Physicians } \\
\text { lack competence in work } \\
\text { advisement; 3) } \\
\text { employers: balance the } \\
\text { interests and the } \\
\text { employee.4) Social } \\
\text { security physicians: } \\
\text { assess work ability and } \\
\text { facilitate RTW options; } \\
\text { 5) OT: need legislation } \\
\text { support their } \\
\text { involvement. }\end{array}$ & $\begin{array}{l}\text { Stakeholders' } \\
\text { coordination and to } \\
\text { facilitate BCS' needs } \\
\text { through flexible with the } \\
\text { legislation to support the } \\
\text { RTW process. }\end{array}$ \\
\hline $\begin{array}{l}\text { Schmalenberger, } \\
\text { Gessert, } \\
\text { Giebenhain, and } \\
\text { Starr (2012b) }\end{array}$ & $\begin{array}{l}\text { To examine } \\
\text { the impact of } \\
\text { breast cancer } \\
\text { on musicians' } \\
\text { working life. }\end{array}$ & $\begin{array}{l}\text { Qualitative: type is } \\
\text { unsure } \\
\text { Individual telephone } \\
\text { interview }\end{array}$ & $\begin{array}{l}38 \text { BCS who are } \\
\text { musician } \\
\text { median age: } 53 \text { yrs } \\
\text { (range 31-78) } \\
\text { United States }\end{array}$ & $\begin{array}{l}\text { Outcomes: work } \\
\text { performance, experience. } \\
\text { Variables: adverse } \\
\text { effects, decreased } \\
\text { physical function, unmet } \\
\text { work demands, health } \\
\text { care providers' support, } \\
\text { coping skill (regain } \\
\text { control over their lives }\end{array}$ & $\begin{array}{l}4 \text { themes: 1) impact of } \\
\text { the adverse effects 2) the } \\
\text { need to be understood as } \\
\text { professionals (musician); } \\
\text { 3) the efforts to regain a } \\
\text { sense of control over } \\
\text { their lives and work; 4) } \\
\text { integration of individual } \\
\text { cancer experience into } \\
\text { musical work and their } \\
\text { world views. }\end{array}$ & $\begin{array}{l}\text { The identities as Musician } \\
\text { after diagnosis and } \\
\text { treatment of breast cancer } \\
\text { were threatened. } \\
\text { Musician survivors } \\
\text { integrated their breast } \\
\text { cancer experience into } \\
\text { their work. }\end{array}$ \\
\hline
\end{tabular}




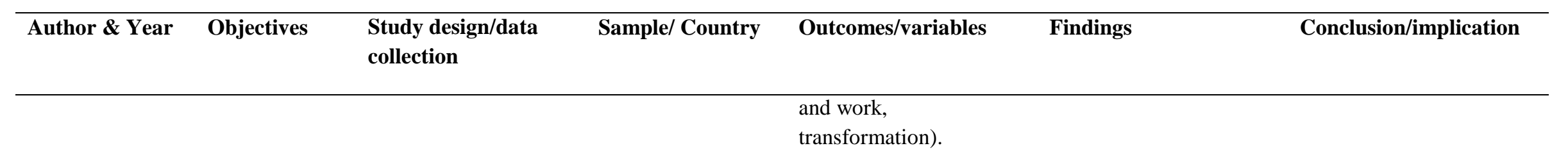

\section{Quantitative studies}

\begin{tabular}{|c|c|c|c|c|c|c|}
\hline Ahn et al. (2009) & $\begin{array}{l}\text { Employment } \\
\text { status and } \\
\text { ability in } \\
\text { Korean BCS } \\
\text { women. }\end{array}$ & $\begin{array}{l}\text { Questionnaire: } \\
\text { sociodemographic } \\
\text { characteristics, } \\
\text { Clinical characteristics }\end{array}$ & $\begin{array}{l}1594 \text { BCS vs. } 415 \\
\text { disease- free. } \\
\text { Age } 20-60 \text { yr. } \\
\text { BCS: } 22.4 \%<=39 \\
\text { yrs, } 48.5 \% \text { 40-49 } \\
\text { yrs, } 2.1 \% \text { 50-59 yrs } \\
\text { South Korea }\end{array}$ & $\begin{array}{l}\text { Outcomes: return to } \\
\text { work } \\
\text { Variables: age, } \\
\text { educational level, marital } \\
\text { status, place of } \\
\text { residency, household } \\
\text { income. Comorbidities, } \\
\text { disease stage, elapsed } \\
\text { time since last surgery, } \\
\text { type of surgery, health } \\
\text { well-being, symptoms. }\end{array}$ & $\begin{array}{l}\text { Employment } \\
\text { significantly decreased } \\
\text { in BCS group. } \\
\text { Low levels of education, } \\
\text { low household income, } \\
\text { multiple comorbidities, } \\
\text { disease stage, and } \\
\text { mastectomy have inverse } \\
\text { association in } \\
\text { employment. Living } \\
\text { with spouse more likely } \\
\text { to not RTW. } \\
\text { fatigue, exhaustion most } \\
\text { frequent reported } \\
\text { difficulties. }\end{array}$ & $\begin{array}{l}\text { Impact of Breast cancer } \\
\text { on Korean women is } \\
\text { greater than on western. } \\
\text { Socio-cultural factors, } \\
\text { certain clinical } \\
\text { characteristics influence } \\
\text { the RTW. }\end{array}$ \\
\hline
\end{tabular}




\begin{tabular}{|c|c|c|c|c|c|c|}
\hline Author \& Year & Objectives & $\begin{array}{l}\text { Study design/data } \\
\text { collection }\end{array}$ & Sample/ Country & Outcomes/variables & Findings & Conclusion/implication \\
\hline & $\begin{array}{l}\text { symptoms on } \\
\text { it. }\end{array}$ & $\begin{array}{l}\text { Followed for } 24 \\
\text { months after } \\
\text { diagnosis. }\end{array}$ & Netherlands & $\begin{array}{l}\text { function (Reaching } \\
\text { above shoulder level) } \\
\text { symptoms (fatigue). }\end{array}$ & $\begin{array}{l}\text { Reaching above shoulder } \\
\text { level }(11,15 \%) \\
\text { significantly correlated } \\
\text { to delayed RTW; fatigue } \\
(9,13 \%)\end{array}$ & \\
\hline $\begin{array}{l}\text { Calvio, Peugeot, } \\
\text { Bruns, Todd, and } \\
\text { Feuerstein } \\
\text { (2010) }\end{array}$ & $\begin{array}{l}\text { Investigate } \\
\text { performance- } \\
\text { based and self- } \\
\text { reported } \\
\text { cognitive } \\
\text { limitation in } \\
\text { work. }\end{array}$ & $\begin{array}{l}\text { Quantitative: case- } \\
\text { control } \\
\text { Questionnaire: work } \\
\text { limitation } \\
\text { questionnaire (WLQ), } \\
\text { hospital anxiety and } \\
\text { depression scale, } \\
\text { MFSI-SF, behavior } \\
\text { risk factor survey, } \\
\text { CSC, VAS }\end{array}$ & $\begin{array}{l}122 \text { BCS vs. } 113 \\
\text { non-cancers. } \\
\text { Mean age: BCS } \\
44.88 \text { yrs } \\
\text { (SD=9.51), non- } \\
\text { cancer group } 39.18 \\
\text { yrs (SD=11.78) } \\
3 \text { yrs post- } \\
\text { treatment. } \\
\text { U.S. }\end{array}$ & $\begin{array}{l}\text { Work output } \\
\text { (performance) } \\
\text { Variables: Symptoms } \\
\text { (distress, fatigue). } \\
\text { Functions (cognitive), } \\
\text { work stress, Medical and } \\
\text { personal characters }\end{array}$ & $\begin{array}{l}\text { Patient-reported } \\
\text { cognitive limitations at } \\
\text { work related to output } \\
\text { only in BCS. }\end{array}$ & $\begin{array}{l}\text { Carefully follow-up } \\
\text { cognitive problems at } \\
\text { work. }\end{array}$ \\
\hline $\begin{array}{l}\text { Carlsen et al. } \\
\text { (2013) }\end{array}$ & $\begin{array}{l}\text { Investigate the } \\
\text { work ability } \\
\text { differences } \\
\text { between long } \\
\text { term BCS \& } \\
\text { cancer-free } \\
\text { group. }\end{array}$ & $\begin{array}{l}\text { Quantitative: cross- } \\
\text { sectional } \\
\text { Questionnaire: single } \\
\text { question (BCS gave } \\
\text { themselves a score on } \\
\text { a full 10-point scale } \\
\text { for their work ability); } \\
5 \text { questions from } \\
\text { General Nordic } \\
\text { Questionnaire (about }\end{array}$ & $\begin{array}{l}170 \text { BCS matched } \\
\text { with } 391 \text { cancer- } \\
\text { free. Diagnosed } \\
1997-2000 . \\
\text { Age mean: BCS } \\
54.2 \text { yrs, cancer- } \\
\text { free } 52.4 \text { yrs } \\
\text { Denmark }\end{array}$ & $\begin{array}{l}\text { Outcomes: work ability } \\
\text { Variables: individual } \\
\text { characters, symptoms, } \\
\text { work environment }\end{array}$ & $\begin{array}{l}\text { BCS reported poorer } \\
\text { work ability. } \\
\text { Factors strongly } \\
\text { associated with work } \\
\text { ability: low income, } \\
\text { fatigue, little help and } \\
\text { support from a } \\
\text { supervisor. }\end{array}$ & $\begin{array}{l}\text { The work ability of long- } \\
\text { term BCS who are } \\
\text { disease-free and RTW is } \\
\text { impaired. }\end{array}$ \\
\hline
\end{tabular}




\begin{tabular}{|c|c|c|c|c|c|c|}
\hline Author \& Year & Objectives & $\begin{array}{l}\text { Study design/data } \\
\text { collection }\end{array}$ & Sample/ Country & Outcomes/variables & Findings & Conclusion/implication \\
\hline & & $\begin{array}{l}\text { colleagues and closest } \\
\text { supervisor). }\end{array}$ & & & & \\
\hline $\begin{array}{l}\text { Fantoni et al. } \\
\text { (2010) }\end{array}$ & $\begin{array}{l}\text { Explore } \\
\text { whether and } \\
\text { when the BCS } \\
\text { RTW. }\end{array}$ & $\begin{array}{l}\text { Quantitative study: } \\
\text { cohort study } \\
\text { 45-items } \\
\text { questionnaire. } \\
\text { Personal, clinical, } \\
\text { work related } \\
\text { characteristics }\end{array}$ & $\begin{array}{l}379 \text { BCS } \\
\text { 18-60 yrs (mean: } \\
48.3 \text { yrs at } \\
\text { diagnosis) } \\
\text { Follow-up } 36 \\
\text { months since } \\
\text { diagnosis } \\
\text { France }\end{array}$ & $\begin{array}{l}\text { Out comes: Return to } \\
\text { work } \\
\text { Variables: individual } \\
\text { medical characters } \\
\text { (educational level), } \\
\text { symptoms, work } \\
\text { environment }\end{array}$ & $\begin{array}{l}\text { 82.1\% RTW. Median } \\
\text { leave: } 10.8 \text { mons } \\
\text { Factors: older age, lower } \\
\text { educational level, chemo } \\
\text { and radio, lymphedema, } \\
\text { psychological or } \\
\text { organizational self- } \\
\text { perceived constraints } \\
\text { (related to their former } \\
\text { job), lack of moral } \\
\text { support from work } \\
\text { colleagues }\end{array}$ & $\begin{array}{l}\text { Self-perceived factors in } \\
\text { sick leave period and } \\
\text { more factors hindering } \\
\text { RTW should be explore. } \\
\text { Work resumption support } \\
\text { includes both personal } \\
\text { and environmental } \\
\text { factors. }\end{array}$ \\
\hline $\begin{array}{l}\text { Hakanen and } \\
\text { Lindbohm } \\
\text { (2008) }\end{array}$ & $\begin{array}{l}\text { Explore the } \\
\text { personal } \\
\text { resources and } \\
\text { job-related } \\
\text { resources as } \\
\text { influential } \\
\text { factors to } \\
\text { RTW. }\end{array}$ & $\begin{array}{l}\text { Quantitative: cross- } \\
\text { sectional } \\
\text { Online survey: Nordic } \\
\text { questionnaire study on } \\
\text { cancer and work life } \\
\text { (NOCWO) } \\
\text { Life Orientation Test } \\
\text { (LOT-R) }\end{array}$ & $\begin{array}{l}398 \text { employed } \\
\text { BCS; } 560 \text { referents. } \\
\text { Mean age: BCS } \\
51.5 \text { yrs, } 49.8 \text { yrs } \\
\text { Finnish or Swedish } \\
\text { speaking } \\
\text { Sweden }\end{array}$ & $\begin{array}{l}\text { Outcomes: RTW } \\
\text { Variables: Job resources } \\
\text { (work environment) } \\
\text { Personal resources } \\
\text { (Emotional function) }\end{array}$ & $\begin{array}{l}\text { Optimism and pessimism } \\
\text { strongly associated the } \\
\text { work engagement. } \\
\text { Avoidance behavior by } \\
\text { supervisors }\end{array}$ & $\begin{array}{l}\text { Optimism is important to } \\
\text { BCS' work related well- } \\
\text { being. }\end{array}$ \\
\hline
\end{tabular}




\begin{tabular}{|c|c|c|c|c|c|c|}
\hline Author \& Year & Objectives & $\begin{array}{l}\text { Study design/data } \\
\text { collection }\end{array}$ & Sample/ Country & Outcomes/variables & Findings & Conclusion/implication \\
\hline $\begin{array}{l}\text { Hansen, } \\
\text { Feuerstein, } \\
\text { Calvio, and } \\
\text { Olsen (2008) }\end{array}$ & $\begin{array}{l}\text { Elucidate the } \\
\text { symptoms } \\
\text { associated } \\
\text { with the } \\
\text { occupational } \\
\text { activity. }\end{array}$ & $\begin{array}{l}\text { Quantitative } \\
\text { Questionnaire: } \\
\text { medical survey, } \\
\text { Behavior Risk Factor } \\
\text { Surveillance survey, } \\
\text { multidimensional } \\
\text { fatigue symptom } \\
\text { Inventory-Short Form } \\
\text { (MFSI-SF), hospital } \\
\text { anxiety and } \\
\text { depressions scale, } \\
\text { cognitive symptom } \\
\text { checklist (CSC), WLQ }\end{array}$ & $\begin{array}{l}100 \text { employed BCS } \\
\text { vs. } 103 \text { non-cancer } \\
\text { Mean age: BCS } \\
49.5 \text { yrs, cancer- } \\
\text { free } 39.8 \text { yrs } \\
\text { U.S. }\end{array}$ & $\begin{array}{l}\text { Outcomes: work ability, } \\
\text { performance (sick leave) } \\
\text { Variables: medical } \\
\text { status, symptoms } \\
\text { (cognitive, depression, } \\
\text { anxiety, fatigue) } \\
\text { Health and social } \\
\text { behaviors (physical } \\
\text { activity, sleep). } \\
\text { Work stress experience }\end{array}$ & $\begin{array}{l}\text { At } 4 \text { yrs post-diagnosis. } \\
\text { BCS reported higher } \\
\text { level of work limitations. } \\
\text { Fatigue \& depression } \\
\text { interaction was } \\
\text { observed. Fatigue -work } \\
\text { limitation in BCS. } \\
\text { Depression-work } \\
\text { limitation in non-cancer. } \\
\text { Fatigue contribute } 71 \% \\
\text { symptom burden overall. }\end{array}$ & $\begin{array}{l}\text { Better understand and } \\
\text { manage of fatigue. }\end{array}$ \\
\hline $\begin{array}{l}\text { Hauglann, } \\
\text { Benth, Fossa, } \\
\text { and Dahl (2012) }\end{array}$ & $\begin{array}{l}\text { Explore the } \\
\text { disability due } \\
\text { to permanently } \\
\text { reduced work } \\
\text { ability in BCS. }\end{array}$ & $\begin{array}{l}\text { Quantitative: cohort } \\
\text { study } \\
\text { Medical data, national } \\
\text { official registries. } \\
\text { FD-Trygd }\end{array}$ & $\begin{array}{l}1548 \text { BCS vs. } 1548 \\
\text { disease-free. } \\
\text { Age: } 45-54 \text { yrs } \\
\text { Norway }\end{array}$ & $\begin{array}{l}\text { Outcomes: work } \\
\text { disability, return to work } \\
\text { rate } \\
\text { Variables: Social } \\
\text { demographic (age, } \\
\text { education, number of } \\
\text { children), Income and its } \\
\text { change }\end{array}$ & $\begin{array}{l}\text { BCS more likely } \\
\text { received disability } \\
\text { pension. } \\
\text { Hazard ratio increased } \\
\text { with mastectomy } \\
\text { compared to conserving } \\
\text { surgery. } \\
\text { BCS experienced a } \\
\text { temporary negative } \\
\text { effect on employment } \\
\text { income. }\end{array}$ & $\begin{array}{l}\text { Permanently reduced } \\
\text { work ability in a } \\
\text { considerable proportion. } \\
\text { Medical personnel should } \\
\text { help survivors with } \\
\text { rehabilitation and } \\
\text { workplace adjustment to } \\
\text { prevent early disability. }\end{array}$ \\
\hline
\end{tabular}




\begin{tabular}{|c|c|c|c|c|c|c|}
\hline Author \& Year & Objectives & $\begin{array}{l}\text { Study design/data } \\
\text { collection }\end{array}$ & Sample/ Country & Outcomes/variables & Findings & Conclusion/implication \\
\hline $\begin{array}{l}\text { Johnsson, } \\
\text { Fornander, } \\
\text { Rutqvist, and } \\
\text { Olsson (2011) }\end{array}$ & $\begin{array}{l}\text { Generating } \\
\text { factors } \\
\text { predicting } \\
\text { RTW among } \\
\text { women treated } \\
\text { for early stage. } \\
\text { Change of life, } \\
\text { satisfaction }\end{array}$ & $\begin{array}{l}\text { Quantitative: cohort } \\
\text { study } \\
\text { Questionnaire and } \\
\text { medical files (6 weeks, } \\
6 \text { months, } 10 \text { months } \\
\text { pot-surgery) }\end{array}$ & $\begin{array}{l}\text { 102 BCS } \\
\text { Age 18-64, } \mathrm{n}=32 \\
\text { (35-50 yrs), } \mathrm{n}=68 \\
\text { (51-63 yrs) } \\
\text { Sweden }\end{array}$ & $\begin{array}{l}\text { Outcomes: return to } \\
\text { work } \\
\text { Variables: Medical, } \\
\text { emotional/psychological } \\
\text { wellness, coping } \\
\text { resources }\end{array}$ & $\begin{array}{l}6 \text { month predictors } \\
\text { (inverse): chemo, low } \\
\text { satisfaction with } \\
\text { activities of daily living, } \\
\text { non-Sweden born. } \\
\text { Global life satisfaction is } \\
\text { higher in working BCS, } \\
\text { and they used more } \\
\text { coping resources }\end{array}$ & $\begin{array}{l}\text { More complex and } \\
\text { additional factors should } \\
\text { be detected. } \\
\text { Life satisfaction and } \\
\text { coping resources } \\
\text { associated with RTW. }\end{array}$ \\
\hline $\begin{array}{l}\text { Johnsson et al. } \\
\text { (2009) }\end{array}$ & $\begin{array}{l}\text { Assess factors } \\
\text { predicting } \\
\text { RTW in } \\
\text { women with } \\
\text { early stage } \\
\text { breast cancer }\end{array}$ & $\begin{array}{l}\text { Quantitative: cohort } \\
\text { study } \\
\text { Questionnaires: sense } \\
\text { of coherence (SOC3), } \\
\text { including items of sick } \\
\text { leave; medical files }\end{array}$ & $\begin{array}{l}102 \text { BCS } 18-64 \text { yrs } \\
\text { (1/3 BCS< } 51 \text { yrs), } \\
\text { early stage } \\
10 \text { months after } \\
\text { surgery } \\
\text { Majority Sweden }\end{array}$ & $\begin{array}{l}\text { Outcomes: return to } \\
\text { work } \\
\text { Influential variables: } \\
\text { work demands, medical } \\
\text { characters }\end{array}$ & $\begin{array}{l}59 \% \text { return to work. } 41 \% \\
\text { sick-listed part-time or } \\
\text { full time. } \\
\text { negative factors to RTW: } \\
\text { high-demand job, } \\
\text { axillary node dissection, } \\
\text { and treatment with } \\
\text { chemo. }\end{array}$ & $\begin{array}{l}\text { Treatment and high } \\
\text { demands of work play the } \\
\text { important role of RTW. }\end{array}$ \\
\hline $\begin{array}{l}\text { Lavigne, Griggs } \\
\text { et al. (2008) }\end{array}$ & $\begin{array}{l}\text { Investigated } \\
\text { the } \\
\text { relationship } \\
\text { among related } \\
\text { variables and } \\
\text { work } \\
\text { outcomes }\end{array}$ & $\begin{array}{l}\text { Quantitative: cohort } \\
\text { study. } \\
\text { Questionnaires: SF-36, } \\
\text { WLQ, self-reported } \\
\text { absences, }\end{array}$ & $\begin{array}{l}83 \text { BCS } \\
\text { 3-year post } \\
\text { treatment. } \\
\text { Diagnosis between } \\
\text { Dec. 1996-Dec. } \\
\text { 2002, had } \\
\text { radiation, finished }\end{array}$ & $\begin{array}{l}\text { Work productivity, } \\
\text { absence (performance) } \\
\text { Variables: medical } \\
\text { (treatment, sage, } \\
\text { comorbidities), hot } \\
\text { flashes, fatigue, mental } \\
\text { health, overall health, } \\
\text { individual characteristics }\end{array}$ & $\begin{array}{l}\text { Productivity reduction: } \\
\text { BCS } 3.1 \% \text { below healthy } \\
\text { worker. Loss of } 2.48 \text { hrs } \\
\text { biweekly. } \\
\text { Stage } 1,2 \text { related to } \\
\text { limitation; fatigue, hot }\end{array}$ & $\begin{array}{l}\text { Fatigue and hot flashes } \\
\text { are important factors that } \\
\text { negatively influence the } \\
\text { survivors' productivity } \\
\text { even in long term. } \\
\text { Therapy for hot flash and } \\
\text { fatigue should be }\end{array}$ \\
\hline
\end{tabular}




\begin{tabular}{|c|c|c|c|c|c|c|}
\hline Author \& Year & Objectives & $\begin{array}{l}\text { Study design/data } \\
\text { collection }\end{array}$ & Sample/ Country & Outcomes/variables & Findings & Conclusion/implication \\
\hline \multirow[b]{2}{*}{$\begin{array}{l}\text { Molina } \\
\text { Villaverde et al. } \\
\text { (2008) }\end{array}$} & \multirow[b]{2}{*}{$\begin{array}{l}\text { Investigate } \\
\text { RTW rate, } \\
\text { discrimination } \\
\text { or obstacles in } \\
\text { remaining to } \\
\text { work. }\end{array}$} & & $\begin{array}{l}\text { all treatment before } \\
\text { 2003, NY } \\
\text { U.S. }\end{array}$ & $\begin{array}{l}\text { (age, race, education, } \\
\text { marital status). }\end{array}$ & $\begin{array}{l}\text { flashes associated with } \\
\text { work productivity } \\
\text { Marriage and greater } \\
\text { personal income are } \\
\text { protective factors. }\end{array}$ & $\begin{array}{l}\text { considered for survivors } \\
\text { with work limitation. }\end{array}$ \\
\hline & & $\begin{array}{l}\text { Quantitative study: } \\
\text { cohort study. } \\
\text { Questionnaire: } \\
\text { personal information, } \\
\text { cancer-related } \\
\text { symptoms, work- } \\
\text { related factors. } \\
\text { Medical details. }\end{array}$ & $\begin{array}{l}96 \text { BCS } \\
\text { Age 18-65 yr; } \\
\text { Mean age at } \\
\text { diagnosis: } 47 \text { yr. } \\
\text { Time since } \\
\text { diagnosis: } \\
\text { 32.5 months } \\
\text { (SD=26.5) }\end{array}$ & $\begin{array}{l}\text { Outcomes: return to } \\
\text { work } \\
\text { Variables: medical } \\
\text { characters and well- } \\
\text { being (sequelae of the } \\
\text { disease, treatment, stage } \\
\text { associated with the } \\
\text { ability to work), work } \\
\text { environment }\end{array}$ & $\begin{array}{l}80 \% \text { off work after } \\
\text { diagnosis } 56 \% \text { RTW at } \\
\text { end of treatment. } \\
\text { No job discrimination } \\
\text { was reported. } 29 \% \text { felt } \\
\text { the changes of relations } \\
\text { with their co-workers } \\
\text { (positive). }\end{array}$ & $\begin{array}{l}\text { Obstacles of RTW mainly } \\
\text { due to sequelae of their } \\
\text { disease or treatment, } \\
\text { instead of discrimination } \\
\text { by colleagues. }\end{array}$ \\
\hline
\end{tabular}




\begin{tabular}{|c|c|c|c|c|c|c|}
\hline Author \& Year & Objectives & $\begin{array}{l}\text { Study design/data } \\
\text { collection }\end{array}$ & Sample/ Country & Outcomes/variables & Findings & Conclusion/implication \\
\hline $\begin{array}{l}\text { Mujahid et al. } \\
\text { (2010) }\end{array}$ & $\begin{array}{l}\text { Investigate the } \\
\text { minority } \\
\text { ethnics' } \\
\text { employment } \\
\text { status }\end{array}$ & $\begin{array}{l}\text { Quantitative: cross- } \\
\text { sectional study } \\
\text { Questionnaires, } \\
\text { information from } \\
\text { SEER registry }\end{array}$ & $\begin{array}{l}\text { Oversampled } \\
\text { Latinas and } \\
\text { African-American } \\
\text { Women (less } \\
\text { white). } \\
\text { Non-metastatic } \\
\text { BCS after surgery } \\
\text { \& initial treatment. } \\
\text { Median time from } \\
\text { treatment: } 8.9 \\
\text { months. } \\
\text { U.S. }\end{array}$ & $\begin{array}{l}\text { Outcomes: Missed work, } \\
\text { work hrs, flexibility of } \\
\text { work } \\
\text { Variables: } \\
\text { sociodemographic } \\
\text { factors (age, race, } \\
\text { education, family } \\
\text { income, acculturation) } \\
\text { medical characteristics } \\
\text { (stage, co-morbidities, } \\
\text { treatment) work } \\
\text { environment }\end{array}$ & $\begin{array}{l}\text { Stop working: } \\
\text { Latinas and African } \\
\text { significantly > white. } \\
\text { Mastectomy, chemo, } \\
\text { unsupportive work } \\
\text { settings, less flexible } \\
\text { schedule. }\end{array}$ & $\begin{array}{l}\text { Health providers should } \\
\text { be aware of minorities' } \\
\text { work situations. }\end{array}$ \\
\hline $\begin{array}{l}\text { Petersson, } \\
\text { Wennman- } \\
\text { Larsen, Nilsson, } \\
\text { Olsson, and } \\
\text { Alexanderson } \\
\text { (2011) }\end{array}$ & $\begin{array}{l}\text { Elucidate the } \\
\text { work situation, } \\
\text { absence, and } \\
\text { the factors } \\
\text { associated } \\
\text { with it at } \\
\text { initial period } \\
\text { after surgery. }\end{array}$ & $\begin{array}{l}\text { Quantitative: Cross- } \\
\text { sectional study. } \\
\text { Demographics, work, } \\
\text { and sickness absence } \\
\text { (developed } \\
\text { questionnaire), } \\
\text { General health } \\
\text { (EORTC QLQ C30), } \\
\text { Strenuous work } \\
\text { posture (questions) }\end{array}$ & $\begin{array}{l}756 \text { participants } 4- \\
6 \text { weeks post- } \\
\text { surgery. } \\
\text { Age: } 20-63 \text { yrs; } \\
44.4 \%<51 \text { yrs. } \\
\text { Sweden }\end{array}$ & $\begin{array}{l}\text { Outcomes: return to } \\
\text { work (employment } \\
\text { status, length and grade } \\
\text { of sick leave) } \\
\text { Variables: health well- } \\
\text { being, work demands } \\
\text { (Strenuous work } \\
\text { posture), individual } \\
\text { characters (age) }\end{array}$ & $\begin{array}{l}<51 \text { yrs, } 86.2 \% \text { survivors } \\
\text { are employed at } \\
\text { diagnosis. }>=51 \mathrm{yr}, \\
85.2 \% \text { employed. } 91 \% \\
\text { work >= } \% \text { full time. } \\
56 \% \text { sick leave at study } \\
\text { time. } \\
\text { Factors associated with } \\
\text { absences: low self-rated } \\
\text { health, poorer health } \\
\text { than before diagnosis, } \\
\text { strenuous work posture, } \\
\text { and younger age. }\end{array}$ & $\begin{array}{l}\text { Work absence and factors } \\
\text { related to it at all phases } \\
\text { of breast cancer trajectory } \\
\text { should be explored. }\end{array}$ \\
\hline
\end{tabular}




\begin{tabular}{|c|c|c|c|c|c|c|}
\hline Author \& Year & Objectives & $\begin{array}{l}\text { Study design/data } \\
\text { collection }\end{array}$ & Sample/ Country & Outcomes/variables & Findings & Conclusion/implication \\
\hline $\begin{array}{l}\text { Quinlan et al. } \\
\text { (2009) }\end{array}$ & $\begin{array}{l}\text { Demonstrate if } \\
\text { the arm } \\
\text { morbidities are } \\
\text { important } \\
\text { factors } \\
\text { contributing to } \\
\text { loss of } \\
\text { productivity in } \\
\text { work. }\end{array}$ & $\begin{array}{l}\text { Quantitative study: } \\
\text { longitudinal research } \\
\text { Clinical staff } \\
\text { assessment. } 3 \text { types of } \\
\text { arm morbidity } \\
\text { (lymphedema, arm } \\
\text { pain, and range of } \\
\text { motion limitations); } \\
\text { Demographics; } \\
\text { Clinical factors (stage, } \\
\text { surgery, adjuvant } \\
\text { treatment) }\end{array}$ & $\begin{array}{l}600 \text { early stage } \\
\text { breast cancer } \\
\text { survivors from } 4 \\
\text { geographical } \\
\text { locations across } \\
\text { Canada. } \\
\text { 6-12 months } \\
\text { following surgery. } \\
\text { Bilateral breast } \\
\text { diseases were } \\
\text { excluded. } \\
\text { Canada }\end{array}$ & $\begin{array}{l}\text { Outcomes: } \\
\text { Work ability, } \\
\text { performance } \\
\text { (productivity) } \\
\text { Functions (Arm- } \\
\text { problems-induced } \\
\text { changes) } \\
\text { work capacity, changes } \\
\text { in occupational status } \\
\text { Sick leave. }\end{array}$ & $\begin{array}{l}\text { Survivors with } \\
\text { limitations of arm } \\
\text { motion and arm pain are } \\
21 / 2 \text { times more likely to } \\
\text { lose productivity } \\
\text { compared to the one } \\
\text { without arm morbidity. } \\
\text { Changes in productivity } \\
\text { among BCS are } \\
\text { significantly different } \\
\text { among four jurisdictions } \\
\text { (related to geographic } \\
\text { locations). }\end{array}$ & $\begin{array}{l}\text { More adequate } \\
\text { rehabilitation programs } \\
\text { should be delivered at } \\
\text { crucial time. } \\
\text { The regulatory framework } \\
\text { governing employment is } \\
\text { a factor which influences } \\
\text { the survivors' } \\
\text { productivity. }\end{array}$ \\
\hline $\begin{array}{l}\text { Schmalenberger, } \\
\text { Gessert, } \\
\text { Giebenhain, and } \\
\text { Starr (2012a) }\end{array}$ & $\begin{array}{l}\text { Examine the } \\
\text { effect of breast } \\
\text { cancer on } \\
\text { survivor's } \\
\text { function as } \\
\text { musician }\end{array}$ & $\begin{array}{l}\text { Quantitative study: } \\
\text { cross-sectional } \\
\text { Online survey, self- } \\
\text { reported } \\
\text { ranked duration and } \\
\text { severity of symptoms } \\
\text { experienced using 7- } \\
\text { and 9-point discrete } \\
\text { visual analog scales. }\end{array}$ & $\begin{array}{l}90 \text { female } \\
\text { musicians who are } \\
\text { BCS } \\
\text { median age: } 53 \text { yrs } \\
\text { (range 31-78) } \\
\text { United States }\end{array}$ & $\begin{array}{l}\text { Outcomes: Work ability } \\
\text { Variables: symptoms } \\
\text { (pain, limitations in } \\
\text { upper body and } \\
\text { extremity movement, } \\
\text { numbness in the chest } \\
\text { and/or arms, } \\
\text { contracture/fibrosis, and } \\
\text { shortness of breath. }\end{array}$ & $\begin{array}{l}\text { Subjects experienced } \\
\text { diminished capacity to } \\
\text { function as musicians. } \\
\text { The work limitations } \\
\text { were due to long-term } \\
\text { effects of breast cancer } \\
\text { treatments. }\end{array}$ & $\begin{array}{l}\text { Musician's ability to } \\
\text { make music could be } \\
\text { profoundly altered by } \\
\text { breast cancer treatment. } \\
\text { How treatment could } \\
\text { affect breast cancer } \\
\text { survivors' ongoing } \\
\text { professional work should } \\
\text { be considered by health } \\
\text { providers. }\end{array}$ \\
\hline
\end{tabular}




\begin{tabular}{|c|c|c|c|c|c|c|}
\hline Author \& Year & Objectives & $\begin{array}{l}\text { Study design/data } \\
\text { collection }\end{array}$ & Sample/ Country & Outcomes/variables & Findings & Conclusion/implication \\
\hline \multicolumn{7}{|c|}{ Interventional study } \\
\hline $\begin{array}{l}\text { Hubbard, Gray, } \\
\text { Ayansina, Evans, } \\
\text { and Kyle (2013) }\end{array}$ & $\begin{array}{l}\text { Assess the } \\
\text { feasibility, } \\
\text { acceptability } \\
\text { of vocational } \\
\text { rehabilitation } \\
\text { (VR) } \\
\text { intervention } \\
\text { for women } \\
\text { with breast } \\
\text { cancer }\end{array}$ & $\begin{array}{l}\text { Quantitative: RCT } \\
\text { Intervention: case } \\
\text { management } \\
\text { vocational } \\
\text { rehabilitation (VR) } \\
\text { service. } \\
\text { Questionnaire (self- } \\
\text { reported sickness } \\
\text { absence; change in } \\
\text { employment pattern, } \\
\text { HRQoL, fatigue) }\end{array}$ & $\begin{array}{l}\text { Randomized } 22 \\
\text { women BCS } \\
\text { Interventional (8) } \\
\text { vs. Control (14) } \\
\text { Mean age: } 50.5 \text { yrs } \\
66.7 \% \text { comorbidity } \\
61.1 \% \text { full-time, } \\
\text { mean hrs 32.5h/w } \\
\text { Scotland }\end{array}$ & $\begin{array}{l}\text { Outcomes: feasibility } \\
\text { and acceptability. } \\
\text { Variables: VR } \\
\text { intervention }\end{array}$ & $\begin{array}{l}\text { Averagely, } 53 \text { fewer } \\
\text { days sick leave over first } \\
6 \text { months in case } \\
\text { management group } \\
\text { compared to control } \\
\text { group. } \\
\text { Changes in employment } \\
\text { pattern, quality of life } \\
\text { and fatigue are not } \\
\text { significant different. }\end{array}$ & $\begin{array}{l}\text { The exact component of } \\
\text { VR service should be } \\
\text { further explored. } \\
\text { VR is an important part of } \\
\text { survivorship care plan. }\end{array}$ \\
\hline
\end{tabular}

*RTW: return to work

*BCS: breast cancer survivors 


\section{VITA}

Yuanlu (“April”) Sun was born in Yichang, China. She’s a registered nurse in both China and United States. She earned her degree of Bachelor of Medicine with Nursing Specialty from Sun Yat-sen University in 2011. She practiced as a registered nurse and clinical research nurse from 2011 to 2012. After that, she started the BSNPHD program at Sinclair School of Nursing, University of Missouri-Columbia. She has been a certified lymphedema therapist since May 2015. 